University of Louisville

ThinkIR: The University of Louisville's Institutional Repository

Electronic Theses and Dissertations

$12-2017$

\title{
LGBTQ+ nondiscrimination laws in Kentucky.
}

Christopher M Wales

University of Louisville

Follow this and additional works at: https://ir.library.louisville.edu/etd

Part of the American Politics Commons, Lesbian, Gay, Bisexual, and Transgender Studies Commons, Other Legal Studies Commons, Public Policy Commons, Social Policy Commons, and the Urban Studies Commons

\section{Recommended Citation}

Wales, Christopher M, "LGBTQ+ nondiscrimination laws in Kentucky." (2017). Electronic Theses and Dissertations. Paper 2874.

https://doi.org/10.18297/etd/2874

This Master's Thesis is brought to you for free and open access by ThinkIR: The University of Louisville's Institutional Repository. It has been accepted for inclusion in Electronic Theses and Dissertations by an authorized administrator of ThinkIR: The University of Louisville's Institutional Repository. This title appears here courtesy of the author, who has retained all other copyrights. For more information, please contact thinkir@louisville.edu. 


\title{
LGBTQ+ NONDISCRIMINATION LAWS IN KENTUCKY
}

\author{
By
}

Christopher Michael Wales

B.A. Northern Kentucky University, 2014

\author{
A Thesis \\ Submitted to the Faculty of the \\ College of Arts and Sciences of the University of Louisville \\ in Partial Fulfillment of the Requirements \\ for the Degree of
}

\author{
Master of Public Administration \\ Department of Public Administration \\ University of Louisville \\ Louisville, Kentucky
}

December 2017 



\title{
LGBTQ+ NONDISCRIMINATION LAWS IN KENTUCKY
}

\author{
By
}

Christopher Michael Wales

B.A. Northern Kentucky University, 2014

A Thesis Approved on

November 16, 2017

by the following Thesis Committee:

Dr. Janet Kelly, Chair

Dr. Matthew Ruther

Dr. Catherine Fosl 


\section{DEDICATION}

This thesis is dedicated to Carrie Donald, who inspired and encouraged me to pursue social justice, and whose guidance will be greatly missed. The thesis is also dedicated to my father, Michael Wales, whose love and actions inspired me to be the person I am today. 


\section{ACKNOWLEDGEMENTS}

I would like to thank the members of my committee, Dr. Janet Kelly, Dr. Matthew Ruther, and Dr. Catherine Fosl for their unbelievable patience throughout this process. This thesis would not have been possible without their much-needed and appreciated insight and assistance. I would also like to thank my mother, Denise Hawkins, for continuing to encourage me to pursue my academic career and for pulling me back from the brink of insanity several times over the past year. 


\section{ABSTRACT \\ LGBTQ+ NONDISCRIMINATION LAWS IN KENTUCKY}

Christopher Wales

November 16, 2017

This thesis explores the political and demographic obstacles facing the Fairness movement in Kentucky in regards to local employment protection ordinances for LGBTQ+ persons (Fairness Ordinances). Using case studies on recent Fairness debates in Berea and Bowling Green, this thesis explores the concern some Kentuckians have about LGBTQ+ nondiscrimination ordinances in their communities. From these cases studies, it can be concluded that many of the concerns espoused by opponents of Fairness are simple scare tactics with no evidence supporting their claims.

This thesis then utilizes a logistical regression to uncover what demographic characteristics increase the odds of a municipality possessing Fairness. The variables included in this analysis include population size, racial/ethnic diversity, wealth, educational attainment, religious composition, and the presence of an LGBTQ+ political organization in the city. From this analysis, only population size and average educational attainment were found to be significant predictors of whether a city would put in place a Fairness Ordinance. 


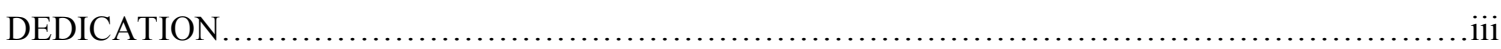

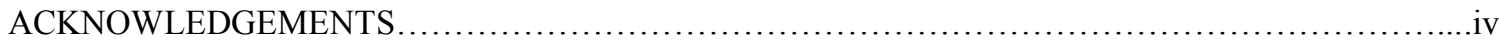

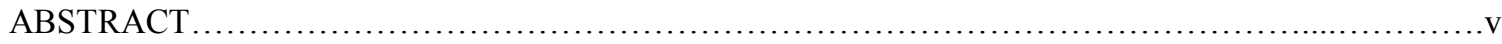

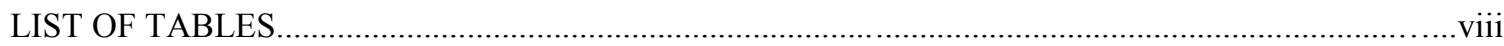

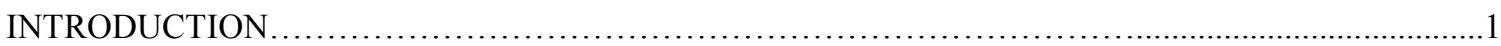

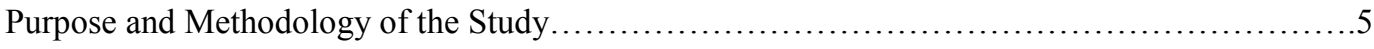

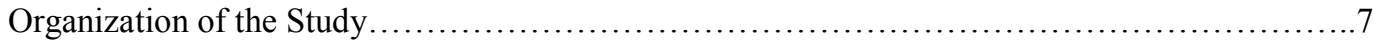

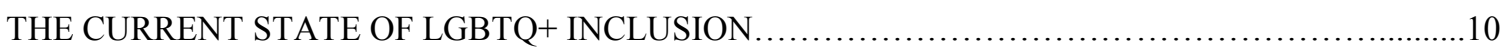

A Review of Federal LGBTQ+ Nondiscrimination Policies...................................12

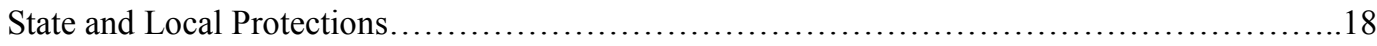

State Employment Protections in Kentucky ........................................... 20

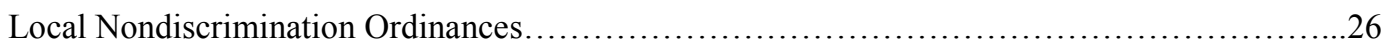

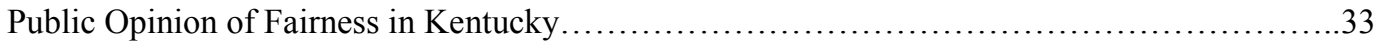

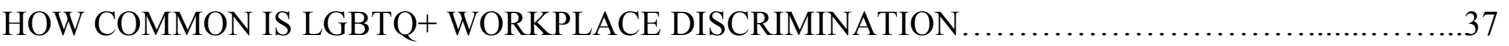

Documented Claims of LGBTQ+ Discrimination in the Workplace..............................38

Survey Data on LGBTQ+ Discrimination in the Workplace.................................41

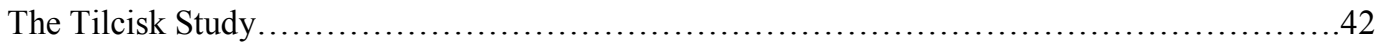

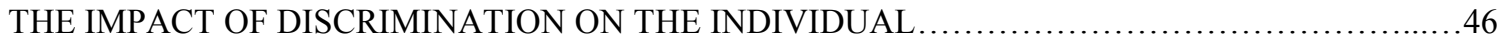

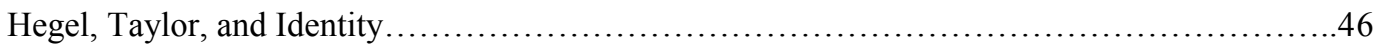

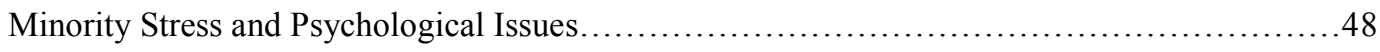

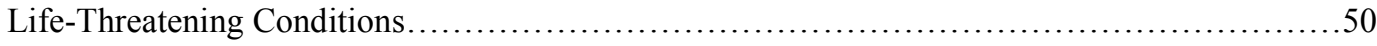

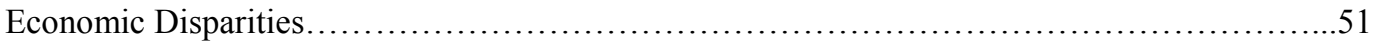

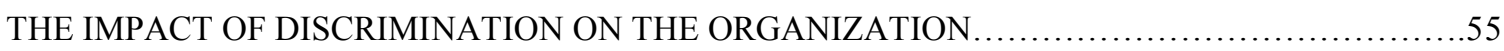

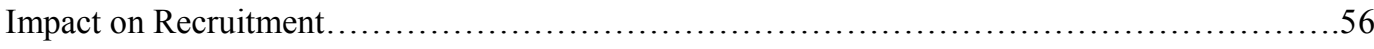

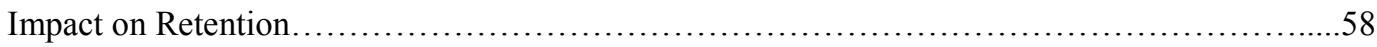




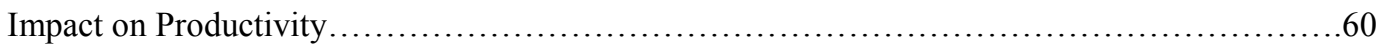

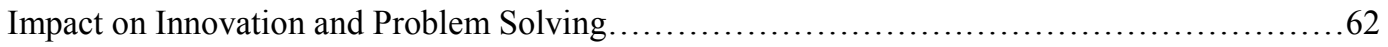

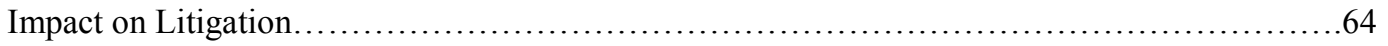

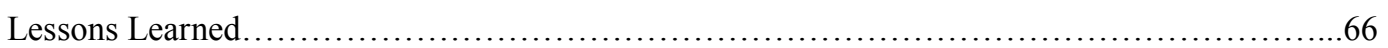

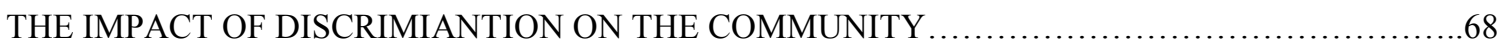

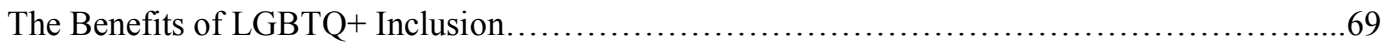

The Costs of LGBTQ+ Exclusion....................................................... 74

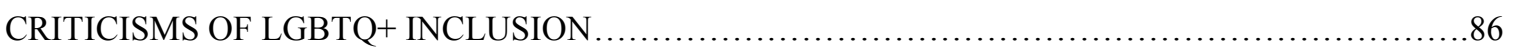

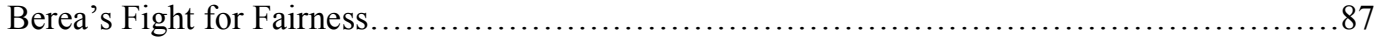

Bowling Green's Fight for Fairness.................................................... 102

Addressing the Misconceptions and Fears of Fairness.........................................114

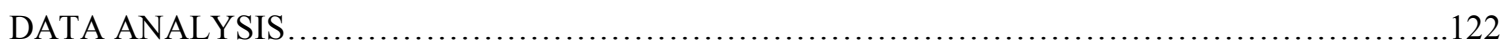

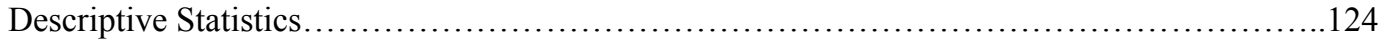

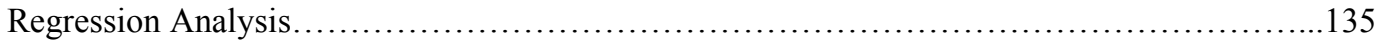

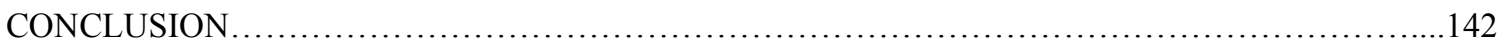

Population Size and Residential Educational Attainment on LGBTQ+ Rights...................140

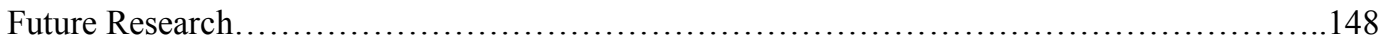

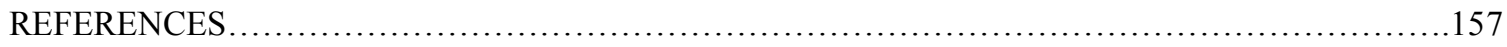

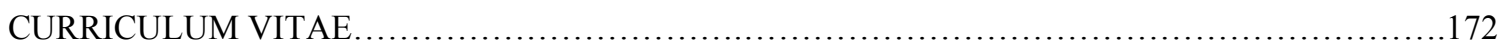




\section{LIST OF TABLES}

TABLE

PAGE

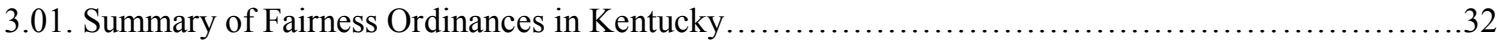

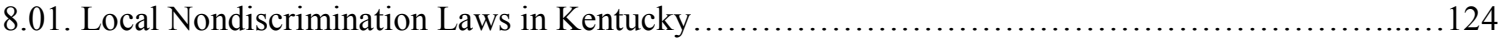

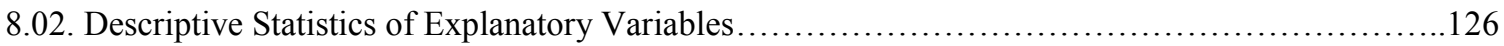

8.03. t-test Results Comparing Population Means ................................................. 128

8.04. t-test Results Comparing Income per capita Means.............................................129

8.05. t-test Results Comparing Educational Attainment Means....................................... 130

8.06. t-test Results Comparing Percent Non-Hispanic White Means....................................131

8.07. t-test Results Comparing Percent Evangelical Means.........................................132

8.08. t-test Results Comparing Percent Democrat Means...............................................133

8.09. Fairness Ordinance * LGBT Organization Crosstabulation..................................135

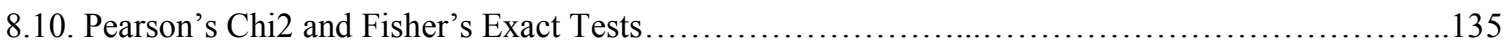

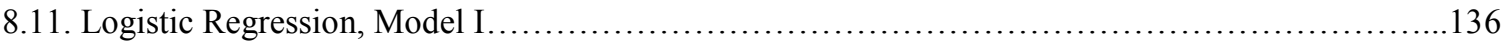

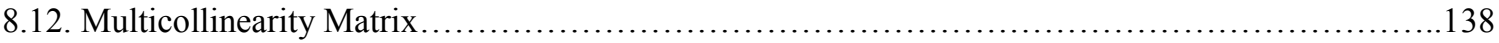

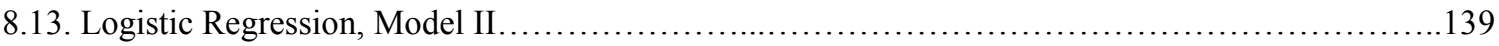




\section{CHAPTER I:}

\section{INTRODUCTION}

Everyone has the right to work, to free choice of employment, to just and favourable conditions of work and to protection against unemployment.

- $\quad$ Article 23.1 of the Universal Declaration of Human Rights

The States Parties to the Covenant recognize the right to work, which includes the right of everyone to the opportunity to gain his living by work which he freely chooses or accepts, and will take appropriate steps to safeguard this right.

- Part III, Article 6 of the International Covenant on Economic, Social and Cultural Rights

The ability to earn a living free from workplace discrimination or harassment is a fundamental human right. Unfortunately, places of employment are often the epicenter of discriminatory practices (Burns 2012). A prejudiced employer could harass employees, promote discriminatory workplace practices - such as unequal wages for equal work - or refuse to hire individuals they are bigoted toward. The history of the United States is packed with such discriminatory actions toward racial and ethnic minorities; women; non-Christians - or sometimes even "wrong" Christians; and lesbian, gay, bisexual, transgender, or queer individuals (LGBTQ+), ${ }^{1}$ among others, being denied full employment opportunities, sometimes by the command of law. This prejudice has resulted in many minority groups being at greater risk of poverty and other unfavorable conditions compared to individuals that have more privilege (Burns 2012).

The various civil rights movements of the mid-20th century began to transform how American government at all levels regarded the civil and employment rights of its citizens. Starting in the mid-

\footnotetext{
${ }^{1}$ A quick word on terminology: Throughout this thesis, I use LGBTQ+ as an umbrella term for persons who identify as neither "straight" nor "cisgender". There are many identities within this signifier - I have seen some acronyms over twenty letters long - and by using "LGBTQ+", I am not attempting to exclude some identities over others. I also use the terms sexual minorities to refer to other sexual orientations beyond heterosexual, and gendered minorities for other genders beyond cisgender.
} 
1960s, the federal government began to enact various laws that protect the American workforce against discrimination stemming from a number of attributes, including race, color, sex, religion, and national origin. These classes have since been expanded through other federal acts to include age (for those forty years or older), disability, membership in the armed forces, and genetic status. Under the purview of these acts, an employee possesses the right to claim financial retribution against an employer that violated their civil rights, thereby making discriminatory workplace policies a hindrance to the profits of most organizations.

Two classes of individuals that have witnessed a great deal of discrimination and harassment throughout United States history but are not protected by a federal employment nondiscrimination law are sexual and gendered minorities. This fact appears to be a surprise to many Americans; a 2011 Center for American Progress poll found that while 73\% of Americans support a federal nondiscrimination bill for LGBTQ+ persons, almost $90 \%$ of those polled erroneously believed that such protections already exist at the federal level. It is not surprising that many Americans are mistaken on this issue. The LGBTQ+ community has undergone a massive transformation in the eyes of the public in the past few decades, gaining rights previously denied to them such as marriage equality and adoption rights. Nonetheless, explicit federal protections for sexual and gendered minorities are still non-existent except in piecemeal fashion.

While the federal government has not extended workplace protections to LGBTQ+ Americans, state and local governments have been enacting such legislation at an increasing rate. As of June 2017, twenty states and the District of Colombia have statewide protections for their LGBTQ+ residents (MAP 2017). This fact underlines the rapid transformation of Americans' opinion on this issue, as Rhode Island became just the second state to grant full workplace protections to its sexual and gender minorities in 2001 . Additionally, two-hundred and twenty-five municipalities across the country have enacted similar ordinances, ensuring that their local LGBTQ+ community has protections against workplace discrimination. According to a report conducted by Movement Advancement Project (2017), 52.3\% of Americans are protected from workplace discrimination stemming from their sexual orientation and gender identity through either state or local laws. 
In the Commonwealth of Kentucky, however, the majority of LGBTQ+ residents are often left with no legal recourse to challenge workplace discrimination when it occurs. As of the writing of this thesis, no bill has been passed in the Kentucky General Assembly that grants LGBTQ+ Kentuckians the right to challenge employment discrimination to the Kentucky Commission on Human Rights, the state agency authorized to enforce state and federal civil rights laws. This fact may not surprise many people, as Kentucky has high proportions of evangelical Protestants and social conservatives (Pew Research Center 2014), groups that have historically been hostile to LGBTQ+ persons and their rights. Despite this demographic reality, two polls that surveyed the attitudes of Kentuckians on this topic demonstrated that most residents are in favor of nondiscrimination laws for their LGBTQ+ coworkers (PRRI 2015; Shapiro 2011), including evangelical residents (Shapiro 2011).

Similar to the recent rise in the number of states with statewide nondiscrimination laws, an increasing number of Kentucky municipalities have taken measures to ensure their LGBTQ+ residents are protected from workplace discrimination. Before 2013, only three Kentucky municipalities (Louisville Metro, Lexington-Fayette Metro, and Covington) had a Fairness Ordinance - the common name of legal LGBTQ+ protections in Kentucky - in their municipal code. In the past five years, this number has almost tripled to eight, with the cities of Vicco, Frankfort, Morehead, Danville, and Midway joining the list of Kentucky municipalities that have enacted Fairness in their communities. Still, an estimated $74 \%$ of Kentuckians live in a municipality that does not possess a Fairness Ordinance (2010 US Census), leaving most of Kentucky's estimated 80,332 LGBTQ+ workforce without such protections (Mallory \& Sears 2011a).

The lack of protections granted to sexual and gendered minorities has severe consequences for many who identify as LGBTQ+. Survey research has regularly demonstrated that over $40 \%$ of sexual minorities have faced discrimination or harassment at their place of employment due to their sexuality (General Social Survey 2008; Mallory \& Sears 2011a). Surveys also suggest that gender minorities face even greater discrimination in employment: well over half of all transgender persons surveyed admitted to facing workplace harassment and almost two-fifths suffer recurrent sexual harassment in the workplace (Mallory \& Sears 2011a; The Task Force 2012). 
The high level of discrimination faced by LGBTQ+ persons has severe impacts on the mental, physical, and economic well-being of those who suffer from it. Several psychological studies have suggested that LGBTQ+ individuals who are subjected to discrimination have weaker measures of mental health compared to LGBTQ+ persons who do not face such harassment (Meyer 1995; Cochran, Mays, \& Sullivan 2003; Herek \& Garnets 2007; Hamilton \& Mahalik 2009). Similar studies have demonstrated that LGBTQ+ persons who face discrimination are more likely to engage in risky behaviors, with the result being that these harassed individuals are more likely to have substance abuse problems (Kalichman \& Cain 2004; West \& Szymanski 2008; Link \& Phelan 2006) and engage in risky sexual practices (Bimbi 2006; Halkitis, Green, \& Carragher 2006; ONAT 2010), increasing their risk for a host of health problems. Discrimination is also linked to an increase in stress levels among the LGBTQ+ population, raising their risk of immune, cardiovascular, and digestive disorders (APA 2015; AHA 2015).

Several policy analysts have found that sexual and gendered minorities are also at a greater risk of poverty compared to heterosexual, cisgender persons (MDoCR 2013; Badget 2013; HRC 2013). This reality is particularly the case for LGBTQ+ persons of color and those who identify as female, suggesting that the intersection of race, gender, and sexuality can multiply discrimination's damaging effects. Transgender persons, in particular, are at an incredibly high risk of poverty and homelessness in the United States, with an average income slightly less than two-thirds of the general population (The Task Force 2009).

LGBTQ+ persons are not the only victims of workplace discrimination. Organizational theorists have also noted that workplace discrimination of all identity groups - including LGBTQ+ discrimination has serious effects on an organization's ability to meet its goals. Employees who are subjected to unfair employment practices or continual harassment have been found to be less productive, take more sick leave, and leave an organization earlier compared to personnel who are treated with respect (Velez 2013; Cooper 2011; Burns 2012). Further, organizations that do not offer internal LGBTQ+ nondiscrimination policies run the risk of repelling potential employees, thereby lowering human capital (Burns 2012). Studies have also demonstrated that organizations that lack a diverse workforce are less innovative than those that embrace diversity (Burt 2014; Hewlett, Marshall, \& Sherbin 2013). All these effects of workplace 
discrimination may reduce an organization's bottom-line, which, as these studies point out, may cause an organization to fail in the increasingly competitive global market.

The negative effects of LGBTQ+ discrimination are not just limited to the employers and employees of an organization that allows such harassment to occur; such discrimination may affect the economic health of entire communities. There is increasing evidence that highly-skilled professionals, particularly younger professionals, are seeking communities that better reflect their values, and many scholars have suggested that these highly-sought after residents are supportive of LGBTQ+ nondiscrimination laws (Florida 2012, 87; MDoRC 2013). Other scholars have noted an upsurge in workforce productivity following the enactment of state or local nondiscrimination laws (Gao \& Zhang 2016). Ensuring private organizations give equal treatment to LGBTQ + residents through a local or state nondiscrimination law might also increase public revenues and decrease government expenditures (Herman 2011; Badgett 2013; MDoCR 2013). The wage gap between LGBTQ+ residents and their straight or cisgender counterparts has been found to be smaller in states with nondiscrimination laws (Badgett 2013), thereby increasing the (taxable) income and spending power of these residents while lowering their need for social services (Herman 2011).

\section{Purpose and Methodology of the Study}

Overall, the literature on LGBTQ+ nondiscrimination policies suggests that workplace discrimination against LGBTQ+ persons affects both the individual and the community as a whole. For this reason, LGBTQ+ non-discrimination laws have had the endorsement of a wide variety of professional organizations, including the American Psychological Association (APA n.d.), the American Medical Association (AMA n.d.), the American Bar Association (ABA 2014), the AFL-CIO (AFL-CIO 2009), the United States Conference of Mayors (Polaski 2017), and the World Economic Forum (Zapulla 2017), among others. Similarly, some of the nation's largest corporations, such as Amazon, Apple, Dow Chemical Company, General Electric, Google, HP, Microsoft, Target, and Walmart have publicly endorsed various LGBTQ+ non-discrimination laws at the federal, state, and local levels (HRC 2015). 
Despite the overwhelming amount of evidence that LGBTQ+ nondiscrimination laws and ordinances benefit the residents, organizations, and local economic health of communities that possess them, $74 \%$ of Kentuckians are still without such workplace protections. This seems even more perplexing when examining the surveys conducted in or on the Commonwealth, both of which suggest that most Kentuckians support legal protections for LGBTQ+ employees. This reality brings forth several questions. Why do some Kentuckians oppose Fairness policies? Is there some demographic commonality among municipalities with a Fairness Ordinance that explains why Fairness exists there? What are the political obstacles that seem to block such policies from wider enactment?

This thesis will explore and attempt to answer these questions using a mixed-methods approach. After reviewing the literature on LGBTQ+ nondiscrimination laws and the problems associated with workplace discrimination, the local Fairness movements of Berea and Bowling Green will be explored using firsthand accounts, video footage of local "town hall" meetings in which Fairness was discussed, and local media reports of the Fairness debates. Local politicians in both cities have introduced a Fairness Ordinance into the local legislative body in 2014 and 2017, respectively, and, in both instances, the ordinances failed. This outcome provides an interesting examination of the local politics of LGBTQ+ rights in Kentucky, as well as the difficulties Fairness advocates run into while attempting to expand the number of Fairness cities.

It is important to note that this study focuses primarily on local Fairness Ordinances as opposed to a statewide Fairness Law, though state and national actions will be discussed. It may seem that concentrating on local ordinances is inefficient, as a federal or state nondiscrimination law would protect all Kentuckians whereas it would take a multitude of local laws to achieve such a feat. There are, however, several important reasons for this local emphasis. First, local governments tend to be more accessible and easier to engage with than higher levels of government (Pratchett 1999; Stocker 2004), thereby allowing more residents the opportunity to voice their support or concern for Fairness in their communities. Also, the history of the LGBTQ+ Movement in the United States has demonstrated that most progress is first made at the lower levels of government, before expanding nationally (Faderman 2015, 136). Most states, for example, had long removed sodomy laws from their books before the 2003 Supreme Court ruling in 
Lawrence v. Texas, which declared such laws as unconstitutional in the fourteen states that continued to regulate the sexual conduct of consenting adults. Finally, it is important to note that no statewide Fairness Law has had any serious chance thus far of passing the General Assembly (Marzian, personal communication, 2015), with only two of the eighteen Fairness Bills introduced into the Kentucky legislature since 1999 having gained even a committee hearing (LRS 2017). This reality severely limits the breadth of information available for analysis and contrasts heavily with some Kentucky municipalities that have had open debates on Fairness for several years prior to a vote on the issue.

It is also important to investigate if demographic characteristics of Kentucky municipalities give insight as to whether a city is likely to possess a Fairness Ordinance. Using data from the American Community Survey, the Association of Religious Data Archives, and the Kentucky State Board of Elections, this study will utilize a logistic regression to examine if certain demographic attributes are associated with a municipality possessing a Fairness Ordinance. There is academic precedent in using logistic regressions to analyze LGBTQ+ nondiscrimination laws, most notably Wald, Button, and Rienzo's 1996 nationwide study. Wald et al. examined the demographic characteristics of 251 American cities to uncover what municipal attributes increase the likelihood of a city possessing a nondiscrimination law. Their findings suggested that population size, ethnic diversity, resident wealth, average education attainment, religious composition, and the presence of an LGBT organization influenced the likelihood that a city would possess such a law (Wald et al. 1996). Their study, however, did not focus on Kentucky municipalities and is now over twenty years old. Its timing is particularly significant given the rapid increase in the number of American cities with such workplace protections. It remains to be seen, then, whether and to what extent Wald et al.'s findings apply to mid-2010s Kentucky municipalities.

\section{Organization of the Study}

Following this introductory chapter, Chapter II provides an overview of the often-confusing network of workplace legal protections that exists for LGBTQ+ Kentuckians. While no federal or state law explicitly grants these Kentuckians full employment protections as various other civil rights laws do for

other minorities, past U.S. Presidents and Kentucky Governors have used their executive powers to protect 
most Kentuckians working in the federal or state executive branch. Further, a recent ruling by the Equal Employment Opportunity Commission may signal a shift in how the judicial system interprets sex discrimination, which is outlawed by Title VII of the Civil Rights Act. If the federal courts accept the EEOC's interpretation of sex as pertaining to gender and sexual minorities, LGBTQ+ Americans will automatically be granted the protection of the EEOC. There is, however, some debate as to whether the federal judiciary will come to accept this interpretation.

Chapter II also explores Fairness Ordinances in Kentucky. As of June 2017, eight Kentucky municipalities have extended employment, housing, and public accommodation protections to their LGBTQ+ residents. This chapter provides a very brief overview of the timeline of these ordinances, as well as explore the legal protections they offer to residents. Chapter II ends with a summary of survey data that suggests that, while these ordinances are rare in Kentucky, Kentuckians across all religions and political ideologies view these laws favorably, dispelling the rumor that LGBTQ+ employment rights are politically unpopular in a conservative state.

Chapter III examines the frequency of LGBTQ+ employment discrimination in the United States. One of the most common arguments made against LGBTQ+ non-discrimination laws is that discrimination of this kind does not occur frequently enough to warrant such protections. To better understand if these criticisms are correct, this chapter examines three different methodological tools that measure such discrimination in the United States: claims made to various human rights commissions, survey data, and an empirical study on LGBTQ+ employment discrimination. Based off these different studies, the chapter concludes that such arguments are unfounded: LGBTQ+ discrimination still frequently occurs in the United States.

Before analyzing the political debate surrounding the LGBTQ+ non-discrimination laws, it is important to establish that lacking such laws has social and economic consequences. Chapters IV, V, and VI explore the micro- and macro-level costs of LGBTQ+ discrimination. Chapter IV provides an overview of the costs individual persons receive when faced with real or perceived discrimination stemming from their sexual orientation or gender identity. Chapter V explores the literature on the organizational effects of discrimination in the workplace while Chapter VI provides an overview of the consequences of 
discrimination at the community level, with an emphasis on local economic development. It is important to note that these consequences of LGBTQ+ employment discrimination could be lessened through the enactment of a nondiscrimination law.

The consequences of LGBTQ+ discrimination outlined in Chapters IV, V, and VI have resulted in an overwhelming consensus by psychologists, medical professionals, policy analysts, business leaders, and economists that LGBTQ+ nondiscrimination laws benefit all residents - whether they are in the LGBTQ+ community or not. Still, roughly $74 \%$ of Kentuckians lack protections from such laws, suggesting there are concerns - whether real or imaginary - with these pieces of legislation. Chapters VII and VIII utilize two different methods to understand better why Fairness is rare in the Commonwealth. Chapter VII provides case studies on two failed attempts at passing a Fairness Ordinance in Kentucky - one in Berea in 2014 and one in Bowling Green in 2017. These case studies provide an overview of the opposition to Fairness in Kentucky, as well as detail some of the challenges proponents of Fairness face when attempting to expand the number of Fairness cities in the state. Chapter VIII presents original findings from the logistic regression models utilized in this study to uncover if municipal demographic information helps determine whether a city in Kentucky will embrace a Fairness Ordinance. Finally, Chapter IX concludes the thesis by summarizing the main conclusions of the study, analyzing the findings from Chapter VII, discussing implications and limitations, and giving direction for future research. 


\section{CHAPTER II:}

\section{THE CURRENT STATE OF LGBTQ+ EMPLOYMENT PROTECTION LAWS}

The Commonwealth of Kentucky is not a leader among states in protecting the civil rights of its LGBTQ+ population. The Human Rights Campaign (HRC), one of the largest LGBTQ+ advocacy groups in the United States, gave the state government an "F" in 2016 for failing to protect LGBTQ+ Kentuckians (HRC 2017a). EqualDex, a global watchdog for LGBTQ+ rights who has a similar index, gave the state a score of 5.5 (out of a possible 11), though it is important to note that many of the laws that Kentucky scored positively for - such as marriage equality and allowing LGBTQ + individuals in the military - were not made in Frankfort, but in the nation's capital (EqualDex 2017). In ranking the best and worst states for LGBTQ+ individuals, Lambda Legal, the nation's largest legal organization that focuses solely on gay and transgender rights, ranked Kentucky as the sixth worst state to reside in (Ring 2016).

Despite this notoriety, there are progressive pockets in the conservative state. The HRC, in addition to releasing an annual state index, published its annual Municipality Equality Index in 2016, which analyzed LGBTQ+ protections in 506 municipalities across the United States. Rating cities on a scale of zero to one hundred, the HRC examined local issues such as employment, hate crime, and housing laws; the city's relationship with its LGBTQ+ community; and the city's public employment practices. In 2016, the national average for the municipalities analyzed was a score of 60.4 (out of 100), up from 52.8 just five years earlier (HRC 2017b). Two Kentucky municipalities, though, received marks much higher than the national average. The Lexington-Fayette Urban County government received a score of 71, including perfect scores on LGBTQ+ legal protections and a higher-than-average score on the city's relationship with its LGBTQ+ community (HRC 2017b). Louisville Metro received even higher praise from the HRC, attaining a perfect score for the second year in a row (HRC 2017b, 2016). Louisville is one of only fiftyone cities in the United States to accomplish this in 2017 (HRC 2017b). 
This chapter examines the often-confusing legal network of LGBTQ+ employment laws in the United States broadly, and in Kentucky specifically. The first section explores what protections are available for Kentuckians at the federal level. Throughout modern United States history, minorities living in areas antagonistic to their civil rights have looked to the federal government to provide them with protections against their discriminating and hostile neighbors, and this has been true for LGBTQ+ advocates for the last half-century (Faderman 2015, 236). As we will see, the federal government particularly Congress - has been largely unwilling to provide LGBTQ+ Americans the protections they need. What few protections do exist at the federal level are extremely limited in scope and are not permanent solutions to this problem.

With no explicit federal law banning employment discrimination against sexual and gendered minorities in the United States, state and local governments, under pressure from their LGBTQ+ residents, have taken the lead in drafting LGBTQ+ protections. The second section of the chapter will provide a brief timeline of these state and local nondiscrimination laws in the United States, detailing which states and localities have expanded their civil rights legislation to include LGBTQ+ residents. As will become evident, over the past decade jurisdictions across the United States have begun implementing LGBTQ+ protections at an accelerated rate.

The third section explores this process in Kentucky, specifically in the Kentucky General Assembly and the Kentucky Governorship. Similar to U.S. Presidents, past Kentucky Governors have used their executive power to protect some LGBTQ+ Kentuckians from discrimination in the areas in which they have unilateral authority to do so. Also similar to the federal government, the legislative body of Kentucky has largely refused to take up the issue of protecting LGBTQ+ residents within its borders. Recent political events have also threatened the progress LGBTQ+ Kentuckians have made in the state. This obstinance appears to make Kentucky an exception to the national trend outlined in the previous section.

The fourth section examines the eight local LGBTQ+ nondiscrimination laws - locally known as Fairness Ordinances - that exist in Kentucky. This section will provide a very brief overview of the timeline of these ordinances, as well as explore the legal protections they offer to residents in these municipalities. The final section will explore various national and Kentucky-specific surveys that suggest 
these protections are - far from being politically toxic - desired by the majority of both Americans and Kentuckians.

\section{A Review of Federal LGBTQ+ Nondiscrimination Policies}

Over the past half-century, the federal government has enacted a series of laws that protect a variety of Americans against discrimination in the workplace. These laws include Title VII of the Civil Rights Act of 1964, the Age Discrimination in Employment Act, the Pregnancy Discrimination Act, the Americans with Disabilities Act, the Uniformed Services Employment and Reemployment Rights Act, and the Genetic Nondiscrimination Act, among others. Under the purview of these laws, the vast majority of Americans are protected from employment discrimination stemming from racism, sexism, xenophobia, religious bigotry, ageism (for those aged forty and above), the disabilities of employees, an employee's status in the armed forces, and discrimination based on the employee's genetic status (EEOC 2015a). Currently no federal protections for sexual or gendered minorities from such discrimination exist.

The absence of federal employment protections for LGBTQ+ workers is not from a lack of effort by some in Congress. Legislation that would extend employment protections to sexual minorities has repeatedly been introduced into Congress since Representative Abzug (D-NY) first introduced the Equality Act of 1974 into the 93rd Congress (Faderman 2015). Similar bills have been introduced in the 94th, 102nd, 103rd, 104th, 105th, 106th, 107th, 108th, 110th, 111th, 112th, 113th, and the 114th Congress (see Congressional Archives a,b,c,d,e). Efforts to protect gendered minorities came later, but all Employment Non-Discrimination Acts and Equality Acts since the 111th Congress (2009-10) have included protections for both sexual and gendered minorities (Congressional Archives d,e). Ultimately, all such attempts to provide Americans with these protections have failed. Rather, what LGBTQ+ Americans have is a network of executive orders (EOs) and EEOC rulings that provide them with piecemeal and both inadequate and potentially short-term legal protections against workplace discrimination.

Protecting the Federal Civilian Workforce: Executive Orders and Unilateral Actions

While Congress has stalled on efforts to outlaw LGBTQ+ discrimination in the workplace, Presidents Clinton and Obama made progress for some in the LGBTQ+ community through their use of 
executive orders. In 1995, President Clinton signed Executive Order 12968, the first action taken by the federal government to outlaw discrimination based on an individual's sexual orientation (Love 2014). ${ }^{2}$ EO 12968 prohibited discrimination in granting access to classified information on the basis of some attributes, including sexual orientation (EO 12968, 2 August 1995). Up to that point, LGBTQ+ federal employees were denied access to classified information, as their sexuality prevented them from receiving a security clearance. This rationale stemmed from the long-standing fear that sexual minorities were prone to blackmail by foreign powers, despite the fact that numerous studies dating back to the 1950s had found this fear to be misguided (Faderman 2015). Clinton's executive order reversed this policy, allowing equal access to information for all security employees regardless of their sexual orientation.

Three years after signing EO 12968, President Clinton signed Executive Order 13087, prohibiting discrimination based on sexual orientation in the federal civilian workforce, the District of Columbia's local public workforce, and the United States Postal Service (EO 13087, 28 May 1998). The order did not apply to those working in the Central Intelligence Agency, the Federal Bureau of Investigations, or the National Security Agency. It also did not cover members of the Armed Forces, for whom Clinton's Don't Ask Don't Tell policy was in place. Nonetheless, the executive order gave the millions of Americans who worked for the federal government protections against discrimination for the first time (Love 2014).

In 2014, President Obama signed Executive Order 13672. EO 13672 explicitly prohibited all civilian federal agencies and private contractors from discriminating against employees or potential employees due to their sexual orientation or gender identity, though the order did provide private contractors with a religious exemption (EO 13672, 21 July 2014). It should be noted, however, that the EEOC had already ruled in Macy v. Holder that discrimination against an employee due to their gender identity was a violation of Title VII's ban on sex discrimination, effectively making discrimination against a gender minority illegal in the federal workforce. Nonetheless, because of Obama's actions, most of the

\footnotetext{
2 Though EO 12968 was the first to give protections to LGB+ federal employees from discrimination, it was not the first to allow these groups access to federal jobs. EO 12107 (signed by President Carter), for example, opened up employment in the IRS and the USFS to sexual minorities after they were barred from these positions by Eisenhower in 1953. These actions, however, did not prevent discrimination from occurring, but rather gave LGB+ individuals the opportunity to work in these agencies.
} 
federal workforce now have employment protections that shield them from discrimination due to their sexual orientation or gender identity.

These protections, though, apply only to the roughly 2.8 million individuals in the federal civilian workforce (BLS 2017) and the roughly 14 million employees of contractors who work with the federal government (Associated Press 2014). This amounts to about 10\% of the U.S. workforce, according to 2017 data from the US Bureau of Labor Statistics. Further, as executive orders, these protections are at the mercy of future Presidents. Recent events provide an excellent example of why EOs are not ideal policy solutions. Although President Trump announced on January 31, 2017, that he had full intentions of enforcing President Obama's EO 13672 (Scott \& Wright 2017), his use of executive orders suggests otherwise.

Executive Order 13782, signed by President Trump on March 27, 2017, rescinded EO 13673, which had been signed by Obama in 2014. EO 13673 required all organizations to disclose their civil rights records - including litigation - to the Department of Labor in applying to be a contractor for the federal government (EO 13673, 31 July 2014). EO 13673 also instructed the government to consider these records in deciding which organizations to contract with, meaning companies with a history of discrimination would be at a disadvantage. Trump's EO, however, eliminated both of these requirements; and now private companies who violate the various employment acts and EOs of the United States are at a lesser disadvantage than they were under the Obama Administration.

There were also rumors in February 2017 that President Trump planned to expand the religious exemptions of Obama's executive orders after a leaked draft of Trump's "Establishing a Government-Wide Initiative to Respect Religious Freedom" was obtained by journalists from The Nation. According to the leaked document, the executive order would allow private organizations to claim sweeping religious exemptions for various civil rights acts and orders, granting these organizations broad religious freedoms in various aspects of business - including employment (Posner 2017). The leaked draft, whose authenticity was never confirmed or denied by the Administration, led to massive outcry from LGBTQ+ advocates over the potential setback in gay and transgender rights (ACLU 2017). Ultimately these anti-LGBTQ+ provisions were not included in the EO’s final draft, which was signed by Trump in May 2017. 
Nonetheless, both this leaked draft and EO 13782 demonstrate that protections stemming from executive orders are not long-term policy solutions to LGBTQ+ employment discrimination in the federal workforce.

\section{Recent Rulings by the EEOC}

A potentially more permanent and far-reaching solution could come from the Equal Employment Opportunity Commission (EEOC). The EEOC is an independent federal agency charged with enforcing civil rights laws against workplace, housing, and public accommodation discrimination across the United States. Created via Title VII of the Civil Rights Act of 1964 (herein referred to as Title VII) to enforce the law, the EEOC's roles and duties have expanded in recent decades as further civil rights laws have been created, most of which is under the purview of the agency (Nelson 2015). The Commission consists of five commissioners who are appointed by the president and confirmed by the Senate ( 42 U.S. Code $\S 2000 \mathrm{e}-4$, subsection a). Once confirmed, commissioners serve five-year terms, which are renewable at the discretion of the President and Senate (Nelson 2015). Title VII also specifies that the Commission shall not have more than three commissioners from the same political party.

Title VII explicitly prohibits employers with fifteen or more employees from discriminating against individuals in the workplace due to their sex, race, color, religion, and national origin (42 U.S. Code $\S 2000 \mathrm{e}-4$, subsection a). Many in the LGBTQ+ community have stated that Title VII implicitly protects LGBTQ+ individuals as well through their interpretation of "sex" discrimination (Muñoz \& Kalteux 2016). These claims often stem from the argument that both sex and LGBTQ+ discrimination are linked to heteronormativity. Heteronormativity is the belief that men and women have distinct gender roles in society, and any deviation from these roles - whether regarding same-sex relationships or women participating in "masculine" disciplines - is unnatural. Discrimination against a gay man, for example, is connected to notions of how "men" should act and therefore is a case of sex discrimination.

Earlier courts and the EEOC were not sympathetic to this interpretation (Marcosson 1992/93). This began to change under the Obama Administration. In the 2012 landmark case, Macy v. Holder [EEOC Appeal No. 0120120821] (herein referred to as Macy), the EEOC unanimously declared that discrimination against an individual based on their gender identity is akin to sex discrimination as outlined in Title VII (EEOC 2012). Macy has thus far been the furthest-reaching decision regarding what transgender 
employment rights are in the United States. The decision reflects the EEOC's new interpretation of Title VII: that discrimination against a transgendered individual is sex discrimination.

Macy, in addition to President Obama's EO13672, ensures that federal agencies are required to have nondiscriminatory practices in their workplaces for their transgender employees. The EEOC sets and adjudicates federal employment policy, meaning the agency has the final say in deciding if a federal agency violated Title VII (EEOC 2016). The ruling also influences state and local government employment, as well as private employers who are under the purview of Title VII, though the EEOC does not possess the power to determine guilt in these cases. Rather, the EEOC may sue discriminating employers on behalf of a discriminated individual. In these circumstances, the federal court has the authority to concur or dissent from the EEOC's interpretation of sex discrimination.

The EEOC made headlines again in the 2015 case of Baldwin v. Foxx (EEOC Appeal No. 0120133080). This case centered on an air traffic control specialist for the Department of Transportation who was denied a promotion by his boss who frequently expressed disapproval about his sexuality (EEOC 2015b). David Baldwin, who is protected by EO 13087, filed a complaint with the EEOC (Muñoz \& Kalteux 2016; EEOC 2015b). The EEOC sided with Baldwin in the case, citing evidence that showed 1) Baldwin was well qualified for the promotion; 2) Baldwin's supervisor had clear prejudices against homosexuals; and 3) this prejudice was a deciding factor in Baldwin not receiving a promotion (EEOC 2015b). The EEOC, however, cited Title VII as justification for their opinion, not EO 13087. In the landmark ruling, the EEOC declared that discrimination against a sexual minority in the workplace violates Title VII's ban on sex discrimination (EEOC 2015b).

While many LGBTQ+ organizations have celebrated the EEOC's recent efforts (HRC 2016; TLC 2013), Ryan Nelson of Washington and Lee Law School notes that these victories might be short-lived. According to Nelson (2015), three scenarios may result in these decisions being overturned in the future: a reversal of opinion within the EEOC, an act of Congress, or a Supreme Court ruling. Since these rulings were interpretations of Title VII by the Commission, future changes to the makeup of the EEOC can result in a change of interpretation of the law. This situation is especially worrisome in light of the recent presidential election. If, for example, President Trump nominates and the Senate confirms commissioners 
who do not agree with the current interpretation by the EEOC, they may either not accept cases made by the LGBTQ+ community or issue their own, non-LGBTQ+ inclusive interpretation of Title VII.

Nelson (2015) has noted that this scenario is perhaps more likely for the EEOC's interpretation of sexual orientation discrimination as sex discrimination, as the vote for the Baldwin v. Fox ruling was threeto-two as opposed to the unanimous decision made in Macy. Still, in either case, there will be at least two Democrats on the Commission, and Nelson (2015) noted that the EEOC rarely reverses itself, making this scenario unlikely. Nelson also does not believe that Congress can muster the votes to create legislation that would define Title VII as not pertaining to sexual or gendered minorities, making this scenario unlikely as well (Nelson 2015).

For Nelson (2015), the most likely scenario that will either solidify or dissolve the EEOC's interpretation is the judicial system accepting - or not - that reading of Title VII as valid. At the time of his article, Nelson noted that no Circuit Court of Appeals had ever ruled that discrimination against sexual and gendered minorities is akin to sex discrimination under Title VII. ${ }^{3}$ These Courts have the ability to set legal precedent over the district courts that fall within their boundaries, meaning it will be challenging for the EEOC to make a credible claim against LGBTQ+ discrimination in any court if the appellate courts have consistently ruled that their argument is not in accordance with Title VII. Nelson, then, remains pessimistic as to the long-term effects of the EEOC's interpretation of Title VII.

Recent events, however, have altered the landscape on this issue. On April 4, 2017, LGBTQ+ advocates won a major victory in the Seventh Circuit Court of Appeals in Chicago after the court ruled that Title VII's ban on sex discrimination applies to sexual minorities as well (Hively v. Ivy Tech Community College, 830 F. 3d 698). In an 8-3 decision, the traditionally conservative Court - five of the eight Judges that made up the majority were nominated by Republicans - overturned the decision made by a lower US District Court that ruled sexual orientation is beyond the scope of Title VII. In the majority opinion released by the Seventh Court, the judges concurred with the EEOC that discrimination against LGBTQ+

\footnotetext{
${ }^{3}$ Between 1978 and 2015, ten of the twelve Circuit Court of Appeals have ruled against the argument that
} LGBTQ+ discrimination is sex discrimination and two courts did not issue any ruling (Nelson 2015). 
individuals ultimately stems from gender-stereotyping, which was outlawed by the U.S. Supreme Court in Price Waterhouse v. Hopkins (Hively v. Ivy Tech Community College, South Bend, 830 F. 3d).

The ruling for Hively v. Ivy Tech Community College came just a month after the Eleventh Circuit Court came to the opposite conclusion in Evans v. General Regional Hospital [No. 15-15234], stating that discrimination against sexual minorities is not sex discrimination. With two Appeals Courts coming to different conclusions about the same legal question, legal analysts have stated that it is likely that the Supreme Court will take up the issue shortly (Williams 2017). If the Supreme Court concurs with the EEOC's interpretation of sex discrimination, then Title VII will protect the vast majority of LGBTQ+ Americans against discrimination in employment (including private employment), as well as in housing and public accommodations. If the Court rules against the EEOC's interpretation, however, it would essentially overturn the EEOC's ruling in both Macy and Baldwin, a major setback for LGBTQ+ rights in the United States.

\section{$\underline{\text { State and Local Protections }}$}

While the federal government has been slow to adopt strong workplace protections for LGBTQ+ Americans, many state and local governments have taken the lead and introduced laws and ordinances that grant these protections to some or all of its residents. Similar to the situation at the federal level, however, progress in many state and local jurisdictions has remained slow, particularly for gendered-minority Americans. Nonetheless, the number of states and localities that possess these laws and ordinances has grown greatly since the turn of the new century.

Progress for gay, lesbian, and bisexual Americans began at the local levels during the 1970s. In 1972, San Francisco became the first city to ban discrimination against sexual minorities in the public sector (Movement Advancement Project 2015a). Seattle and Washington D.C. quickly followed suit in 1973, but these cities provided employment protections in both the public and private sectors. Following these victories, liberal college towns began implementing LGB employment protections in greater numbers, including Austin, Tucson, Amherst, Champaign, Berkley, Ann Arbor, and Madison (Johnson 
2015). The only cities not known for their large university presence to implement an LGB employment protection ordinance during this decade were Aspen and Detroit (Johnson 2015).

State politicians were also beginning to discuss implementing a ban on discrimination against sexual minorities during this time. In 1975, Pennsylvania Governor Milton Shapp signed Executive Order 1975-5, prohibiting discrimination in state employment due to "sexual or affectional orientation" (Rimmerman, Wald, Wilcox 2000; Shapp EO 1975-5). In 1982, Wisconsin became the first state to protect sexual minorities against employment discrimination in both public and private employment (Rimmerman et al. 2000). By 1999, twelve states had added the term "sexual orientation" to their state civil rights laws, protecting $24.3 \%$ of all Americans at the time (Rimmerman et al. 2000; MAP 2015a).

Protections for gendered minorities would similarly begin at the local level. In 1974, Minneapolis became the first city to protect their gay, lesbian, bisexual, and transgendered residents from discrimination in the public and private sectors (MAP 2015a). Unlike protections for LGB residents, however, this new initiative did not appear to inspire other cities to enact a nondiscrimination ordinance for gendered minorities. By 1990, 6\% of Americans lived in jurisdictions that outlawed LGB discrimination in employment (MAP 2015a). At the same time, only $0.2 \%$ of Americans lived in areas that provided the same protections for gendered minorities (MAP 2015a). In 1993, Minnesota became the first state to protect gendered minorities in all areas of employment (MAP 2015a). Again, this event did not seem to inspire other states to act, as it was not until 2001 when Rhode Island became just the second state to grant such protections (MAP 2015a). This reality demonstrates how progressive the Kentucky municipalities of Louisville and Lexington were in 1999, when they became among the first cities in the United States to protect their gendered minority residents.

As of June 2017, twenty states, the District of Columbia, and the territories of Puerto Rico and Guam have protections against both gender identity and sexual orientation discrimination in the public and private sectors (HRC 2016a). Wisconsin and New Hampshire have statewide protections against discrimination stemming from sexual orientation - but not gender identity - in the public and private sectors, though New Hampshire does ban discrimination against gendered minorities in public employment (HRC 2016). Nine states - including Kentucky - have protections against sexual orientation and gender 
identity discrimination in public employment and four states have these protections only for sexual minorities (HRC 2016).

At the same time, 305 municipalities have some form of employment protections for their LGB + residents, and 225 have similar protections for gendered minorities as well (HRC 2016a). Most of these protections occur in cities and counties with large populations, though the Movement Advancement Project (2015a) and the Human Rights Campaign (2016a) both have stated that these protections are becoming increasingly common in smaller municipalities as well. A 2015 study by the Movement Advancement Project found that about $192,000,000$ Americans (roughly $59.1 \%$ of the U.S. population) live in areas that prohibit discrimination against sexual minorities in all employment, and 157,000,000 Americans (52.3\%) live in areas with similar protections for gendered minorities.

\section{$\underline{\text { State LGBTQ+ Employment Protections in Kentucky }}$}

While state governments have become increasingly active in protecting their LGBTQ+ residents, the Commonwealth of Kentucky has, at best, stalled on the issue and, at worst, taken steps to reverse the progress made by some local governments in the state. The state legislature of Kentucky has enacted no law prohibiting employment discrimination stemming from an employee or potential employee's sexual orientation or gender identity. Because of this, LGBTQ+ Kentuckians have no legal recourse to challenge discrimination with the help of the Kentucky Commission on Human Rights, the state agency charged with investigating and adjudicating discrimination complaints in employment, housing, and public accommodation. Instead, LGBTQ+ Kentuckians are reliant on local governments to pass Fairness Ordinances - of which only eight have. Otherwise, they must depend on their places of employment to have internal LGBTQ+ nondiscrimination policies.

Effort has been made by some Kentucky lawmakers to protect LGBTQ+ Kentuckians from employment discrimination. The first Fairness Bill introduced into the Kentucky General Assembly was House Bill 7, introduced during the 2000 Regular Session by Representative Mary Lou Marzian (D- 
Louisville) and Representative Kathy Stein (D-Lexington) (Marzian, personal communication (PC) 2016). ${ }^{4}$ HB7 would amend the Kentucky Civil Rights Act of 1966 (KRS 344) to include the words sexual orientation (Kentucky Legislative Research Commission (LRC), HB7). Similar to the federal Civil Rights Act, the Kentucky Civil Rights Act prohibits discrimination from occurring in housing, public accommodations, and employment based on various attributes including skin color, religion, or even smoking status. HB7, however, died in the Judiciary Committee without receiving a hearing (LRC, HB7 2000).

Despite this setback, Representative Marzian and her growing number of allies in the General Assembly have continued to introduce similar bills in every legislative session since the year 2000, with provisions for protecting gender identity included starting in 2001 (LRC, HB116 2001). For over a decade, these bills would receive no committee hearings in either the House or Senate. This changed in 2014 when the House Judiciary Committee held a hearing on that session's Fairness Bill, HB171 (LRC, HB171 2014). Though no further action was taken on HB171 or its Senate counterpart (SB140), many LGBTQ+ advocates in the state saw this as a significant step in the right direction (Cheves 2014).

While the General Assembly has refused to hold a vote on the various Fairness Bills that have been introduced, two former Kentucky governors have used executive orders to protect some of the state's LGBTQ+ workforce. At the state level, Kentucky's first ban on LGBTQ+ discrimination came in May 2003 when Governor Patton signed Executive Order 03-533, banning discrimination against some categories of public employees due to their sexual orientation or gender identity. This move made Kentucky just the fourth state to protect employees in the public sector against discrimination due to their gender identity (Brown 2008). While Governor Patton made Kentucky a leader in protecting its transgendered public workforce, his order was limited. The executive order did not protect employees of local municipalities, non-executive branch state employment, or the private sector. In total, the EO only covered 34,000 jobs in the state, accounting for $0.02 \%$ of all employment (Mallory \& Sears 2015).

Despite its limited scope, the executive order was not without its controversies. Many conservatives in Kentucky, including within the Kentucky Democratic Party, denounced the decree on the

\footnotetext{
${ }^{4}$ Representative Mary Lou Marzian was interviewed on October 06, 2016 at Heine Brothers Café.
} 
grounds of religious liberty and promoting what they saw as an unnatural lifestyle (Brown 2008). The issue of gay rights was a major political concern in the country at this time, and many conservatives feared LGBTQ+ activists were gaining ground, especially after Massachusetts became the first state in the union to grant marriage licenses to same-gender couples in 2004. In April of 2006, Republican Governor Ernie Fletcher eliminated former Governor Patton's executive order, thereby reopening the door for LGBTQ+ discrimination in state employment. Fletcher claimed the protections were erroneous because they were “unnecessary, legally expensive, and provided for 'special treatment”" (Brown 2008). Governor Fletcher's policy reversal was temporary, however. Just seven months after taking office, the new governor of Kentucky - Steve Beshear - signed Executive Order 2008-473, restoring LGBTQ+ protections to state employees (Brown 2008).

Following the 2015 Kentucky gubernatorial election, in light of the transience of executive orders depending on who was in charge, many LGBTQ+ activists feared that this protection was in danger yet again. Newly elected Republican Governor Matt Bevin had taken a hard stance against LGBTQ+ rights in his campaign, including praising Rowan County Clerk Kim Davis and her fight against authorizing samegender marriage certificates. This was particularly worrisome early into the new administration, as Governor Bevin made it clear he was not against using his executive powers to reshape the state government. In December 2015, Governor Bevin issued a string of executive orders, many of which nullified several of Beshear's orders (Wynn 2015). EO 2008-473 was not, however, one of them.

All indications make it seem unlikely that Governor Bevin will alter or eliminate EO 2008-473. Both Michael Aldridge, Executive Director of the ACLU of Kentucky, and Representative Marzian (DLouisville) expressed their convictions that the governor will not touch Beshear's executive order (Aldridge, PC 2016; Marzian, PC 2016). ${ }^{5}$ Noting that Governor Bevin is first and foremost a "business man," Aldridge expressed his belief that "Bevin might be against [same-gender] marriage, but he knows the value of non-discrimination from a business angle...You'll notice he never speaks out against [Fairness]" (Aldridge, PC 2016). Governor Bevin is primarily focused on economic growth, and eliminating the executive order would bring unwanted attention to the state of Kentucky that could discourage businesses

\footnotetext{
${ }^{5}$ Michael Aldridge was interviewed on September 15, 2016 at the ACLU of Kentucky office in Louisville.
} 
from locating there. Governor Bevin, then, appears not to want Kentucky to become the next Indiana or North Carolina, a situation that may save EO 2008-473. ${ }^{6}$

Executive Order 2008-473 is not the only anti-discrimination policy that may be under threat from the conservative state government, as recent political events have also threatened the status of the eight local Fairness Ordinances that are currently in effect. During the 2016 legislative session, several bills were introduced in the General Assembly that would restrict or eliminate the progress LGBTQ+ advocates have made in the Commonwealth (see $L R C$ ). One of the more notable bills was Senate Bill (SB) 180, which passed in the Republican-dominated Senate and sought to weaken local Fairness Ordinances by granting significant religious exemptions to existing and future civil rights legislation (LRC, SB180 2014).

The Democrats, however, narrowly controlled the Kentucky House, and Speaker Greg Stumbo told the press that SB 180 would be "dead on arrival" after the Senate passed the bill (ACLU 2016). Stumbo's reign as House Speaker would end less than a year after he successfully tabled SB 180, however. In the 2016 state elections, voters across the Commonwealth gave Republicans control of the Kentucky House for the first time since 1921 (Brammer \& Blackford 2016). Given that the party also maintained firm control over the Senate and with Bevin as Governor, Republicans have near total autonomy in Frankfort, opening the door for more bills such as SB180 to be signed into law.

Before the 2017 legislative session even began, three bills were introduced into the General Assembly that would have had an adverse impact on the Commonwealth's LGBTQ+ population. House Bill 106, introduced by Democrat Rick Nelson, sought to segregate all public, multi-occupancy bathrooms in the state based on an occupant's birth-assigned sex (LRC, HB106 2017). ${ }^{7}$ HB 106, however, was unsuccessful in the General Assembly, failing even to receive a hearing in the House. Jeff Hoover, the new

\footnotetext{
${ }^{6}$ While an increasing number of state and local governments have begun expanding civil liberties to their LGBTQ+ residents, a few conservative governments have enacted legislation that has restricted such rights. Among these are the state governments of Indiana and North Carolina, whose actions will be discussed in Chapter VI of this thesis.

${ }^{7}$ Despite the economic losses seen in North Carolina, Kentucky is one of fifteen states that had filled a "Bathroom Bill" during the 2017 legislative session. What is unique about HB106, however, is that it is the only such bill to be filed by a Democrat (KFTC 2017). Nelson's actions demonstrate the unique political environment that exists in Kentucky, in which Fairness advocates must convince both Democrats and Republicans of the benefits of Fairness.
} 
Republican House Speaker, mirrored his predecessor when he told the media that the bill would not see a vote during the 2017 legislative session (Desrochers 2017). In addition to Hoover's actions, Governor Bevin dismissed the concept of a Kentucky "Bathroom Bill" at a news conference in December 2016, calling the proposed legislation "silly", "unnecessary", and addressing a "nonexistent problem" (Brammer \& Desrochers 2016), giving credit to Aldidge's claim that Bevin understands the economic consequences of discrimination.

Apparently, Governor Bevin does not hold all anti-LGBTQ+ bills in such low esteem. Among many things, SB17 - also known as the Charlie Brown Law - would allow student organizations at public secondary and post-secondary institutions to discriminate in membership and organizational affairs if the group has a religious reasoning for doing so (LRC, SB17 2017). Many civil rights activists feared SB17 would allow student organizations the right to reject LGBTQ+ students under the pretext of religious freedom (Duffy 2017). Unlike HB106, however, SB17 easily made its way through the Legislature with broad bipartisan support and Governor Bevin signed the Charlie Brown Law (LRC, SB17 2017).

While SB 17 will surely be harmful to LGBTQ+ Kentuckians, the most destructive recent bill to threaten Fairness in Kentucky is almost certainly HB105. Dubbed by its opponents as the "License to Discriminate" bill, HB105 was introduced by Representative Nelson - who also introduced HB106 - and mirrored SB180, which was passed in the Senate a year earlier (LRC, HB105 2017, SB180 2016). HB105 would prohibit any statute - including a local ordinance - from "impairing, impeding, infringing upon, or otherwise restricting the exercise of protected rights or the right of conscience by any protected activity provider" (LRC HB105 2017).

The specific language of HB105 is vague, which has led to disagreements between opponents and supporters of the bill on what activities are protected and which organizations can claim to be a "protected activity provider." Representative Nelson and other supporters of the bill have stated that the scope of HB105 is limited to a narrow set of public accommodations: specifically, to activities that may contradict an individual's First Amendment rights. As an example, Nelson told the media (HRC 2017) that under HB105, a clothing manufacturer could refuse to print and sell shirts endorsing same-sex marriage, as doing so may be a violation of their religious beliefs. What would not be allowed under HB 105 , according to 
Nelson, is for the same clothing manufacturer to refuse to sell any merchandise at all to an LGBTQ+ individual (HRC 2017). To try to reassure opponents of HB105 of this limited scope, Nelson utilized the same definition of "protected activity provider" that was used in SB180 a year earlier. Under this definition, HB105 would apply only to individuals who provide "customized, artistic, expressive, creative, ministerial, or spiritual goods or services" (LRC, HB105 2017).

Opponents of legislation such as HB105 and SB180 argue that these bills are more encompassing than their supporters suggest. While discussing SB180, Director Aldridge (PC 2016) noted that most business owners could argue that they provide a "customized" or "expressive" service to the community, as these attributes are broad and unspecified in these bills. This interpretation would suggest, according to HB105 opponents, that the majority of businesses and services located in a municipality with a Fairness Ordinance would have the right to claim a religious exemption to the ordinance if HB105 were passed, curtailing the impact of local nondiscrimination laws in Kentucky.

Director Aldridge also appeared quite adamant that these exemptions would go beyond the scope of public accommodations and curtail the authority local human rights commissions have in protecting other clauses of Fairness, including employment rights. Referencing the recent events in Indiana regarding their own Religious Freedom Restoration Act, Aldridge asked, "Why don't they just clarify it in the bill if that is not the intent like [Indiana lawmakers] had to do after they passed their version [of HB105] (Aldridge, PC 2016)?”8 As will be evident in later chapters, business owners who refuse to hire members of the LGBTQ+ community often justify their actions by claiming it is their right to do so under the First Amendment. Neither SB180 nor HB105 specifies - or limits - what "the exercise of protected rights" guaranteed by the bills are (LRC, HB105 2017, SB180 2016). This unclarity suggests that business owners can justify a whole host of actions under the guise of religious liberty or freedom of speech, including employment practices.

\footnotetext{
${ }^{8}$ Following the protests and scrutiny Indiana lawmakers received after they passed their RFRA in 2015, which many interpreted as nullifying the existing local non-discrimination ordinances in the state, the Indiana General Assembly signed an amendment to the bill clarifying that the act did not dictate which categories of people local officials are allowed to protect in employment and public accommodations.
} 
Despite the considerable amount of concern garnered by HB105 in Kentucky's LGBTQ+ community, the bill was less successful than was its earlier Senate counterpart. Speaker Hoover and Governor Bevin quickly dismissed the bill, both stating that they wanted to focus on economic initiatives, not "social policies" (ACLU 2017). ${ }^{9}$ Despite the lack of support HB105 received in the House, Chris Hartman, Executive Director of the Fairness Campaign, the largest LGBTQ+ rights organization in the state, warned activists that conservatives would likely introduce a similar bill in 2018 (Hartman 2017).

With a longer legislative session scheduled for 2018, Hartman noted that more pressure would be needed to ensure existing Fairness Ordinances remain robust (Hartman 2017).

\section{Local Nondiscrimination Ordinances in Kentucky}

While the General Assembly has refused to protect LGBTQ+ Kentuckians from workplace discrimination, local governments across the Commonwealth have passed ordinances that give these protections to their residents. Fairness Ordinances work to protect local LGBTQ+ residents by granting safeguards against discrimination in employment, public accommodations, and housing. As of June 2017, eight municipalities in Kentucky have such ordinances. In two of these cases, the local Fairness Ordinance prohibits discrimination across the entire county (both cases have a consolidated metropolitan county government). Most Fairness Ordinances in the state, however, are proposed and implemented on a city-bycity basis. As of 2017, roughly $26 \%$ of Kentuckians are protected from workplace discrimination by a Fairness Ordinance (US Census 2010).

\section{Timeline of Fairness in Kentucky}

The pre-consolidated city of Louisville was the first local government in Kentucky to pass a nondiscrimination ordinance in all areas of employment for its LGBTQ+ community, which occurred on January 26, 1999 (Bennett 2011). The Fairness Ordinance was hard fought for over a decade, as the Louisville Board of Aldermen defeated the bill three times throughout the 1990s (Bennett 2011). The resulting ordinance, however, was historic, as Louisville became among the first cities in the South to

\footnotetext{
${ }^{9}$ Although Fairness laws and ordinances are just as much economic policies as social policies.
} 
protect its residents against discrimination due to their sexual orientation (Mallory and Sears 2015) and among the first in the country to offer these protections for gendered minorities (Fosl 2016).

In October 1999, the Jefferson County Fiscal Court - the center of government for the nonLouisville areas of Jefferson County before the merger - followed suit, passing a Fairness Ordinance that gave residents across the county equal employment protections (Bennett 2011). These protections, however, were in jeopardy as of 2003 due to a recent Louisville-Jefferson County merger (Bennett 2011). The new Metro Council was given five years to amend or adopt ordinances from its two predecessors, meaning that these employment protections granted to Jefferson County residents could have expired at the end of 2007. Despite a strong push by Louisville conservatives to let the ordinance expire, the new Louisville Metro Fairness Ordinance easily passed the Metro Council in 2004 by a vote of nineteen to six (Bennett 2011).

Following Louisville's lead, Lexington also passed a nondiscrimination ordinance (Ord. No. 20199) later in 1999, joining Louisville as being among the most progressive cities in the United States when it came to gendered minority rights. While it took eight years for the Fairness Ordinance in Louisville to come to fruition after first being introduced to the Board of Aldermen in 1991, the process in Lexington was much shorter - only about two weeks. In June of 1999, the Lexington-Fayette Urban County Human Rights Commission unanimously voted to recommend the Urban County Council to adopt the Fairness Ordinance, which the Council did on July 8, 1999, by a vote of eight to three (Bennett 2011).

The fact that both Louisville and Lexington were among the first in the Commonwealth to give their LGBTQ+ communities employment protections is hardly surprising. As easily the two largest metropolitan regions in the state, Louisville and Lexington have long been major centers of life for the state's LGBTQ+ population (Truman 2015) and each host the largest LGBTQ+ advocacy groups in the Commonwealth - Fairness Coalition (Louisville) and Lexington Fairness. Progress throughout the rest of the state, however, has remained slow. In fact, the first decade of the $21^{\text {st }}$ century witnessed a great deal of regression when it came to LGBTQ+ rights in the state. In 1999, Henderson passed its own Fairness Ordinance, though this order did not extend protections to gendered minorities (Ord. 43-99 1999). Though the Fairness Ordinances in both Louisville and Lexington had their share of opponents, the most vocal 
Henderson residents appeared to be overwhelmingly opposed to offering LGB individuals employment protections in their town (Bennett 2011). Before the passage of the Henderson Fairness Ordinance, many residents threatened to remove any commissioner who supported the ordinance from office at the next election (Council 2012). Following the 1999 vote, Henderson residents made good on their promise, and only one of the three Commissioners who voted in favor of Fairness was reelected during the 2000 election. With a more conservative government in power, the Henderson Commission voted to remove these protections from their ordinance code in January 2001 (Bennett 2011).

The repeal of the Henderson Fairness Ordinance was just the start of a string of defeats LGBTQ+ activists would face in Kentucky during the first decade of the 2000s. In 2004, 75\% of Kentucky voters said "Yes" to Kentucky Constitutional Amendment 1, amending the Kentucky Constitution to define marriage as between "one man and one woman." As already mentioned, in 2006 Governor Fletcher canceled Governor Patton's EO 03-533, again permitting discrimination in state employment based on sexual orientation and gender identity. ACLU Director Aldridge stated that these actions sent a message to city officials who might have otherwise been open to a Fairness Ordinance for their communities:

“After the 'Yes' vote, gay rights became politically toxic for many local officials... Many local governments wouldn't discuss Fairness, even if they were supportive of these measures... It was largely out of fear, they were afraid that supporting gays and lesbians would anger residents. (Aldridge, PC 2016).

These highly publicized series of events may help explain why in the first decade of the $21^{\text {st }}$ century $-\mathrm{a}$ decade that witnessed an expansion of LGBTQ+ nondiscrimination laws elsewhere - in Kentucky, only Covington passed a Fairness Ordinance (Ord. O-20-03).

The small, Appalachian town of Vicco broke this drought and in doing so made history as the smallest town (population 334) in the United States to pass a comprehensive LGBTQ+ employment protection ordinance (Hunter 2013). On January 14, 2013, the Vicco Commission passed the Fairness Ordinance by a vote of three-to-one (Aldridge, PC 2014). Following the vote, Vicco made national headlines, with institutions such as The Huffington Post, The Washington Post, The New York Times, and even The Colbert Report covering the historic event. Although the Vicco Fairness Ordinance covers only 0.0004\% of Kentucky's population (2010 Census), the actions taken in Vicco would have far-reaching consequences for the LGBTQ+ movement in Kentucky. 
The series of setbacks that had been occurring for over a decade up to the vote in Vicco generated a significant amount of tension between several of the state's LGBTQ+ advocacy groups, particularly following the Kentucky Constitutional Amendment 1 vote (Aldridge, PC 2016). When asked the source of this tension, Aldridge noted that:

"People's feelings were hurt [after the 2004 vote]. Many of the smaller groups felt isolated and ignored by the larger organizations in the state during the campaign... After that, no one would speak to each other... Each group did their own thing for a while, but that really wasn't working." (Aldridge, PC 2016)

This isolation was partly remedied in 2008 when five of the larger LGBTQ+ advocacy groups in the state - the Fairness Campaign, the Kentucky Fairness Alliance, the ACLU of Kentucky, Lexington Fairness, and the Kentucky Commission on Human Rights ${ }^{10}$ - formed the Kentucky Fairness Coalition (KFC). Though the Coalition required these organizations to work in close cooperation with one another, Aldridge noted that there was still a considerable amount of distrust among the KFC organizations (Aldridge, PC 2016). Contributing to this tension was the coalition's lack of victories, as no city in Kentucky enacted a Fairness Ordinance during the first four years of the KFC's existence (Aldridge, PC 2016). Aldridge noted that the KFC was "desperate for a win" and, to the surprise of many, this win would come in Vicco. Aldridge described the significance of this victory:

"Vicco really rejuvenated the [LGBTQ+] movement in Kentucky... We needed to see a victory soon. We were never going to give up on nondiscrimination laws, but after Richmond, it was looking like it would be years before another city passed Fairness. Vicco helped set into motion all the success we have had up to this point." (Aldridge, PC 2016) ${ }^{11}$

The actions taken by the Vicco Commission inspired other cities in the Commonwealth to act.

Vicco Mayor Johnny Cummings, who is a gay man, told host Stephen Colbert that shortly after passing the

\footnotetext{
10 The Kentucky Commission on Human Rights is not an LGBTQ+ advocacy group, but a state agency formed to investigate discrimination and enforce the Kentucky Civil Rights Act. Nonetheless, the KCHR has been a strong advocate for Fairness in the State and chose to join the KFC in 2008.

${ }^{11}$ In the quote, Director Aldridge was referring to the failed attempt made by the KFC of passing a Fairness Ordinance in Richmond in 2012. There was a strong grassroots movement already established in the city, and the residents appeared to have supported it, yet the Richmond Commission never held a vote on the ordinance. It was from this movement in Richmond, though, that Aldridge met the sister of the Mayor of Vicco, who convinced the KFC to try to pass a Fairness Ordinance in the small town.
} 
ordinance, five other Kentucky mayors contacted him about passing a similar ordinance in their communities (Hunter 2013). The Vicco Fairness brought national attention to the lack of employment protections faced by rural LGBTQ+ Americans and demonstrated that Fairness can be enacted in a politically beneficial way in Kentucky. Within a year of Mayor Johnny Cummings signing the Vicco Fairness Ordinance, the cities of Frankfort (Am. Ord. 7) and Morehead (Ord. 29:2013) passed ordinances protecting their LGBTQ+ residents. These actions were then followed by the cities of Danville (Ord. No. 1836) in 2014 and Midway (Ord. 2015-002) in 2015. Though no new municipality has enacted a Fairness Ordinance since 2015, Vicco's significance cannot be overstated. At the start of 2013, only three Kentucky municipalities possessed a Fairness Ordinance, despite the first ordinance passing thirteen years earlier. Within three years of the Vicco ordinance, this number almost tripled to eight.

\section{Fairness Ordinances in Kentucky}

In 2013, the Michigan Department of Civil Rights (MDCR) released a study that examined the social and economic benefits that could be made if its state government extended civil rights protections to LGBTQ+ residents. In their report, the MDCR noted that, while most businesses in Michigan supported local nondiscrimination ordinances, many were frustrated by the sheer variability that existed between cities that possessed such laws. Even seemingly simple concepts such as the definition of sexual orientation or gender identity made knowing what the companies were legally responsible for difficult, as the MDRC noted that fourteen different definitions of sexual orientation were used by the thirty-three municipalities that possessed local nondiscrimination ordinances. Other potential inconsistencies included whether gender identity was protected in the city, which organizations were potentially liable under the ordinances - and which were exempt - and which services had to be free from discrimination (MDCR 2013).

For the most part, municipalities in Kentucky have avoided these problems, as there is an almost remarkable amount of conformity between the eight Fairness Ordinances in the state (see Table 3.01). This consistency is in large part due to the work of both the Fairness Campaign and the ACLU of Kentucky, which have long aided local governments in drafting Fairness Ordinances (Aldridge, PC 2016). In fact, one accomplishment that Aldridge is most proud of as Director of the ACLU is the Coalition's continued success at ensuring that when a Fairness Ordinance is passed, it covers gender identity in addition to sexual 
orientation (Aldridge, PC 2016). In the United States, 22.6\% of municipalities that prohibit employment discrimination based on sexual orientation do not have similar protections for gender identity (MAP 2017). In the state of Kentucky, this disparity does not exist.

Each ordinance also defines the terms sexual orientation and gender identity identically. These ordinances define sexual orientation as "an individual's actual or imputed heterosexuality, homosexuality or bisexuality” (Ord. 43-99; Jeff. Ord. 36-1999; Ord. No. 201-99; Am. Ord. 7; Ord. 29:2013; Ord. No. 1836; Ord. 2015-002). Similarly, these ordinances define gender identity as "manifesting an identity not traditionally associated with one's biological maleness or femaleness" (Ord. 43-99; Jeff. Ord. 36-1999; Ord. No. 201-99; Am. Ord. 7; Ord. 29:2013; Ord. No. 1836; Ord. 2015-002). All eight ordinances also protect against discrimination not only in employment but also in public accommodations and housing. Religious corporations and associations - including schools or universities tied to a particular religion - are given certain exemptions from all eight Fairness cities as well.

There is, however, one potentially telling difference between these otherwise identical ordinances. This relates to the definition of employer in each of these municipalities, specifically the number of employees an organization is required to have to be termed an employer (Table 3.01). Lexington-Fayette has the most extensive definition of employer, as it does not have a minimum number of employees required for its ordinance to take effect. In other words, all employers with at least one employee - which, assumedly, would be all employers - are required to adhere to Lexington's Fairness Law unless they possess a religious exemption (Charter and Code of Ordinances Ch. 2, Art. 2, Sec. 33). Title IX, Chapter 32 of Louisville-Jefferson County's Ordinance Code defines employer as “any organization who employs two or more employees for four or more weeks within a calendar year" limiting only slightly the number of organizations that fall under the ordinance's purview. While Louisville and Lexington may have differing definitions of "employer," the other six municipalities with a Fairness Ordinance define employer the same: "any person with fifteen or more employees for four or more weeks within a calendar year" (Covington Code Ch. 37.02; Morehead Code Ch. 96.02; Midway Code 94.02; Frankfort G.R. 96.02; Danville Code Chap. 5.5-2). 


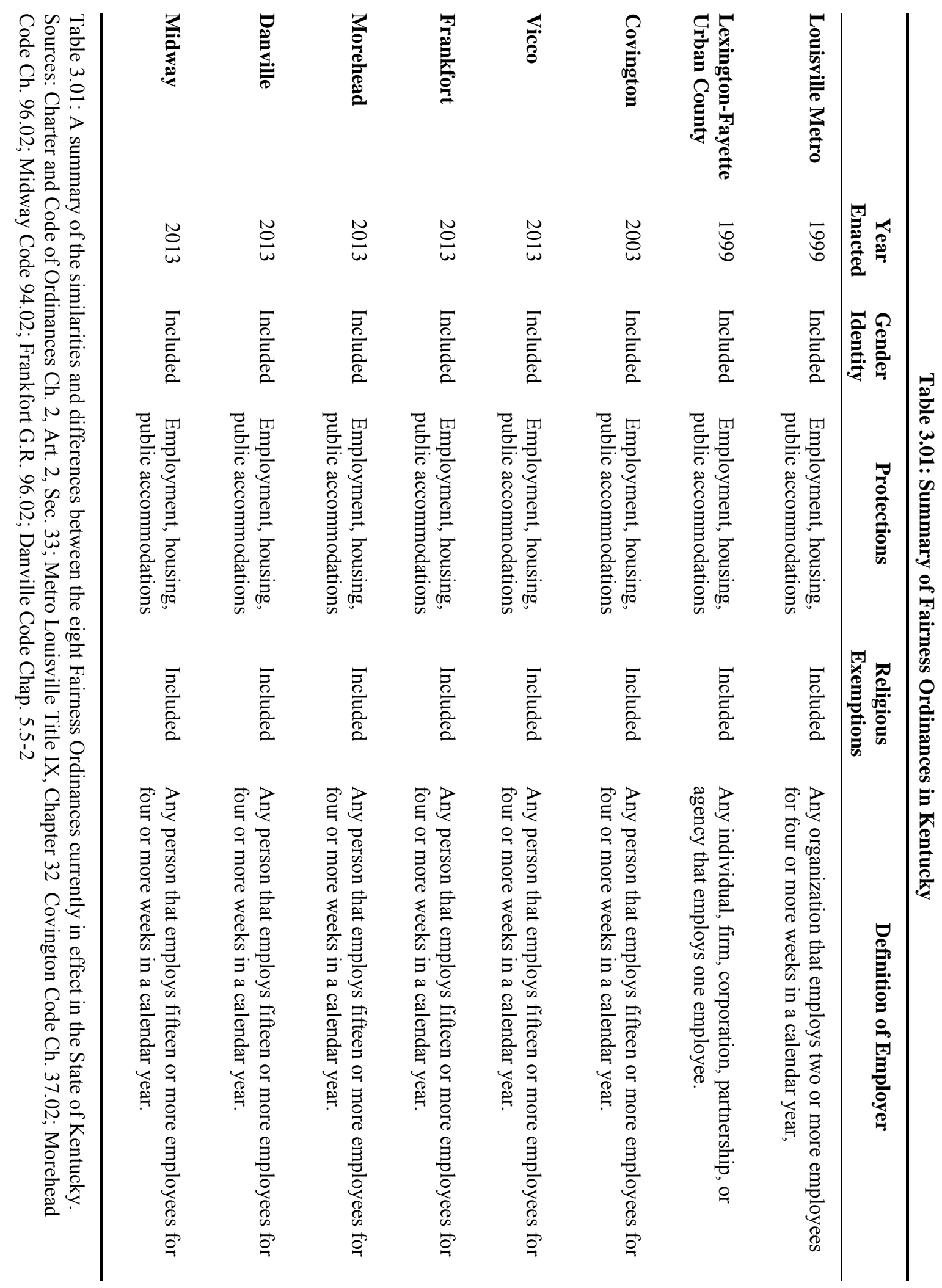




\section{Public Opinions of Fairness in Kentucky}

Public polling has consistently shown that a majority of Americans support workplace protections for LGBTQ+ individuals. Gallup has been tracking American attitudes on equal employment rights for gays and lesbians since 1977, and every poll taken has shown that most Americans support equal work protections for LGB Americans (Gallup 2017). Further, support for these nondiscriminatory practices has increased drastically, from $56 \%$ in 1977 to $89 \%$ in 2008 , the last year this question was included in the poll (Gallup 2017). A majority of Americans also support codifying these beliefs into law: a 2015 poll conducted by the Public Religion Research Institute (PRRI) found that 70\% of Americans support nondiscrimination laws for not only sexual minorities but transgender individuals as well (PRRI 2015).

Several surveys have also shown that anti-discrimination laws are supported by segments of the American population often seen as less supportive of LGBTQ+ rights. A 2011 poll conducted by the Human Rights Campaign demonstrated that a majority of evangelicals (54\%), Republicans (61\%), those without college degrees (68\%), senior citizens (69\%), and residents of the Deep South (72\%) support a federal nondiscrimination law for LGBTQ+ individuals (HRC 2011). A survey conducted by the Center for American Progress (2011) demonstrated that support for LGBTQ+ workplace protections (71\%) is greater than support for other LGBTQ+ civil rights issues, such as civil unions (62\%), child adoption (53\%), or marriage equality $(47 \%)$.

Most institutions that conduct surveys on American attitudes on LGBTQ+ nondiscrimination laws do so at the national, as opposed to a state-specific, level. This makes it difficult for one to understand state attitudes toward such policies, especially in smaller states (such as Kentucky) where fewer resources for such data collection are found. Since 2010, only two surveys have been conducted in the Commonwealth that examine the attitudes of Kentucky residents when it comes to LGBTQ+ employment rights. From these polls, one might suspect that support for LGBTQ+ legal protections would be minimal in conservative Kentucky. The results from both surveys, however, have found otherwise. 
In 2011, the Kentucky Fairness Coalition polled residents across the state to measure support for laws such as Fairness Ordinances in the Commonwealth. ${ }^{12}$ When asked, Should gays, lesbians, and transgendered persons should be protected from anti-gay and gender identity workplace discrimination, $83 \%$ of those surveyed either agreed or strongly agreed with the statement, compared to only $11 \%$ who disagreed or strongly disagreed (Schapiro 2011). A majority agreed with the prompt in all six federal congressional districts in the state, with Kentucky's Third Congressional District having the most support (91\%) and Kentucky’s Fifth Congressional District having the least (80\%) (Shapiro 2011). Further, support for these laws was found among both Democrats (87\%) and Republicans (77\%), as well as ideological liberals (93\%), moderates (87\%), and conservatives (77\%) (Schapiro 2011).

This poll also asked Kentuckians if LGBTQ+ persons deserve the same legal protections as other people. Again, a clear majority (70\%) of those polled either agreed or strongly agreed that LGBTQ+ individuals deserve the same legal protections as other people (Shapiro 2011). This poll also supported the notion that these laws are favored by Kentuckians across the political spectrum, with $80 \%$ of Democrats and $57 \%$ of Republicans answering either agree or strongly agree (Shapiro 2011). Conservatives (55\%) also either agreed with the prompt, as did moderates (77\%) and liberals (87\%) (Shapiro 2011).

The Public Religion Research Institute (PRRI) also questioned Kentuckian attitudes toward nondiscrimination laws for LGBTQ+ individuals in their 2015 American Values Atlas survey. ${ }^{13}$ There are three noticeable differences between the survey conducted by the Kentucky Fairness Coalition and that of the Public Religion Research Institute. While the KFC's survey was conducted only in the state of Kentucky and focused solely on Fairness, the PRRI polled residents across all fifty states and included other LGBTQ+ issues such as marriage equality (PRRI 2015). Importantly, the PRRI also differed from the KFC survey in that it focused on national legislation rather than state or local laws and ordinances. This

\footnotetext{
12 The Kentucky Statewide Fairness Coalition surveyed 600 Kentuckians, and an equal proportion (about $17 \%$ ) of the survey was conducted in each of the six Kentucky congressional districts. A majority/plurality of those surveyed were female (55\%), white (90\%), conservative (39\%), Democrat (40\%), and attended church weekly (42\%). The Shapiro Group in Atlanta conducted the surveys via landline telephone.

13 The Public Religion Research Institute surveyed 42,586 Americans in its American Values Atlas survey, including 690 residents of Kentucky. No further demographic information for Kentucky survey takers was provided in the report, though a national snapshot of those who took the survey was included.
} 
emphasis on federal law may explain why support for nondiscrimination laws in Kentucky decreased in the PRRI survey in comparison to the inquiry conducted by the Kentucky Fairness Coalition, as Kentuckians tend to be warier of federal interference in their daily lives.

Despite the apparent discrepancy in support between the KFC survey and the PRRI survey, the latter still demonstrated that a majority of Kentuckians support nondiscrimination laws for LGBTQ+ individuals. Of those surveyed in Kentucky, $63 \%$ favored federal legislation that would protect LGBTQ+ individuals from discrimination in employment, housing, and public accommodations (PRRI 2015). This is more than double the number of Kentuckians surveyed who opposed such legislation (31\%) (PRRI 2015). Compared to the rest of the country, Kentucky residents did tend to support these laws at a lower rate (the national average was $71 \%$ in favor), and Kentucky had the eighth-least supportive population of any state when it came to a federal nondiscrimination law (PRRI 2015).

The 2015 American Values Atlas also surveyed Americans across the country on their support for a federal law that would permit for-profit businesses to refuse to provide goods or services to LGBTQ+ individuals given they have a religious reasoning for doing so. Of those surveyed in Kentucky, only $37 \%$ reported that they would support such legislation, compared to $56 \%$ of Kentuckians who would oppose the LGBTQ+ discrimination law (PRRI 2015). Kentuckians were much more aligned with the rest of the country on this issue - the survey found that only $35 \%$ of Americans support religious refusal laws (PRRI 2015).

The goal of this chapter was to explore the network of laws and executive orders that protect some Kentuckians against discrimination stemming from their sexual orientation or gender identity. Despite aggressive lobbying from LGBTQ+ activists and their allies for decades on this issue, neither the federal government nor the Kentucky General Assembly has passed a comprehensive law. And though some Kentuckians do possess workplace protections from their local governments, this amounts to a little more than a quarter of the entire Kentucky population. Despite this reality, surveys that explore Fairness in Kentucky have suggested that most Kentuckians support the enactment of legally binding employment protections for LGBTQ+ individuals in the state. It is interesting, then, to ask why these ordinances are so 
rare in the state. Before analyzing the political debate surrounding LGBTQ+ nondiscrimination laws, it is important to establish that such discrimination actually occurs in the United States and that lacking such laws is problematic. If for instance workplace discrimination does not take place against LGBTQ+ individuals then there would be no practical need for Fairness Ordinances, though there certainly would be a moral reason for such ordinances. The next four chapters of this thesis attempt to explore this issue in detail. 
CHAPTER III:

HOW COMMON IS LGBTQ+ WORKPLACE DISCRIMINATION?

Before analyzing the personal, organizational, and societal consequences of LGBTQ+ employment discrimination, it is important to attempt to map out the frequency of this type of discrimination in the United States. If employment discrimination against sexual and gendered minorities has been eradicated as these individuals have become more accepted by heterosexual, cis-gendered Americans, then non-discrimination laws would be, in a strictly practical sense, unnecessary. This is the argument made by many opponents of LGBTQ+ anti-discrimination statutes, including former Louisville Alderman Steve Magre who stated his belief that discrimination against LGBTQ+ persons did not occur frequently enough to warrant such protections (Williams 1999).

Proving that discrimination against LGBTQ+ individuals occurs in the workplace is more difficult than one might imagine, as historical trend analyses examining the changing rate of employment discrimination faced by the LGBTQ+ community are rare. This difficulty stems from the historical and contemporary legal ambiguity faced by many LGBTQ+ persons regarding what their legal rights are in the workplace. As no federal law holistically protects sexual and gendered minorities from employment discrimination, quantitative data on the number of claims of this form of discrimination does not exist at a national level in the way that it does for other (sex, racial, religious, etc.) minorities that have more broad and long-standing federal employment protections.

This chapter is organized into three sections, each of which will analyze a different approach to understand the frequency of LGBTQ+ employment discrimination in the United States. First, the number of claims made against employers will be examined at the federal level (using data from the Equal Employment Opportunity Commission) and the local level (using data from the Louisville Metro and the 
Lexington-Fayette Urban County Human Rights Commissions). ${ }^{14}$ While it is helpful to examine these claims, Director Aldridge has noted that both the legal ambiguity of these laws and the public nature of filing a complaint against an employer often contributes to an underreporting of discrimination. Therefore, these cases alone do not paint an adequate picture of LGBTQ+ employment discrimination, even in areas where protections exist (Aldridge, PC 2016).

To help remedy this matter, the second section will analyze various sets of survey data, each of which attempts to map out the frequency of different forms of employment discrimination in the United States based on the actual experiences of the LGBTQ+ community. These surveys suggest that, while the proportion of LGBTQ+ Americans who face discrimination in the workplace has declined over the years, these persons still face a great deal of harassment and discrimination in their places of employment. This is particularly the case for gendered minorities: studies have consistently shown that well over half of transgender Americans face discrimination in the workplace (Mallory \& Sears 2011a).

Finally, Tilcsik's study on LGBTQ+ employment discrimination will be examined, as it is one of the largest and unique studies of its kind. In his study, Tilcsik was able to demonstrate that association with the LGBTQ+ community decreased one's chances of being interviewed for employment. Importantly, the study also provides insights into how having nondiscrimination policies may affect the rate of discrimination at a locale. Having examined the data, I conclude that there is clear evidence that LGBTQ+ persons are frequent targets of discrimination in the workplace. Therefore, the claim made by Fairness opponents that employment protections for the LGBTQ+ community are unnecessary is misguided.

\section{Documented Claims of LGBTQ+ Discrimination in the Workplace}

As discussed in the previous chapter, there are currently no federal laws that explicitly protect LGBTQ+ persons from employment discrimination. Accordingly, until recently the federal government had not collected data on the number of claims filed against employers who have discriminated against an

\footnotetext{
${ }^{14}$ The state of Kentucky does not offer employment protections for most of its LGBTQ+ residents and, therefore, the state does not currently publish data on discrimination claims in Kentucky.
} 
LGBTQ+ employee. This changed after the EEOC reinterpreted sex discrimination as discrimination, not only against cisgender Americans but against gendered and sexual minorities as well. Beginning in the 2013 Fiscal Year (FY), the EEOC began compiling data on discrimination against both gendered and sexual minorities, just as it does for other protected classes.

Having made these rulings so recently, EEOC data showing the prevalence of discrimination against LGBTQ+ individuals is still limited. Between FY2013 and FY2016, the EEOC received 5,088 receipts from employees who claimed to have been discriminated against in the workplace due to their sexual orientation or gender identity (EEOC 2015a; EEOC 2016d; EEOC 2017). The number of receipts filed by the LGBTQ+ community has increased every year thus far: from 808 in FY2013, to 1,100 in FY2014, to 1,412 in FY2015, and to 1,768 in FY2016 (EEOC 2015; EEOC 2016; EEOC 2017). These numbers indicate complaints made directly to the EEOC and do not include complaints made to state or local human rights commissions.

These figures are not adequate representations of the level of discrimination faced by LGBTQ+ employees in the United States. Despite the EEOC's recent rulings, Director Aldridge noted that in many circumstances it remains legal to discriminate due to an employee's sexual orientation or gender identity (Aldridge, PC 2016). Movement Advancement Project (2015a) found that only 59.1\% of Americans live in areas that possess anti-discrimination protections for sexual minorities and just $48.3 \%$ of Americans reside in locales that possess these protections for gender minorities. These figures indicate that many LGBTQ+ persons do not have the legal power to challenge an employer's discrimination, a fact that contributes to the underreporting of LGBTQ+ discrimination in the United States.

Jefferson and Fayette Counties are two such municipalities that possess protections against LGBTQ+ discrimination in the workplace, and these protections date back to 1999. Claims filed against employers are collected and investigated by the Louisville Metro Human Relations Commission (LMHRC) in Jefferson County and the Lexington-Fayette Urban County Human Rights Commission (LFUCHRC) in Fayette County. These records are available to the public in accordance with the Kentucky Open Records Act. I contacted both the LMHRC and the LFUCHRC to collect the records of employment discrimination 
on the grounds of sexual orientation or gender identity in both Jefferson and Fayette counties from January 1, 2010, to December 31, 2016.

During this timeframe, the LMHRC and the LFUCHRC received a combined 164 employment discrimination receipts (101 in Jefferson County and 63 in Fayette County) on the grounds of the employee's sexual orientation or gender identity (LMHRC 2017; LFUCHRC 2017).$^{15}$ Of these receipts, eighty-four individuals claimed bullying or harassment at their workplace, seventy-six stated that they were terminated from their place of employment due to their sexual orientation or gender identity, twenty-four were denied employment outright, fourteen individuals reported being denied advancement opportunities, and eight were sexually harassed (LMHRC 2017; LFUCHRC 2017).

Surprisingly, heterosexual, cis-gendered residents made eighteen of these complaints (LMHRC 2017; LFUCHRC 2017). Ten of the complaints filed by non-LGBTQ+ residents were in response to the hostile atmosphere made by coworkers toward their LGBTQ+ colleagues, while five were perceived as homosexual - but are not - and the perception of being gay caused them to face discrimination. Perhaps most surprising, a further three claimed that their heterosexuality was a factor in not receiving employment opportunities (LMHRC 2017; LFUCHRC 2017). For example, one heterosexual man complained that he was not hired at a local clothing store due to his sexuality, as the manager worried that women would be uncomfortable with any man not "super gay" helping them with fitting (anonymous complaint, LMHRC 2017). Complaints made by non-LGBTQ+ individuals made up roughly $11 \%$ of the total number of claims between the two commissions, suggesting that Fairness Ordinances protect heterosexual, cisgender residents in addition to the LGBTQ+ community.

Despite both Jefferson and Fayette counties having relatively strong anti-discrimination policies, underreporting still occurs, according to local experts (Aldridge PC 2016). In particular, Michael Aldridge noted that the public nature of filing a legal claim against an employer often leads to an underreporting of discrimination complaints. Though more Americans are open about their sexual orientation and gender identity than in the past due to the growing acceptance of the LGBTQ+ community, many Americans

${ }^{15}$ I only asked for complaints regarding employment discrimination. Both Louisville and Lexington's Fairness Ordinances cover other forms of discrimination such as housing and public accommodations. These complaints are not included in either count. 
remain "in the closet." Filing a complaint with the EEOC or a state or local equivalent requires going on public record to one's community that they were discriminated against due to some protected status. Those who have kept their sexual orientation or gender identity hidden from family and friends are less likely to "out" themselves by filing a discrimination complaint, even if they work in a location that has specific LGBTQ+ employment protections.

The final barrier that contributes to the underreporting of LGBTQ+ discrimination is the difficulty of determining if the incident was, in fact, discrimination (Aldridge, PC 2016). Some forms of discrimination are explicit, such as verbal and physical harassment stemming from an employee's sexual orientation or gender identity. Often, however, discrimination is subtle (Barskey, Bradley, Chan, \& Dietch 2003). For instance, if a transgendered employee is not given a promotion, how can one prove that it was because of their gender identity and not simply because the cisgendered employee was more qualified? Proving discrimination is often difficult, and employees may fear retaliation if they file a complaint. Faced with this uphill battle, many LGBTQ+ employees may simply refuse to make a claim against an employer.

\section{Survey Data of LGBTQ+ Discrimination in the Workplace}

Although not perfect, surveys provide a clearer picture of the level of harassment and discrimination faced by the LGBTQ+ community in their places of employment (Mallory \& Sears 2011a). By allowing researchers to ask members of the LGBTQ+ community directly and anonymously about their firsthand experiences with harassment in the workplace, surveys can be more extensive, flexible, and dependable than looking at claims alone. Survey data is also more geographically extensive than analyzing claims, as the latter tool relies on some government agency to have the authority to collect complaints, a requirement not always met in many communities across the United States.

One of the largest and most extensive surveys conducted in the past decade that explored this issue was the 2008 General Social Survey (GSS) (Mallory \& Sears 2011a). The GSS is a biennial sociological survey used to collect information and keep a record of the concerns and practices of residents of the United States. In 2008, the GSS introduced a new subject into its survey: perceived harassment and 
discrimination of LGB individuals at their places of employment. This survey has been widely used by scholars to highlight levels of perceived and real discrimination faced by LGB employees in the workplace (Mallory \& Sears 2011a; Fienstein, Goldfried, \& Davila 2012; Gates 2010). It should be noted that this study focused on workplace discrimination experienced by sexual minorities only; it did not survey transgender or gender-queer employees on their experiences with employment discrimination.

The findings from the survey support the claim that LGB employees in the United States often face harassment and discrimination in the workplace. Of those surveyed, $42.8 \%$ of self-identified LGB employees reported having suffered employment discrimination at some point in their lives (Gates 2010). The most common form of employment discrimination was harassment (experienced by $35.6 \%$ at some point in their lives), followed by a refusal of promotion or increased benefits $(24.8 \%)$, the existence of a pay differentiation compared to their heterosexual co-workers (18.4\%), and termination of employment (15.8\%) (Gates 2010). Being open about one's sexuality at work drastically increased the rate of discrimination: $56 \%$ of those surveyed who are "out" to their coworkers admitted had faced discrimination at their place of employment (Gates 2010). This figure drops to just $9.8 \%$ for those who remained "closeted" at work (Gates 2010).

This survey also suggests that this kind of discrimination has not ended in recent years, though it certainly has been reduced. When asked if they have experienced any form of employment discrimination in the past five years, $27 \%$ of LGB respondents admitted to being discriminated against due to their sexuality (Gates 2010). A further 15.8\% of respondents claimed to have been passed over for a promotion or increased benefits, and 6.7\% have lost their job due to their sexuality (Gates 2010). These numbers indicate that while Americans are becoming more open to hiring, promoting, and ensuring a positive working environment for the LGB community, an unacceptably high level of discrimination and harassment still exists.

The GSS, though perhaps the largest, is not the only survey that has documented the extent to which workplace discrimination occurs against LGB persons. The Williams Institute, a think tank at the UCLA School of Law that focuses on policy issues for sexual and gendered minorities, has also been a leader in tracking discrimination across the country. In 2011, the Institute released a review of numerous 
studies, each of which surveyed the level of discrimination faced by sexual and gendered minorities. ${ }^{16}$ The Williams Institute found that, with some variation, all surveys analyzed suggest that there is a great deal of discrimination against LGBTQ+ employees in the United States (Mallory \& Sears 2011a).

The surveys that focused on LGB employees support the claims made by the GSS. One study reviewed by the Williams Institute found that $58 \%$ of employees have heard derogatory comments about homosexuality in the workplace (Mallory \& Sears 2011a). Another reported that 44\% of LGB respondents faced discrimination in employment due to their sexuality (Mallory \& Sears 2011a). A third report found that $26 \%$ of respondents stated that their sexuality was a "major contribution" to their missing a job opportunity or promotion (Mallory \& Sears 2011a). Overall, the Institute suggests that roughly half of LGB employees face workplace bullying or harassment from their coworkers, $19.8 \%$ have been denied employment or a promotion, and $12.3 \%$ have been fired from a job due to their sexuality (Mallory \& Sears 2011a).

While these numbers suggest that the level of employment discrimination for LGB individuals is high, the reality for transgender persons is even bleaker. In all surveys which focused solely on the transgender community, well over half $(58 \%$ to $88 \%)$ of the respondents reported that they face workplace discrimination (Mallory \& Sears 2011a). The Williams Institute estimates that $82 \%$ have faced workplace bullying from co-workers, $47 \%$ have been denied employment, $34 \%$ have been fired, and $29 \%$ have been denied a promotion due to their gender identity (Mallory \& Sears 2011a). One study even reported that $38 \%$ of transgender individuals faced frequent sexual harassment while at work (Mallory \& Sears 2011a). The Institute concluded their report by stating that employment discrimination against transgendered individuals is a "national crisis" and urged policymakers to take actions that will resolve these issues.

\footnotetext{
16 The eleven surveys analyzed by the Williams Institute varied in sample size (ranging from 27 to 6,400 respondents) and location of the study (eight were national, three were state-specific). Four of the surveys analyzed LGB discrimination only, four trans discrimination only, and three were LGB and Trans-inclusive.
} 


\section{The Tilcsik Study}

One does not need survey data to suggest that LGBTQ+ persons face discrimination in employment. In one of the more unique empirical studies on this subject, Tilcsik (2011) sent out 1,769 resumes to job postings to uncover if employment discrimination against GBT men exists in the United States. Tilcsik developed two nearly identical resumes with one key difference: the experimental resume listed experience with an LGBT organization and the control group did not. These resumes were sent to various job postings in seven different states over the course of three years. Tilcsik then examined the number of callbacks each group received to analyze whether the inclusion of experience in an LGBT center had any effect on receiving an interview with a potential employer.

The results of the study indicate that the inclusion of experience at an LGBT center did affect the number of callbacks received. Overall, both resumes received a call back $9.31 \%$ of the time (Tilcsik 2011). However, the control group - the set of resumes that did not include experience at an LGBT center - had an $11.5 \%$ chance of being called for an interview while the experimental group only received callbacks $7.2 \%$ of the time (Tilcsik 2011). Having been involved in an LGBT center reduced the likelihood of being interviewed for a position by $37.4 \%$, which was a significant difference (Tilcsik 2011).

What is perhaps even more interesting was that this level of discrimination was not uniform throughout the United States. Employers in states with strong anti-discrimination laws were more likely to respond to LGBT-center-experienced candidates with an invitation for an interview than those without strong protections. The three states with strong LGBTQ+ protections in this study had a callback differentiation of only $2.4 \%$ (10.9\% vs. $8.5 \%$ ). In California, this difference was only $1.8 \%$, which was statistically insignificant (Tilcsik 2011). In the other four states without such protections, however, the opposite occurred: the differentiation was $5.4 \%$ (12.2\% vs. 6.8\%) (Tilcsik 2011). Tilcsik's study, then, suggests that having strong anti-discrimination laws does influence businesses into interviewing known members of the LGBTQ+ community for employment opportunities.

In this chapter, three methodologies - complaints filed, survey data, and an empirical study - were explored to underline the fact that members of the LGBTQ+ community are the frequent victims of employment discrimination in the United States. These studies make it clear that discrimination against 
LGBTQ+ individuals, while perhaps not as common as it was in the past, still exists at significant levels, particularly for gendered minorities. Further, Tilcsik's study indicates that the presence of nondiscrimination laws deters businesses from discriminating against potential LGBTQ+ employees. Therefore, the claim often made by Fairness opponents that discrimination against LGBTQ+ individuals does not occur frequently enough to justify expanding protections for this community is both unfounded and detrimental. One might argue on the grounds of ethics that even one case of LGBTQ+ discrimination is sufficient to warrant protective laws, yet as these studies attest, discrimination against the LGBTQ+ community is still commonplace in the United States, with devastating consequences on all Americans, not just LGBTQ+ persons. The next three chapters will examine the literature that details the effects of LGBTQ+ discrimination at the micro level - on individual persons and organizations - and macro levelon society. 


\section{CHAPTER IV:}

\section{THE IMPACT OF DISCRIMINATION ON THE INDIVIDUAL}

Discrimination ultimately stems from an individual's lack of recognition or status within a larger society. Western society has long attempted to vilify and ostracize LGBTQ+ individuals as immoral, unnatural, and dangerous. This practice has had severe consequences for members of the LGBTQ+ community. Being demonized simply because of one's sexual orientation or gender identity has adverse consequences to an individual's mental, physical, and economic well-being. This concept is not new; political and social philosophers, psychologists, and medical experts have long noted the personal effects of marginalization in society. Nevertheless, discrimination against persons for many reasons remains a reality in the United States.

This chapter will explore the literature and research on the effects of group marginalization in society, with emphasis on the LGBTQ+ community. This literature suggests that LGBTQ+ individuals, particularly those with internalized homophobia and guilt, have a higher risk of destructive behaviors and stress levels, contributing to a lower quality of life and a shorter lifespan. Additionally, research has also demonstrated that those in the LGBTQ+ community, particularly transgender individuals and LGBTQ+ persons of color, have a much higher rate of poverty than cisgender, heterosexual Americans (particularly white ones), further lowering the well-being of LGBTQ+ persons categorically.

Hegel, Taylor, and Identity

Though the concept of recognition and further discussion on its importance to the development of the self can be traced back through centuries of political thought, one of the forbearers of recognition politics (or identity politics, as it more commonly known), as we conceptualize it today, was Georg 
Wilhelm Friedrich Hegel. In his influential work The Phenomenology of Spirit, Hegel explores the concept of alienation and domination in society and the harmful effects they have on an individual's psyche. Though I will not go into detail on Hegelian philosophy, some concepts espoused by Hegel are crucial in understanding how the experience of being relegated as an inferior "other" can cause the LGBTQ+ community to suffer significant mental and physical injury. harmful effects this has on an individual's psyche. Though I will not go into detail on Hegelian Philosophy, some concepts espoused by Hegel are crucial in understanding how the experience of being relegated as an inferior "other" can cause the LGBTQ+ community to suffer significant mental and physical injury.

Arguably the most influential section of The Phenomenology of Spirit, Hegel's "Master-Slave Dialectic" explores how the conflict of competing consciences often leads to the domination of one self over others. According to Hegel, when two conscience beings meet, there is a struggle of recognition between them. Each autonomous individual desire recognition of their superiority over the other, resulting in what Hegel termed a "battle to the death" (Trans. Miller \& Findlay 1977). Death rarely occurs, however. In Hegel's thought experiment, the victor of the conflict presents an ultimatum to the loser: submit and recognize the victor as the superior self or die. Not wanting to perish, the other offers their new "master" the recognition that he or she is superior to themselves. Therefore, the master's recognition is validated through the slave's recognition of his/herself as a subordinate, lesser self (Miller \& Findlay 1977 111-124).

This explanation of the "Master-Slave Dialectic" is an incomplete and oversimplified analysis of Hegel's theory, but for our purposes, it provides insight into the very basis of recognition (i.e. identity) politics. That is, for Hegel the development of the "self" was intrinsically dialectic in nature (Taylor 1994, 28), meaning that we develop our identities and self-worth through our relationships and interactions with society. People come to understand themselves through the lens that society sees them, both the good and the bad. Therefore, those who are perceived negatively by their peers are not only ostracized by society, but often develop self-loathing as well.

Charles Taylor (1994) expanded Hegel's analysis in his essay “The Politics of Recognition.” Taylor concurs with Hegel that the core feature of human life is that it is dialectic in nature and that recognition from others is essential to self-acceptance (Taylor 1994, 28). Taylor, however, takes this a step 
further by suggesting that, if it is true that individuals need recognition from society to possess selfacceptance, then recognition is a fundamental human right (Taylor 1994, 56). In other words, it is the state's responsibility to provide recognition and protection to all peoples and groups. A government that chooses to remain neutral on subjects such as LGBTQ+ rights is ultimately submitting this community to an often hostile, heteronormative world. In this way, the LGBTQ+ community will not only be subjected to discrimination but will often reflect on themselves in a way that is in accordance with the dominant culture.

\section{Minority Stress and Psychological Issues}

Many scholars have attempted to provide empirical support to Taylor's theory by analyzing the mental health of various minority groups. In one of the more influential studies on the effects of social discrimination on the physiological and psychological health of the LGBTQ+ community, Ilan Meyer (1995) analyzed 741 gay men to understand the links between minority stressors, self-acceptance, and mental health. To test his hypothesis, Meyer utilized the psychological notion of minority stress. Minority stress is a Hegelian concept that suggests that the juxtaposition of minority and dominant values in a society can lead to significant levels of stress in minority communities as they struggle for self-acceptance against a stigmatizing dominant culture (Meyer 1995).

Three minority stressors were analyzed in Meyer's study: internalized homophobia, perceived social stigma, and actual experiences with external homophobia. The effects of these stressors were analyzed against four measures of psychological distress: demoralization, guilt, suicidal behaviors and thoughts, and sexual problems. Respondents were asked questions relating to the three minority stressors. These would include such questions as How often have you tried to be sexually attracted to women? (internalized homophobia), Would most people feel that homosexuality is a sign of personal failure? (perceived societal stigma), and In the past year, have you been the victim of anti-gay violence? (external homophobia) (Meyer 1995). Meyer then utilized the Psychiatric Epidemiology Research Instrument to measure psychological distress during the year prior to the interview (Meyer 1995). 
The results from Meyer's study suggests that minority stress is real and has consequences to the mental health of those that suffer from it (Meyer 1995). Those respondents with elevated levels of minority stress stemming from internalized homophobia, perceived social stigma, or actual cases of discrimination were more likely to suffer from demoralization, guilt, thoughts of or attempts at suicide, and have various sexual dysfunctions (Meyer 1995). In contrast, those who were more accepting of their sexuality - and thus had less internalized homophobia and perceived social stigma - and who had not experienced actual experiences with homophobia were less likely to suffer from these mental conditions (Meyer 1995). This study gives support to Taylor's theory that how our peers recognize certain individuals has a significant impact on our mental health.

Meyer's study inspired further research that attempted to understand how members of the LGBTQ+ community handle these different stressors and the effects they have on their physical and mental health. Several scholars have shown a direct link to substance abuse problems in the LGBTQ+ community with those who suffer from high levels of internalized homophobia and real-world discrimination (Kalichman \& Cain 2004; Kashubeck-West \& Szymanski 2008; Dressler, Oths, \& Gravlee 2005; Link \& Phelan 2006). Many scholars have suggested that gay men who have self-acceptance issues are more likely to engage in unprotected sex with multiple partners, leading to a higher rate of HIV and other sexually transmitted diseases (Bimbi et al. 2006; Halkitis, Green, \& Carragher 2006; Halkitis, Green, \& Mourgues 2005; Office of National AIDS Policy 2010). Researchers have also concurred with Meyer's study that LGBTQ+ persons with internalized shame and guilt express greater rates of suicidal behaviors than those who are more accepting of their sexuality or gender identity (Hamilton \& Mahalik 2009; Herek \& Garnets 2007; Cochran, Mays, \& Sullivan 2003).

One method governments can utilize to lower the psychological effects of discrimination is by introducing a nondiscrimination law or ordinance. Riggle, Rostosky, and Horne (2010) conducted a national survey in which 2,511 LGB Americans were asked questions like those used by Meyer. These participants were divided into two groups: LGB persons who lived in a jurisdiction with a nondiscrimination law and LGB persons who did not. The results of the study indicated that those LGB persons who are protected from employment, housing, and public accommodation discrimination stemming 
from their sexual orientation were less likely to suffer from internalized homophobia and actual experiences with discrimination (Riggle et al. 2010). In addition, individuals living in areas with LGB protections were more likely to report having strong social support and were more likely of being "out" to their family, friends, and coworkers (Riggle et al. 2010). The presence of a nondiscrimination ordinance, then, may improve the mental health of LGBTQ+ individuals living in these areas.

\section{$\underline{\text { Life-Threatening Conditions }}$}

LGBTQ+ discrimination not only increases the likelihood that an individual will have mental health conditions and partake in risky behaviors, but the added stress can also have a detrimental impact on the physical body as well. The American Psychological Association (APA) released a report that compared the stress faced by various minority groups to that of the general population. In the study, the APA (2015) analyzed the stress of 233 LGBTQ+ individuals against 3043 straight, cisgender persons. Their findings suggest that sexual and gendered minorities are $41 \%$ more likely to report having "extreme stress" compared to the non-LGBTQ+ population (APA 2015). Relevant to this thesis, the APA also found that stress relating to job stability was more prominent among the LGBTQ+ population ( $57 \%$ of these respondents claimed to suffer from this stress) compared to heterosexual, cisgender Americans (36\%) (APA 2015). This may suggest that LGBTQ+ individuals are concerned that their sexual orientation or gender identity will have a profound effect on their employment opportunities.

The APA (2015) also reported that, regardless of the cause, experiencing discrimination is directly associated with higher levels of stress and poorer indicators of mental and physical health. Those with "extreme stress" were $37 \%$ more likely to suffer from depression, $42 \%$ more likely to suffer from an anxiety disorder, $46 \%$ more likely to lose patience or yell at a family member or friend, and $20 \%$ more likely to lose patience or yell at coworkers than those reporting normal stress levels (APA 2015). Extreme stress also has a direct link to many physical conditions, such as overeating (those with extreme stress were $40 \%$ more likely to over eat), skipping meals (30\%), sleep deprivation (70\%), and suffering from frequent headaches or migraines (39\%) (APA 2015). 
Chronic stress also has the potential to do long-term, fatal damage to the individual who experiences it. Chronic stress is known to increase high blood pressure in individuals, explaining the causal link between stress, heart attacks, and strokes (AHA 2015). The American Heart Association (AHA) states that high levels of daily stress can increase one's risk of having heart disease by up to 250\% (AHA 2015). The AHA cites that stress levels in the United States are far greater than in most developed countries, partially explaining why Americans are more overweight, often get fewer hours of sleep, and have a higher chance of developing heart disease in their lifetime compared to citizens of other developed countries (AHA 2015).

Chronic stress also has the potential to do damage an individual's immune system. Hanson (2007) notes that increased stress leads to high levels of the hormone cortisol in the blood stream. Over time, the body begins to become immune to cortisol and produces cytokines, which are associated with a host of chronic inflammatory and autoimmune conditions (Hanson 2007). The body essentially begins to attack itself, leading to conditions like fibromyalgia, rheumatoid arthritis, lupus, irritable bowel syndrome, and even certain cancers (Hanson 2007). Cortisol and cytokines also suppress the protein lymphocyte, which is vital for the immune system and can slow recovery time for illnesses such as the flu, strep, and other diseases (Hanson 2007).

\section{Economic Disparities}

Discrimination against LGBTQ+ persons not only affect an individual's physical and mental health but their financial situation as well. As noted in Chapter II, several studies provide compelling evidence that LGBTQ+ persons face discrimination in the job market. It is, therefore, not surprising that these individuals also face income and wage disparities compared to the non-LGBTQ+ community. It is true that, as a whole, gay-identifying men make more than straight men, and gay-identifying women make more than straight women (MDoCR 2013). This fact, however, undercuts the reality that an incomedisparity exists among LGB and non-LGB individuals. 
The Michigan Department of Civil Rights (2013) reviewed nine studies on the wage gap between heterosexuals and sexual minorities and found that gay employees made 10 to $32 \%$ less than similarly qualified heterosexuals. This paradox - that gays tend to be wealthier, yet there exists a pay disparity stems from the fact that the gay community is more educated than the general population and, therefore, tend to hold higher paying jobs (MDoCR 2013). Within these higher paying positions, however, a wage gap between gay employees and their straight coworkers exists.

Badgett, Durso, and Schneebaum (2013) found that single LGB individuals and most LGB partnerships are more likely to be impoverished when compared to similarly educated heterosexual individuals and couples. Drawing on information from Gallup Daily Tracking Polls, the American Community Survey, and the National Survey of Family Growth, Badgett et al. (2013) found that $17.2 \%$ of single, male-identifying GB and $21.5 \%$ of single, female-identifying LB individuals lived in poverty. This rate is higher than the $13.4 \%$ of single, straight males and $19.1 \%$ of single, straight females who are living in poverty (Badgett et al. 2013).

It also appears that discrimination builds upon itself: female same-sex partnerships of all races have a poverty rate of $13.6 \%$, while African American same-sex partnerships of any gender have an incidence of poverty of $28.8 \%$ (Badgett et al. 2013). In another study, The Williams Institute (2013) found that African American lesbian relationships had a poverty rate of $34.6 \%$. This is notably larger than is the case with white, male same-sex partnerships, which have a poverty rate of only $3.1 \%$. In fact, partnerships that include two white men are less likely to live in poverty than even white, heterosexual couples, which have a poverty rate of $4.8 \%$ (Badgett et al. 2013).

This report suggests racial and sex discrimination can build upon LGB discrimination to increase the risk of poverty in these at-risk groups, while racial and gender privilege can overcome these effects. In other words, being a single, white, gay male puts one at a greater risk for poverty compared to a single, white, straight man. This same gay white male, however, has less of a risk of being impoverished compared to a single straight woman (of any race) or a single black man (of any sexuality). At the same time, being a gay white male in a relationship with another gay white male puts one at a lower risk of poverty compared 
to most groups (gay Asian partnerships have the lowest poverty rates) due to the lack of a presence of a female or person of color in the relationship.

Transgender persons of any race have even lower wages and higher levels of unemployment than sexual minorities. In 2013, trans-individuals had an unemployment rate of $15 \%$, much higher than the national unemployment rate of $8.3 \%$ at that time (HRC 2013). In 2010, the average personal income of transgender persons in the United States was $\$ 26,058,34 \%$ less than the average income for all Americans at that time (MAP 2015b). A study by The Task Force (2009) found that $15 \%$ of transgender persons had incomes of less than $\$ 10,000$ a year, while this figure was just 4\% for the general American population. Again, it appears that discrimination builds upon itself: while only $8 \%$ of white transgendered individuals live on less than $\$ 10,000$ a year, 34\% of African American and 28\% of Latinx transgendered individuals face this extreme poverty (The Task Force 2009). Overall, being transgender makes one four times more likely to live in poverty compared to cisgender Americans (The Task Force 2009).

The high levels of poverty faced by transgender persons have led to a homelessness crisis in the transgender community. The HRC (2013) reported that $11 \%$ of transgender individuals had been evicted from their home due to their gender identity. One national survey found that trans-individuals were twice as likely to be homeless and only half as likely to be homeowners compared to cisgender Americans (The Task Force 2009). In another study, Movement Advancement Project (2015b) found that 19\% of transgender persons have been homeless at some point in their lives, higher than the national average of $11 \%$. A further $29 \%$ of homeless trans-individuals reported being turned away from a homeless shelter due to their gender identity (MAP 2015b). It is evident from these reports that trans-Americans face incredible economic and housing discrimination in the United States due to their gender identity.

The psychological, physiological, and economic stressors faced by members of the LGBTQ+ community result in not only a lower quality of life but lower life spans as well. In 2014, researchers at Columbia University released the results of their study that compared the lifespans of LGB individuals living in areas of the United States with higher levels of anti-gay prejudice with LGB persons living in 
communities that are more tolerant. ${ }^{17}$ The researchers found that LGBs living in highly prejudiced areas had a life span twelve years shorter compared to LGBs living in tolerant communities (Hatzenbuehler, Bellatorre, Lee, Finch, Muennig, \& Fiscella 2014). In particular, the researchers found that LGB persons living in hostile communities suffer higher rates of cardiovascular disease and suicidal behaviors compared to sexual minorities residing in more accepting areas (Hatzenbuehler et al. 2014).

As noted in this chapter, discrimination can have severe consequences for those who routinely experience it. Many psychologists have demonstrated that those who have been subjected to anti-gay propaganda throughout their lives can develop internal homophobia, shame, and guilt. This internalized homophobia leads to a higher risk of drug and alcohol dependence, suicidal behaviors, mental illnesses, and contracting sexually-transmitted diseases. Several psychological and medical associations have correlated being LGBTQ+ with greater stress levels, often resulting in heart disease and immune disorders that can significantly decrease the quality of life of that individual. Further, many civil rights organizations have demonstrated that LGBTQ+ individuals - especially women, trans-persons, and persons of color - are often paid less than their similarly qualified coworkers, leading to higher poverty rates in these groups.

This research suggests that homophobia, biphobia, and transphobia can be deadly to those that experience it. Further research has suggested, however, that these detrimental effects of discrimination not only affect the individual persons who are subjected to workplace harassment but can prove to be harmful to the entire organization as well. Chapter IV will explore the literature on the effects that LGBTQ+ discrimination can have on an organization's ability to be successful in an increasingly competitive marketplace.

\footnotetext{
${ }^{17}$ The researchers used data from the General Social Survey to determine which areas of the United States
} were "tolerant" and which were not. 


\section{CHAPTER V:}

\section{THE IMPACT OF DISCRIMINATION ON THE ORGANIZATION}

As noted in the previous chapter, discrimination against the LGBTQ+ community has detrimental consequences to the physical, mental, and economic health of those who experience it. Individual persons are not the only victims of this discrimination, however, as organizations that allow discrimination to occur in their workplace face severe economic consequences as well. The Center for American Progress (2012) estimates that American businesses lose $\$ 64$ billion a year due to discriminatory organizational practices, and this figure does not account for litigation. It has been well established that, in most industries, labor expenses are the largest expenditure faced by organizations (Cooper 2011). It should not be surprising, then, that individuals who incur the mal-effects of discrimination transfer some of these costs to the organization that allows such harassment to occur.

This chapter will review the literature on the consequences of discriminatory practices in organizations. Research on the effects of discrimination in the workplace suggests organizations face five consequences of discriminatory practices: an inability to hire top talent, a decrease in an organization's innovation and problem-solving apparatus, high turnover rates, low employee productivity, and potential litigation. In attempting to overcome these costs, many organizations have taken the lead in developing non-discriminatory policies regarding their LGBTQ+ workforce (HRC 2016b). Much of the literature on the costs of discrimination in the workplace focus on the LGB community; very few studies exploring the organizational costs of gender identity discrimination exists. This is a tragic error on the part of the scholarly community and future research should work to fix this lapse. 


\section{$\underline{\text { Impact on Recruitment }}$}

For an organization to be profitable, it must recruit and hire the best candidates from its industry. While this has always been the case, the dawn of the Information Age has rapidly increased the importance of human capital in organizations of all types (Earle 2003). While capturing top talent has never been more critical to an organization's success, organizations are experiencing fierce competition with one another in regards to capturing these qualified employees. McKinsey \& Company, a global marketing firm, noted that by the year 2025 there would be a 33\% rise in the demand for "talented" employees (Pullen, Hartjes, Metselaar, Canchola, \& Murtough 2002). At the same time, the stock of these potential employees is expected to fall by $15 \%$ by 2025 (Pullen et al. 2002). It is crucial, then, that organizations implement policies that attract these talented individuals. One way hiring managers can attract the best recruits for their organization is by implementing a non-discrimination policy for its LGBTQ+ workforce.

Burns (2012), an analyst at the Center for American Progress, notes three ways LGBTQ+ employment discrimination can affect an employer's ability to facilitate a strong workforce. First, lacking comprehensive protection policies for these employees deters potential recruits from applying for positions at an organization (Burns 2012). Survey data gives support to Burn's claim; in a study conducted by Whiteck-Combs (2006) of 2,501 adults, 89\% of LGBT respondents agreed that it was important to work for businesses that have inclusive nondiscrimination policies for LGBTQ+ employees. It is not just LGBTQ+ persons that desire these benefits, however: the survey also showed that $72 \%$ of straight, cisgender individuals desired inclusive company policies for their LGBTQ+ coworkers (WCC 2006).

Burns also notes that discrimination hiring is inefficient. Asking potential employees about their sexual orientation or gender identity is not only irrelevant to the candidate's ability to contribute to the organization, but is unethical, possibly uncomfortable for both the candidate and hiring manager, and may prevent top talent from entering a company's workforce (Burns 2012). Cortina and King (2010) note that, just as it is vital for potential employees to give a good impression during interviews, it is equally important for hiring managers to do the same. Employees who walk away from an interview feeling attacked will not likely accept the position in the organization, reducing the human capital of that entity. 
Finally, Burns (2012) notes that employees who are the frequent victims of workplace harassment or discrimination are unlikely to recommend that others apply for a position at their place of employment. As advancement and use of communication technologies have increased in recent decades, the importance of networking to an organization's human capital has grown as well (Segal 2014). Sites such as LinkedIn are becoming crucial to an organization's success, and current and former employees are playing an increasingly significant role in recruiting new hires. Therefore, establishing a good relationship with an organization's workforce is critical in recruiting future human capital.

Other research has similarly shown that the main rationale for an organization's internal LGBTQ+ nondiscrimination policies is that these guidelines increases the human capital of the entity. Sears and Mallory (2011b) analyzed the statements made by various organizational leaders since 2005 and found that $84 \%$ of organizations that possessed non-discriminatory policies stated that their main rationale was to attract and retain talent. One such example is that of Marilyn Hewson, CEO of Lockheed Martin, who stated that: "Ensuring a positive and respectful workplace and robust set of benefits for everyone is critical to retaining employees." (Quote is taken from Mallory \& Sears 2011b).

Not all organizations analyzed in Sears and Mallory’s report possessed internal nondiscrimination policies for their employees. In many of these cases, however, current employees chastised their organization's leadership for failing to promote LGBTQ+ acceptance (Sears \& Mallory 2011b). One such employee was Provost Robert Holub of the University of Tennessee, who made the following statement regarding the university's lack of an anti-discrimination policy:

"We fool ourselves if we believe that the absence of a direct statement regarding discrimination against gays and lesbians does not harm our institution...We are probably hurt not only by gay and lesbian candidates preferring to go elsewhere but by heterosexuals who are as horrified as I am that we will not pledge to treat gay and lesbian applicants without prejudice" (Quote is taken from Mallory \& Sears 2011b).

This research supports the statement made by Provost Holub. One of the complaints made to the Louisville Metro Human Rights Commission came from a straight, cis-female who claimed that her coworker was habitually harassed in their workplace due to his sexual orientation. Eventually, the harassment was too much to take, and her coworker left his position at the organization (LMHRC, 13 May 
2012). Upset at the way her organization allowed harassment in the workplace, the straight, cis-female employee also resigned from her position and filed a complaint with the Commission. In the complaint, the former employee cited that the continued harassment faced by gay individuals at the organization created an atmosphere that was "too hostile for anyone with a drop of decency to continue to work in." (LMHRC, 13 May 2012). This former employee's experience was not rare. As reported in Chapter III, ten of the LGBTQ+ discrimination claims made in Jefferson and Fayette counties were made by straight, cisgender individuals complaining that their workplace environment was intolerable due to the level of LGBTQ+ harassment that was occurring there.

\section{$\underline{\text { Impact on Retention }}$}

As important as it has become for managers to attract top talent, it is equally essential that these managers retain this human capital in their organizations. Just as it has become more difficult for organizations to find qualified recruits, however, it has also become equally challenging to convince current employees to stay with the organization. Loyalty to one's employer has been decreasing rapidly in the United States since the 1970s (Tolbize 2008). Though the voluntary turnover rate fell during the Great Recession to a two-decade low of $9.1 \%$ in 2010 , it has been rising steadily as the economy has improved, and in 2015 stood at $13.4 \%$ (Bares 2015). There are many theories for this occurrence, including generational differences (Tolbize 2008), the loss of American manufacturing jobs (Thomas 2011), the decrease in employment benefits over time (Litchfield, Swanberg, \& Sigworth 2011; Johnson, Noble, \& Richmond 2011), and the increasing competitiveness of the job market (Meister \& Willard 2010).

Whatever the reason for this trend, organizations incur an enormous cost due to employee turnover. The Center for American Progress (2012) estimated that turnover cost the U.S. economy roughly $\$ 90$ billion in 2010 - the same year that turnover rates were low. These costs come in the form of advertising for the newly opened position, interviewing potential employees, pre-employment administration expenses, training new hires, and loss of productivity (Tolbize 2008). Moreover, these costs seem to increase for the highest positions in an organization. Replacing an employee whose salary was less than $\$ 30,000$ costs an organization roughly $16.1 \%$ of the former employee's annual salary (Boushey \& 
Glynn 2012). Replacing an employee whose salary was greater than $\$ 75,000$, however, will cost an organization up to $24.8 \%$ of that person's wages to find a suitable replacement (Boushey \& Glynn 2012).

Evidence suggests that places of employment that promote a hostile and discriminating working environment possess higher turnover rates than those organizations that promote a healthier working environment. This turnover may come in two forms: through direct termination of the discriminated employee or by creating such a hostile environment that the employee leaves voluntarily (Einarsen, Hague, \& Skogstad 2010). The enormous costs of turnover in an organization signal the need for organizations to create healthy environments for their workforce, including their LGBTQ+ employees. However, research has suggested that employee retention is difficult to produce when employees are subjected to continual harassment and discrimination at their places of employment.

Einarsen, Hauge, and Skogstad (2010) conducted a study that analyzed workplace discrimination and bullying to discover its effects on retention, productivity, and workplace satisfaction. Einarsen et al. sent questionnaires to 4,500 employees and asked them about their history of workplace bullying and the effects it had on their mental health and career path. Their research suggests that those who experience workplace bullying are more likely to suffer from anxiety and depression, to have a lower job satisfaction rate, and to leave their place of employment than those who are not subjected to workplace bullying (Einarsen et al. 2010).

Often, however, actual cases of bullying do not need to occur to increase turnover rates. Hebl, King, and Medera (2012) conducted a study that analyzed the effects of suppressing one's identity on perceived discrimination, job dissatisfaction, and turnover. Hebl et al. (2012) surveyed 211 individuals and questioned them on six factors: group identification (including LGBTQ+ identification), manifest identification, suppressed identification, perceived discrimination, job satisfaction, and turnover intentions. Their analysis suggests that those who have suppressed their identity at work due to perceived discrimination are more likely to have both lower job satisfaction and higher turnover rates compared to those who are "out" or those who do not perceive discrimination in their workplace - whether they are "out" or not (Hebl et al. 2012). 
In a similar study, Velez (2013) surveyed 324 LGB employees to test his hypothesis that the presence of LGB discrimination in the workplace will have a negative relationship to job satisfaction and a positive relationship to turnover intentions. Velez also hypothesized that the presence of an LGBsupportive climate at a place of employment would have the opposite effect: a positive relationship to job satisfaction and a negative relationship to turnover rates. Velez (2013) found that both hypotheses were supported by the data, as the presence of LGB discrimination in the workplace led to a decrease in job satisfaction and an increase in turnover intentions. Inversely, the presence of an LGB-supportive environment was likely to increase the job satisfaction and reduce the turnover intentions of gay and bisexual employees (Velez 2013).

\section{Impact on Productivity}

Even if an organization manages to avoid high turnover rates due to its hostile culture and discriminatory policies regarding its LGBTQ+ employees, it may still face economic consequences stemming from this form of discrimination. Several studies have demonstrated that a link exists between discrimination in the workplace and both lowered productivity and increased absenteeism and burnout in employees that face harassment. This lowered productivity has serious economic consequences for organizations. In his study, Burns (2012) estimated that discrimination against LGBTQ+ employees costs organizations $\$ 1.4$ billion each year due to reduced productivity, absenteeism, and turnover.

Cooper (2011) notes that original empirical studies on the effects of workplace bullying on the productivity of employees, however, remains sparse. This is mostly due to the great difficulty of defining and measuring productivity and efficiency in the workplace (Cooper 2011). To help remedy this lack, scholars have used survey research to analyze the link between harassment and productivity. While more limiting than empirical research, surveys have suggested that employees who are the victims of discrimination at their workplace do demonstrate lower productivity than those who do not face workplace bullying. 
One study was conducted by Berry, Gates, and Gillespie (2012) who surveyed 197 nurses to understand the effects of discrimination on work productivity. Of those surveyed, $58.4 \%$ stated that they had been subjected to workplace bullying at least once since beginning their career with the organization (Berry et al. 2012). When asked how this has affected their productivity, $46.7 \%$ reported that workplace bullying negatively affected their productivity, $23.9 \%$ reported no effect on productivity, and $29.4 \%$ indicated that it increased their productivity (Berry et al. 2012). Those who face daily bullying, however, reported more adverse effects on productivity compared to those who only faced occasional or one-time harassment (78.2\% vs. 39.5\%), and this difference was significant (Berry et al. 2012).

Ayoko, Callan, and Hartel (2003) examined how workplace bullying influenced counterproductive behaviors in the workplace. They surveyed 510 staff members from five public organizations using a self-administered questionnaire in which bullying, emotions stemming from harassment, and counterproductive behaviors were documented. For this study, Ayoko et al. (2003) defined counterproductive behaviors as purposefully wasting or destroying company property, purposefully missing set deadlines, or purposefully doing one's work incorrectly (Ayoko et al. 2003). The results of their study suggest that bullying is linked to an increase in counter-productive behaviors for those who experience harassment in the workplace (Ayoko et al. 2003). Interestingly, it made little difference if the employee was the recipient of the bullying behavior or simply a witness to it; counterproductive behaviors increased for all employees who were exposed to harassment (Ayoko et al. 2003). This suggests that having a hostile atmosphere in the workplace will affect the productivity of all employees, regardless of whether they were the targets of discrimination.

As research conducted by Meyer, the American Heart Association, and the American Psychological Association has demonstrated, discrimination can lead to negative mental and physical health outcomes for those who habitually experience it. The Michigan Department of Civil Rights (2013) contributes to this literature by suggesting that the mental and physical effects of harassment are magnified when individuals feel as if there is no way of escaping, as in their places of employment. Therefore, burnout occurs much faster in people who are subjected to frequent bullying at work, leading to an increase in absenteeism and voluntary turnover (MDoCR 2013). Burn's study (2012) also supports these findings: 
$71.7 \%$ of LGBTQ+ workers who are subjected to workplace harassment reported taking time off from work to avoid the hostile atmosphere.

The Michigan Department of Civil Rights also contributes to the literature provided by the American Medical Association and the American Heart Association. These studies have shown stress stemming from discrimination can lead to debilitating illnesses such as cancer, heart attacks, strokes, and diabetes. The Michigan Department of Civil Rights (2013) notes that those who suffer from these physical ailments are more likely to file for medical leave, further decreasing the productivity of an organization. All these instances have a negative effect on employee productivity within an organization. The Harvard Business Review (2013) notes that in the ever-increasing competitiveness of the global markets, a reduction in workforce productivity can "kill" an organization faster than any other labor difficulty.

\section{$\underline{\text { Impact on Innovation and Problem Solving }}$}

By implementing a policy that discriminates against a set of individuals, business leaders are rejecting diversity within their organizations. This can have severe economic consequences for an organization, as several studies have shown that lacking a diverse workforce decreases the sustainability of an organization. In particular, an organization that lacks diversity runs the risk of being unimaginative, inflexible, inaccessible, and ineffective, all of which can decrease an organization's outlook.

Hewlett, Marshall, and Sherbin (2013) surveyed 1,800 professionals, analyzed forty case studies, and conducted "numerous" focus groups and interviews in their study on the effect diversity has on organizational growth. They defined diversity in two ways: inherent diversity stems from traits such as race, sex, gender identity, and sexual orientation, while acquired diversity derives from an individual's personal experiences and life experiences. Hewlett et al. (2013) found that workforces that possessed both inherent and acquired diversity were $45 \%$ more likely to report growth in market share over the previous year and $70 \%$ more likely to have captured a new market compared to more homogeneous organizations. This research particularly emphasized the importance of inherent diversity within the organization's leadership: without diverse leadership, people of color were $24 \%$ less likely than straight white men to 
achieve endorsement of their ideas, women were $20 \%$ less likely, and LGBT individuals were $21 \%$ less likely (Hewlett et al. 2013).

Hewlett et al. (2013) note that organizations with a great deal of inherent and acquired diversity were more likely to have better problem-solving skills than homogeneous organizations. This problemsolving apparatus stems from the diversity of ideas and experiences that reduce the likelihood of groupthink, expanding the organization's ability to confront problems going forward (Hewlett et al. 2013). Therefore, increasing diversity within an organization's workforce enhances the ability of the organization to adapt to a changing business environment. This study suggests that having a diverse workforce and establishing a culture of inclusion is crucial for developing innovation within an organization.

A survey conducted by Robert Burt (2004) gives further support to these claims. Burt surveyed 673 supply-chain managers and their employee's "internal connections" to test the hypothesis that employees with more diverse networks produce a higher quality of ideas. His study analyzed sixteen variables pertaining to both an employee and an employee's proposal to discover which factors significantly affected the possibility that management would discuss the idea. Out of the sixteen variables looked at in the study, only network constraint (i.e. inherent and acquired diversity) was statistically significant (Burt 2004). Burt's (2004) study suggests that the diversity of an employee's network connectivity has a major influence on the quality of ideas in an organization, leading to an increase in innovation and problem-solving in the entity.

Possessing a diverse workforce also increases innovation in ways that one might not expect. The Center for American Progress (2012) notes that globally, LGBTQ+ individuals had a cumulative buying power of nearly one trillion dollars, spent eight-hundred and thirty-five billion dollars on goods and services, and represented $6 \%$ of the entire global market in 2011. By employing, promoting, and giving attention to the ideas and networks of LGBTQ+ employees, organizations are better able to tap into this growing market, as these employees are better able to produce and market goods and services to the LGBTQ+ community (CAP 2012). Therefore, providing equal employment opportunities for LGBTQ+ employees can introduce an organization to new markets, thereby increasing profits. 
Inversely, an organization possessing a record of LGBTQ+ discrimination can do severe damage by alienating this growing market. In a survey of over 4,000 individuals, Diversity Taskforce (2012) found that $78.3 \%$ of LGBTQ+ individuals are less likely to support a business that has a history of LGBTQ+ discrimination in their workplace. It is not just the LGBTQ+ community these companies are alienating, however. The survey also found that $42.1 \%$ of straight, cisgender consumers were less likely to support a business that had a history of LGBTQ+ discrimination compared to only $28.3 \%$ of non-LGBTQ+ consumers who are more likely to support such a policy (Diversity Task Force 2012).

\section{Impact on Litigation}

A final issue that stems from LGBTQ+ employment discrimination that may severely affect an organization's bottom line is litigation. Economic losses arising from discrimination suits are a growing expenditure faced by employers of all sizes in the United States (Burns 2012). In the year 2000, an employee lawsuit costs organizations, on average, \$66,000 in legal and settlement expenses (CERS 2017). By 2015, this figure almost quadrupled to $\$ 248,000$ (CERS 2017). In the year 2016 alone, the EEOC secured over $\$ 404,000,000$ from employers in representing employees who were subjected to discrimination or harassment stemming from some protected class (CERS 2017), and this figure does not include settlements made in state or local human rights commissions.

Although a national nondiscrimination policy for LGBTQ+ employees does not exist, many LGBTQ+ individuals are protected from this form of discrimination via state or local laws. Thirty-four states, the District of Columbia, and 255 local governments have some level of protections for their LGBTQ+ residents (Movement Advancement Project 2015a). An increasing number of Americans are protected by these state and local nondiscrimination laws, meaning many employers are required to have internal nondiscrimination policies regarding their LGBTQ+ employees. To protect themselves from the growing number of discrimination lawsuits, employers must not only implement nondiscrimination policies but also enforce them. 
Further, an increasing number of federal courts have begun to accept the EEOC's interpretation of "sex discrimination" - which is prohibited by Title VII of the Civil Rights Act - as pertaining to members of the LGBTQ+ community. On April 9, 2015, U.S. District Court Judge Scriven approved a consent decree between a Florida-based eye clinic and the EEOC, ordering the clinic to pay $\$ 150,000$ in damages to a transgendered employee who was fired due to her gender identity (Shaw 2015). That victory was followed by a settlement between the EEOC and IFCO Systems, who agreed to pay a woman $\$ 202,000$ after she was fired due to her sexual orientation (EEOC 2016b). These cases would suggest that the cost of discriminating against employees due to their sexual orientation or gender identity is quickly becoming a costly affair.

\section{Lessons Learned}

Numerous studies outlined in this chapter have demonstrated the adverse effects that employment discrimination against LGBTQ+ employees has on an organization's economic health. These findings are increasingly becoming accepted by business leaders across the country, which explains why the number of Fortune 500 (F500) companies that have internal nondiscrimination policies for their LGBTQ+ employees have increased over the past two decades. In 1999, 72\% of F500 companies protected their LGB employees, and only $8 \%$ had similar protections for gender minorities (Mallory \& Sears 2011b). By 2009, $87 \%$ of F500 companies adopted LGB protections, and the percent of these businesses that had gender identity protections swelled to $41 \%$ (Mallory \& Sears 2011 b). As of $2017,89 \%$ of Fortune 500 companies prohibit discrimination due to sexual orientation, and $66 \%$ of F500 organizations have similar protections for gender identity (HRC 2017).

It is not just F500 companies that are supporting and implementing policies that protect LGBTQ+ employees from discrimination in the workplace. According to a 2011 Center for American Progress survey, $77 \%$ of small businesses with fifteen or more employees had internal LGB + nondiscrimination policies, and $62 \%$ had similar policies for gendered minorities. For businesses with fewer than fifteen employees, these figures dropped slightly to $64 \%$ and $51 \%$ respectively (CAP 2011). Small businesses are also favorable to national legislation that would prevent such discrimination from occurring: $63 \%$ of small 
business owners support a national nondiscrimination bill for LGBTQ+ workers, while only $15 \%$ noted their opposition (CAP 2011).

Many of Kentucky’s largest employers also possess internal nondiscrimination policies for their LGBTQ+ employees. Seven of the nine F1000 companies headquartered in Kentucky - Humana, YUM! Brands, Kindred Healthcare, Ashland, Lexmark International, Tempur Sealy International, and BrownForman Corporation - offer employees and potential employees protection from discrimination stemming from their sexual orientation and gender identity (HRC 2017). The other two Kentucky-based F1000 corporations - General Cable Company and PharMerica Corporation - offer these protections for sexual orientation, though not gender identity (HRC 2017). Kentucky's public universities also offer many of these protections, with the University of Kentucky, University of Louisville, Western Kentucky University, Eastern Kentucky University, Northern Kentucky University, and Morehead State University offering protections to LGBTQ+ students and staff. Murray State University and Kentucky State University offer similar protections to sexual minorities, though not gendered minorities.

This chapter analyzed numerous studies that give overwhelming support to the idea that promoting or tolerating a hostile atmosphere for LGBTQ+ employees is detrimental to an organization's success. To protect themselves and their employees from these harmful effects, American employers - both large and small - are increasingly implementing internal nondiscrimination policies that protect LGBTQ+ employees from workplace discrimination and harassment. Despite this growing trend, however, data analyzed in Chapter III suggests that discrimination against sexual and gendered minorities is still occurring in the United States.

One method governments can take to protect individuals from discrimination is enacting strong anti-discrimination laws for their LGBTQ+ residents. Doing so will not only benefit the residents and businesses in these communities, but it may even spur local economic development in the region. Several empirical studies have suggested that having LGBTQ+ non-discrimination laws and ordinances may result in economic growth in a locale. Inversely, recent political events have demonstrated that governments that appear to promote this form of discrimination in their communities run the risk of losing economic 
development in their constituencies. The effects of LGBTQ+ nondiscrimination laws on local economic development will be the subject of the next chapter. 


\section{CHAPTER VI:}

\section{THE IMPACT OF DISCRIMIANTION ON THE COMMUNITY}

The previous two chapters explored the literature on the benefits that LGBTQ+ inclusive laws and policies have on individual persons and organizations, as well as the costs these entities face when such discrimination occurs. It should not come as a surprise, then, that these nondiscrimination laws - or lack thereof - affect not only the micro, but the macro as well. Research suggests that possessing LGBTQ+ nondiscrimination laws may greatly benefit a community’s local economic development. After all, communities inhabited by confident, healthy, fully employed residents and successful businesses should be at an advantage when it comes to economic development and growth. Inversely, the widespread criticism aimed at the governments of Indiana and North Carolina following the enactment of their "Religious Freedom" laws in 2015 and 2016 respectively have demonstrated that communities that appear to tolerate discrimination against their LGBTQ+ residents face national criticisms, political instability, and economic consequences, hampering development.

This chapter consists of two sections: Benefits of LGBTQ+ Inclusion and Costs of LGBTQ+ Exclusion. The first section includes a literature review on the potential benefits communities may receive by implementing LGBTQ+ nondiscrimination laws and ordinances. Several scholars have suggested that these laws may attract both new, prosperous residents and private investment. Further, by preventing discrimination from occurring, local and state governments may both increase public revenue and decrease expenditures. These studies suggest that nondiscrimination laws make communities more resilient for all residents, not just LGBTQ+ persons.

The second section will explore the economic and political costs of discrimination using two case studies in the states of Indiana and North Carolina. In the past two years, these states have attempted to 
recognize LGBTQ+ employment discrimination as legitimate through their respective "Religious Freedom" laws. These events demonstrate that there are real consequences in being LGBTQ+-unfriendly. Just as individuals and organizations appear to be drawn to localities with strong protections for their LGBTQ+ residents, communities that seem to encourage employment discrimination repel them. This tendency is particularly relevant to this thesis, as several Kentucky state legislators have announced that they are looking into passing a Religious Freedom Law in the Commonwealth.

\section{Benefits of LGBTQ+ Inclusion}

Just as organizations are experimenting with new workplace policies in hopes of recruiting top talent, municipalities across the country are similarly looking for ways to attract prosperous residents and growing industries into their communities. Also similar to private organizations, these municipalities are finding this task increasingly difficult as the United States continues into the post-industrial economy (Leigh \& Blakely 2013; Florida 2002). Increasing mobility among Americans and the rise of communication technologies have resulted in a heavy concentration of many profitable industries in just a handful of American cities, with the consequence being that many communities are being left behind regarding economic investment and development (Florida 2002, 26). This has led to fierce competition between cities across the country in trying to recruit highly productive industries and residents into their communities (Leigh \& Blakely 2013; Florida 2002, 27).

One simple tool governments may employ to entice highly productive residents into their communities is by enacting nondiscrimination laws, ensuring potential residents that discrimination is not tolerated within their jurisdiction. This tool has been supported by research from the policy theorist Richard Florida. Highly regarded in some academic circles and heavily criticized in others, Florida has written extensively on local economic development in the 21 st-century economy. In his book, The Rise of the Creative Class (2002), Florida concurs with many scholars that one of the most daunting challenges local economic practitioners face is attracting both highly productive professionals - a class Florida termed the creative class - and "creative" industries (Florida 2002, 8). 
Florida noted that the creative class is becoming more concentrated in specific geographic locations, not dispersed across the United States, and this trend is not likely to reverse itself anytime soon (Florida 2012, 73). Increased personal mobility and recent advances in communication technologies have made the need to perform many of these services within a reasonable distance to the consumer obsolete. For example, a computer programmer can develop software for a business in Louisville while remaining in San Francisco. For this reason, the technology sector is concentrated in just a handful of cities such as San Francisco-San Jose (Silicon Valley), Boston, and Raleigh-Durham-Chapel Hill (the Research Triangle).

So how can a city entice the creative class - and the wealth they bring with them - into its community? The creative class theory has several recommendations for local economic practitioners, much of which will not be discussed here. One notable characteristic of cities that have high concentrations of creative professionals, though, is that these places also score high on the Gay Index (Florida 2012, 84). The Gay Index is an indicator of the proportion of LGBTQ+ individuals within a community. As expected, gays are highly concentrated in areas which LGBTQ+ protections are strongest (Florida 2012, 85).

Along with the Bohemian Index, the Foreign-Born Index, and the Integration Index, the Gay Index is used in computing what Florida termed the Tolerance Index (Florida 2012, 84). The Tolerance Index measures the degree to which a community is open to a diverse set of people and ideas. Florida states that having a highly tolerant community is crucial for attracting the creative class to resettle in a city (Florida 2012, 86). This is because those in the creative class tend to live a "Bohemian" lifestyle (Florida 2012, 64). Florida writes that it is vital to the economic health of communities that they attract these creative Bohemians, and one such way to do so is to promote tolerance for LGBTQ+ persons (Florida 2012, 87). One way a government might promote tolerance to their LGBTQ+ communities is by passing a comprehensive civil rights ordinance for these residents.

Florida's conceptualization of the creative class and his Tolerance Index are not without critics. Many scholars believe that the traditional measure of human capital - educational attainment - is a better indicator of regional economic development (Glaeser 2004; Clark 2004). Markusen (2006), for example, noted that the higher education attainment of LGBTQ+ persons might explain the connection between the Gay Index and economic development. These scholars suggest that human capital builds on itself, 
particularly in areas that hold prominent universities, which then produce higher educational attainment for these regions. The tech industries - the prototype of Florida's creative economy - for example, are concentrated in areas with exceptional universities: Silicon Valley (Stanford and UC Berkley), Boston (MIT and Harvard), and the Tech Triangle (UNC Chapel Hill and Duke).

Florida, Mellander, and Stolarick (2008) note, however, that average educational attainment does not always paint an accurate picture of the economic realities of a region, as vital factors such as talent, intelligence, creativity, accumulated experience, and on-the-job knowledge are left out in this equation. In this way, Florida believes that his utilization of the creative class - i.e. the proportion of residents in the creative economy - presents a more detailed understanding of regional economic health. Furthermore, in some areas, the existence of a prominent university has not produced a strong regional economy (Florida et al. 2008). Florida et al. (2008) state that this is because as communication technology and mobility improve, there is less keeping residents and recent graduates from relocating to cities that provide them with a better social and economic fit.

Florida also claimed that these critics misunderstood his intentions for the Gay Index (Florida 2012, 78). Florida never argued that the presence of a strong LGBTQ+ community is vital for the economic health of a city. If that were the case, Florida would not be discussing how to attract the creative class, but LGBTQ+ residents in general. Rather, what Florida is getting at is that the presence of a strong LGBTQ+ community is a robust indicator that a region is open to many kinds of people; a community which freely allows creativity to flourish. Having a strong LGBTQ+ community has been shown not to cause, but to indicate that a region has low barriers to entry into its economy, possesses the mechanisms for efficient spillovers of knowledge-production, is tolerant of risk and self-expression, and has productive entrepreneurship; all of which contribute to strong economic performance (Florida et al. 2008).

There is empirical evidence that suggests Florida's theory has merit. Using a difference-indifference regression, Gao and Zhang (2016) analyzed 58,009 firms between 1976 and 2008 to examine the effect state nondiscrimination laws had on innovation output. Their study found that the adoption of an LGBTQ+ nondiscrimination law increased the number of patents issued in the state by $8 \%$ compared to states that did not possess such a law (Gao \& Zhang 2016). Gao and Zhang also tracked the mobility of 
"inventors" using the Harvard Business School Patent Dataverse and found that states experience an inflow of these creative professionals following the enactment of LGBTQ+ nondiscrimination laws, particularly from states that do not possess these protections (Gao \& Zhang 2016). This study appears to suggest that communities witness a rise in innovation and an influx of creative professionals after enacting LGBTQ+ workplace protections, which complies with Florida's creative class theory.

While Florida's theory remains controversial among academics and practitioners, his idea that individuals want to live in a community that shares their values also appears to have merit. The Michigan Department of Civil Rights held several public forums, asking residents to provide their opinions on what the economic impact of a statewide LGBTQ+ nondiscrimination law would be. In their report, the Department stated that the only consistent theme in their forums was residents threatening to leave the state if the law was not enacted (MDoCR 2013). In one forum at the University of Michigan, approximately onefifth of LGBTQ+ and non-LGBTQ+ students alluded to their desire to leave the state once they have attained their degree due to Michigan's lack of protections (MDoCR 2013). Here is one testimony given by a straight, cis-female student at the forum:

“Michigan's lack of laws promoting equal rights for gay and lesbians and the near passage of an anti-bullying law allowing bullying based on sexual orientation are appalling and though it does not affect me personally, it does influence my desire to live here." (Quote taken from the Michigan Department of Civil Rights 2013)

This forum inspired the Department to conduct a study of 449 graduate students -28 of which identified as LGB - at Michigan's top universities to see what proportion of students planned to leave the state after graduating and what factors were causing them to do so. According to the survey, $92 \%$ of LGB students and $73 \%$ of non-LGB students had definite plans for leaving Michigan following graduation (MDoCR 2013). Those surveyed then ranked how important - on a scale from one (not important) to five (extremely important) - each of the twelve factors was to their decision to leave. The LGB students listed job prospects (mean score was 4.36), job security (4.16), and employment laws (3.93) as the top reasons for their decision to leave Michigan (MDoCR 2013). Similarly, the non-LGB population listed employment laws as a factor for wanting to leave the state (3.37), though this mean was notably lower than in the LGB population. The study concluded that Michigan's lack of an LGBTQ+ nondiscrimination law played a 
factor in highly educated individuals leaving Michigan for other states that do offer these protections (MDoCR 2013).

\section{Lowering Local and State Public Expenditures}

LGBTQ+ nondiscrimination laws not only attract new residents and private investment, but they also affect the government's ability to perform public services. According to the Urban Institute (2012), state sales taxes (23.2\%), individual income taxes (17.2\%), and corporate income taxes (2.6\%) make up, on average, $43.0 \%$ of state government revenue in 2012 . The Urban Institute also noted that property taxes (29.7\%), local sales taxes (6.7\%), and local individual income taxes (1.8\%) make up $38.2 \%$ of local government revenue as well. These sources of public revenue are directly affected by discrimination. As noted in Chapter IV, LGBTQ+ individuals are frequently paid less than their similarly qualified heterosexual, cisgender coworkers, reducing the amount of income tax that state and local governments may collect. Further, this discrimination also reduces the amount of money LGBTQ+ persons may spend in the local economy, reducing sales and property taxes as well. The research outlined in Chapter V also suggested that organizations are less productive when discrimination occurs on their premises. This loss of productivity leads to a loss of profits, thereby reducing the corporate income taxes these organizations pay to all levels of government. Reducing discrimination through the enactment of a nondiscrimination law, then, can increase the sources of public revenue for a municipality or state.

These nondiscrimination laws may not only increase local and state government revenue, but they may also lower government expenditures. When an employee is terminated from their place of employment, they are usually eligible for public assistance programs paid for by the state. Several studies have shown that LGBTQ+ individuals are more likely to require public assistance than their heterosexual, cisgender neighbors, despite generally being more educated than the population as a whole. In a report conducted for the Williams Institute, Badgett, Durso, and Schneebaum (2013) found that 2.2\% of male same-sex couples and $1.3 \%$ of female same-sex couples received state emergency cash assistance in the United States. Further, the Williams Institute found that the LGBTQ+ individuals are $13.4 \%$ more likely to than non-LGBT individuals to receive food stamps (Badgett et al. 2013). 
Interestingly, these statistics are not representative of the entire United States. The Williams Institute notes that in some states - California being their prime example - the LGB population needed less public assistance than straight residents, and though the trans-community were still overrepresented in needing public assistance in California, they were better off than in most states (Badgett et al. 2013). The Williams Institute states that having strong LGBTQ+ employment protections may lower the poverty rate of these individuals (Badgett et al. 2013), thereby reducing the burden state and local governments face regarding public assistance.

It is difficult to quantify exactly how much discrimination costs American taxpayers each year due to the need of the LGBTQ+ community for these public services (MDoCR 2013). In her report on the public costs of trans-discrimination in Massachusetts, Herman (2011) estimated that the state and local governments lost over $\$ 2,000,000$ in tax revenue due to the high unemployment rates and lower average incomes of the transgendered community. Further, the state lost roughly $\$ 3,750,000$ a year in expenditures due to the transgendered community's higher rate of utilizing public services such as Medicaid, housing programs, and work-related assistance programs (Herman 2011). Herman's research did not examine the indirect economic impacts - such as lost sales tax revenues or business profits - of transgender employment discrimination in the state, suggesting these costs were even higher than Herman reported.

\section{$\underline{\text { Costs of LGBTQ+ Exclusion }}$}

The past decade has seen state governments go in increasingly different directions when it comes to protecting their LGBTQ+ residents from employment discrimination. While many states began implementing statewide nondiscrimination laws en masse during the first decade of the $21^{\text {st }}$ century, several states have attempted to legalize LGBTQ+ discrimination through the use of various religious freedom laws. In the past two years, two states - Indiana and North Carolina - have enacted such anti-LGBTQ+ legislation. These examples provide an interesting and empirical look into what occurs when states enact policies that not only do not discourage discrimination but appear to promote it in the public or private sector. Based on these two case studies, it can be concluded that even the appearance of LGBTQ+ hostilities by state governments may result in significant economic and political consequences. 


\section{Indiana and Senate Bill 101}

In 2015, Indiana caused a national firestorm of controversy after the state's governor (and future Vice President) Mike Pence signed the Religious Freedom Restoration Act (RFRA). Despite the heavy criticisms the government of Indiana received due to its RFRA, such legislation is not rare in the United States. In 1993, Congress drafted and approved a federal RFRA, which was then signed by President Clinton (Volokh 2013). Following the federal government's lead, between 1993 and 2014, twenty-one states enacted their own RFRAs (NCSL 2017). Unlike Indiana's RFRA, however, many of these earlier pieces of legislation were not highly contested or polarizing. The federal RFRA, for example, had broad bipartisan support: it received a unanimous vote in the House and only three Senators voted against it (Volokh 2013). In fact, the American Civil Liberties Union - a long time defender of LGBTQ+ rightsopenly supported the bill at the time (ACLU of Ohio 2015).

This broad support stemmed from the original intent many of the drafters of RFRAs had for their bills. The federal RFRA came after the Supreme Court ruled in Employment Division v. Smith that the State of Oregon had not violated the Free Exercise Clause when it denied two Native Americans unemployment benefits after they tested positive for mescaline, a banned drug often used in Native American religious ceremonies (Volokh 2013). This decision was highly contested by both liberal and conservative groups and led to the enactment of the federal and various state RFRAs (ACLU of Ohio 2015). Under these laws, federal, state, and local governments cannot pass legislation that significantly impedes a person's religious freedom guaranteed by the Free Exercise Clause of the First Amendment (HR 1308, 1993). LGBTQ+ rights, then, were not within the scope of these early laws.

In 2014, this limited scope began to widen significantly. In a 5-4 decision, the Supreme Court ruled in Burwell v. Hobby Lobby Stores that closely-held, for-profit organizations qualified as individual persons under the federal RFRA (Haberkorn \& Gerstein 2014). This decision granted these corporations the ability to protest federal laws if they feel these acts hamper their religious beliefs. Energized by the Hobby Lobby ruling, several conservative state governments began drafting expanded RFRAs to give organizations in their state the right to claim similar religious beliefs (Pizer 2014). Unlike the original RFRAs, however, one of the targets of these new laws did appear to be the LGBTQ+ community. The 
decision in Hobby Lobby was made at a time when many Federal Circuit Courts began ruling that state bans on same-sex marriage violate the Equal Protection Clause of the $14^{\text {th }}$ Amendment. Conservative state governments, fearing that LGBTQ+ rights would interfere with the rights of the religious community, explored RFRAs as one tool of permitting businesses to discriminate against an individual if they have a religious reason for doing so (Pizer 2014).

Conservative Indiana lawmakers made the push for an RFRA in Indiana following the Seventh Circuit Court's ruling in Baskin v. Bogan, which made same-gender marriage legal in the state. At the start of the 2015 legislative session, Senator Kruse introduced Senate Bill 101 (SB101) -the Religious Freedom Reformation Act - into the Indiana General Assembly. The bill was heavily criticized by the state's Chamber of Commerce, which warned Indiana lawmakers that the bill would bring national embarrassment and corporate protests to the state (Steiger 2015; Ketzenberger 2015). Indiana lawmakers ignored these warnings, and the bill easily made its way through the General Assembly. On March 26, 2015, Governor Pence signed SB101 into law (Jones 2015).

SB101 stated that no government in Indiana "may substantially burden a person's exercise of religion, even if the burden results from a rule of general applicability" (Indiana SB101, Section 8, Subsection A). Following the Supreme Court's lead, SB101 further defines "person" as any individual or organization that is driven by "religious beliefs" and is capable of being part of litigation (Indiana SB101, Section 8, Subsection A). SB101 works by preventing an "applicant, employee, or former employee" from pursuing litigation against an employer if the complaint in question is founded on the organization's religious beliefs (Indiana SB101, Section 8, Subsection A).

Though SB101 did not contain the words sexual orientation or gender identity, many legal scholars and activists understood the law as directed against LGBTQ+ Hoosiers (Jones 2015). By allowing organizations the ability to possess religious freedoms and preventing local governments from burdening these liberties, SB101 may have derailed LGBTQ+ rights in two ways. Under one interpretation of the law, business owners can claim that the twenty-three local LGBTQ+ nondiscrimination ordinances in Indiana interfere with their fundamental beliefs by forcing them to serve or hire LGBTQ+ persons, nullifying these ordinances. Under a second interpretation, by preventing employees from suing employers who 
discriminated against them due to such religious beliefs, those who face discrimination have no legal recourse to challenge their employers, making nondiscrimination laws unenforceable in these settings.

Even some supporters of SB101 suggested that the law works to protect business owners who implement discriminatory policies. The American Family Association, a conservative advocacy group, announced that God had been "victorious" when SB101 was signed, stating that the bill would "prevent Christians across the state from serving sexual deviants" (Tashman 2015). A pizza parlor in Walkerton also announced that they would no longer provide their services for same-sex marriages, claiming the Indiana RFRA allows them to decide for themselves if they want to provide such services (Wong 2015). Advance America, a conservative Christian group based in Indiana, released the following statement about Indiana's then-proposed RFRA:

"SB 101 will help protect individuals, Christian businesses and churches from those supporting homosexual marriages. Christian bakers, florists and photographers should not be punished for refusing to participate in a homosexual marriage!" (Quote taken from Cook 2015)

Despite the consensus from both the left and right that SB101 gives business owners the right to discriminate against LGBTQ+ employees and consumers, both the Republican lawmakers in the General Assembly and Governor Pence repeatedly stated that the purview of the bill did not allow for such actions. When asked his opinion on the backlash the state had received following the enactment of SB101, Senator Krusse - the bill's sponsor - told the press that he believed the criticisms were "unnecessary" and suggested that these critics had not "read the bill" (Kennedy 2015). In a press conference that took place a day after he signed SB101, Pence similarly told the media:

"The Religious Freedom Restoration Act in Indiana does not give anyone the right to deny services to anyone in this state. It is simply a balancing test used by our federal courts and jurisdictions across the country for more than two decades." (Quote taken from Washington Post Staff, 2015)

In spite of these reassurances that the bill did not target LGBTQ+ Hoosiers, the backlash against the state was severe. After the bill had been signed, companies, celebrities, and government leaders from across the country vowed to boycott the state. The NCAA announced that it was reconsidering allowing their championship tournaments to be held in Indiana, stating that they were "concerned for both student 
athletes and [NCAA] employees" (Alesia 2015). The web-based company Angie's List halted an expansion of one of their facilities that would bring \$40 million in investment and 1000 new jobs to Indianapolis (Evans 2015). Yelp! stated that it would no longer expand its operations in Indiana and even threatened to shut down its mobile services in the state (King 2015). The governments of Connecticut, New York, and eight cities banned publicly funded travel to Indiana (Alesia 2015). The Indy Big Data Conference, designed to bring the biggest names in online retail and logistics to Indianapolis, was canceled after Apple, Amazon, and Walmart protested the event (King 2015).

Within four days of Pence signing the RFRA, the Center for American Progress estimated that the law would cost the Indiana economy $\$ 250$ million due to the loss of private investments, jobs, entertainment and sporting events, and individual persons boycotting the state (McBride 2015). The Indianapolis Star, the most widely circulated daily newspaper in Indiana, issued a front-page headline on March 31 entitled "FIX THIS NOW!" set in large white letters on a black background that took up the entire front page of the issue. The article pleaded for Governor Pence and the Indiana General Assembly to reverse its actions, stating:

"We are at a critical moment in Indiana's history. And much is at stake. Half steps will not undo the damage. Gov. Mike Pence and the General Assembly need to enact a state law to prohibit discrimination in employment, housing, education and public accommodations on the basis of a person's sexual orientation or gender identity. Governor, Indiana is in a state of crisis. It is worse than you seem to understand." (Quote taken from Taylor 2015)

After one week of protests, national embarrassment, and economic damage, Governor Pence called on the General Assembly to issue an amendment to SB101 that would clarify its intent. On April 2, Senate President David Long introduced the amendment, which clarified that the RFRA does not allow an organization to "deny service to anyone on the basis of sexual orientation, race, religion or disability" (Amendment 50,2015). Two days after the amendment was introduced into the General Assembly, it easily passed the Indiana legislature and was subsequently signed by Governor Pence (Lowery 2015).

The original SB101 was to take effect on July 01,2015 , and thus the RFRA never had the opportunity to be carried out, so it may never be known the extent to which the law would have been implemented. Nonetheless, SB101 cost the state dearly. Visit Indy, the official tourism site of Indiana, 
estimated that the bill cost the economy $\$ 60$ million in the week leading up to the amendment, mostly in the tourism industry (Broverman 2016). Angie's List CEO Bill Oesterle, who halted expansion in Indianapolis due to SB101, expressed his belief that the amended RFRA was "insufficient" and the company's planned expansion has yet to occur (Briggs 2015). Most organizations, however, appeared to have been satisfied with Amendment 50, as most entities ended their boycotts after Pence signed the revision (Broverman 2016).

Indiana was not the only state debating a "Religious Freedom Law" in 2015. That year, legislatures in fifteen other states introduced bills similar to SB101. The negative press and steep economic loss generated by SB101, however, appears to have deterred most states from enacting such a law. Following the passage of SB101, the state governments of Kansas, South Dakota, and Idaho rejected their RFRAs, despite all having solid Republican majorities in their legislatures and Republican governors (McBride 2016). As noted in Chapter II, Kentucky lawmakers - both Democrat and Republican - have also introduced several RFRAs into the General Assembly, yet these bills have been unsuccessful as well. Both ACLU Director Aldridge and Representative Marzian suggested that the national reaction to Indiana's RFRA has helped prevent such legislation from being enacted in Kentucky (Aldrige, PC 2016; Marzian, PC 2016). Not all states, however, have followed this trajectory.

\section{North Carolina and House Bill 2}

In early 2016, the Charlotte City Council was gearing up to be the first municipality in North Carolina to enact a local nondiscrimination ordinance for its LGBTQ+ population. The Council attempted to pass a similar bill a year earlier, but opposition from two Democrats ultimately caused the ordinance to fail. It was not that these Democrats opposed granting protections to LGBTQ+ Charlotteans; rather, they announced they could not support a nondiscrimination ordinance that did not cover all in the LGBTQ+ community (Portillo \& Price 2015).

The original nondiscrimination ordinance introduced into the Charlotte City Council in 2015 included protections for sexual and gendered minorities and, as is often the case, conservatives came out to 
plead to the Council to vote against the ordinance. It appears that many of these Charlotteans were not concerned with protecting gay individuals from employment discrimination; rather, opponents of the ordinance were troubled about the provisions that would allow a person to choose the restroom that corresponds with their gender identity rather than their birth-assigned sex (Portillo \& Price 2015). In an attempt at compromise, the Council amended the ordinance, removing gender identity from the list of protected classes. These actions were contested by Councilpersons LaWana Mayfield and John Autry, who refused to support a bill that did not grant protections to all LGBTQ+ persons (Portillo \& Price 2015). The loss of Mayfield and Autry resulted in the ordinance being defeated by a vote of six to five.

In February of 2016, however, the Council reintroduced the original ordinance, which would protect both sexual and gendered minorities (Charlotte Ord. 7056 2016). The ordinance, however, would become the target of a new political actor: North Carolina Governor Pat McCrory. In an attempt to subdue the Council, Governor McCrory threatened to take "immediate legislative action" against the Council if it passed the ordinance. At first glance, this threat from Governor McCrory appeared to signal a shift in his policy priorities, as the Governor had previously expressed concern over "legislative action" that would permit discrimination against LGBTQ+ North Carolinians. In fact, after the state's General Assembly introduced a Religious Freedom Restoration Act in 2015, Governor McCrory promised to veto the legislation if it ever came to his desk (Binker 2015).

Despite his earlier opposition to laws that permit LGBTQ+ discrimination in North Carolina, Governor McCrory continued to threaten the Charlotte Council throughout February of 2015 to take state action that would nullify the ordinance. This shift in policy intentions appeared to be triggered not by employment law, but by bathroom and locker room access, mirroring the argument made by many Charlotteans a year earlier. When asked why he was opposed to the Charlotte nondiscrimination ordinance, McCrory responded that:

"It is not only the citizens of Charlotte that will be impacted by changing basic restroom and locker room norms but... this shift in policy could also create major public safety issues by putting citizens in possible danger from deviant actions by individuals taking improper advantage of a bad policy." (Quote taken from Harrison 2016a) 
On February 22, the Charlotte City Council ignored the governor's threat, passing a non-amended Ord. 7056 by a vote of 7-4 (Harrsion 2016b). McCrory, however, would make good on his promise. On March 23 - a week before Ord. 7056 was scheduled to take effect - the North Carolina General Assembly held a special joint session to discuss legislation that would nullify the Charlotte City Council's actions House Bill 2. After less than three hours of debate, the General Assembly voted in favor of HB2 by a combined vote of 114 to 32 (Lacour 2016). Two hours after the legislature passed HB2, Governor McCrory signed the bill into law (Lacour 2016).

HB2 went far beyond the original scope of the session, which was first convened to create legislation restricting restroom use in public areas (Lacour 2016). Not only did HB2 deny individuals the right to choose the restroom that corresponds with their gender identity, but it also prevented the Charlotte government from enforcing other aspects of their nondiscrimination ordinance. The bill states that:

The provisions of this Article supersede and preempt any ordinance, regulation, resolution, or policy adopted or imposed by a unit of local government or other political subdivision of the State. (Section 2.1 of HB2 2016)

To "create statewide consistency in employment law," the act specified which classes of individuals in the state were protected from discrimination in employment, housing, and public accommodations (HB2 2016). HB2 prevented local governments from enacting ordinances that provide additional protections to those already outlined in the North Carolina State Code (HB2 2016). Unsurprisingly, neither sexual orientation nor gender identity were among these classes (Sections 134-142.1).

Like the national response regarding SB101 in Indiana, the passage of HB2 was met with widespread criticisms both within and outside of North Carolina. Within two weeks of signing the bill, Governor McCrory received over 130 letters from business leaders around the country threatening to boycott the state in future business opportunities if HB2 was not rescinded (Durso, Mirza, \& McBride 2016). After it had become apparent that the bill would not be revoked, many business leaders acted on their threats, halting expansion plans in the state. PayPal pulled plans to open its new global operations center in Charlotte, which would have created 400 skilled jobs and contributed $\$ 44$ million to the local economy (Durso et al. 2016). Deutsche Bank also canceled an expansion plan in the state, resulting in 250 
lost jobs and an estimated \$21.4 million in lost public revenue (Bracken 2016). The real estate company CoStar Group announced that it had chosen to open a new research operations center in Richmond, rather than Charlotte, due to the passage of HB2. This research operations center would have brought 730 new jobs to the State, pumping an estimated $\$ 250$ million into the local economy (Rothacker 2016). In all, eleven companies announced that they would not be moving into or expanding their operations in North Carolina after previously announcing they would do so, costing the state an estimated 4,000 new jobs (Durso et al. 2016).

The organizers of major conferences, sporting events, and concerts also announced plans to move their operations out of North Carolina following the passage of HB2. Bruce Springsteen canceled a show in Greensboro, resulting in a $\$ 700,000$ loss to the local economy, largely in the hospitality industry (KFTC 2016). Maroon 5, Nick Jonas, Boston, Ringo Starr, Demi Lovato, and Pearl Jam are just some of the acts that similarly canceled tour stops in the state due to the bill (Isidore 2016). The W.K. Kellogg Foundation moved its annual conference out of Asheville, resulting in an economic loss of \$1.5 million (Boyle 2016). The Charlotte Regional Visitors Authority announced that twenty-nine conferences had pulled out of the city in 2016 alone, resulting in an estimated \$28 million loss to the city’s economy (Perlmutt 2016).

The NCAA relocated all future championship events scheduled to take place in North Carolina, seven of which were scheduled in 2016 and 2017 (NCAA 2016). The National Basketball Association announced that the 2017 All Star Game was to be moved from Charlotte to New Orleans due to HB2, resulting in an estimated loss of $\$ 100$ million to the local economy according to the Charlotte Chamber of Commerce (Isidore 2016). The Atlantic Coast Conference announced that Charlotte would no longer host the 2016 ACC Football Championship, resulting in a \$30 million loss to the local economy (KFTC 2017). The National Football League, the National Hockey League, and the ESPN X-Games also announced they would no longer hold championship competitions in the state, though at the time there were no such events scheduled (Alexander 2016; Peralta \& Rothacker 2016).

North Carolina also received significant backlash from other governments in the United States. The state governments of Connecticut, Vermont, New York, California, Minnesota, and Washington, as well as forty-two local governments across the country, boycotted North Carolina, not allowing public 
funds to be used while traveling to the state (Durso et al. 2016). The Obama Administration also spoke against HB2, taking actions to pressure Governor McCrory to repeal the law. The Department of Justice threatened to withhold $\$ 4.7$ billion in education funding, stating that HB2 violates Title VII of the Civil Rights Act (Durso et al. 2016). In response to this threat by the federal government, Governor McCrory sued the Justice Department in federal court.

It is difficult to determine just how much HB2 has cost the North Carolina economy. The Charlotte Observer estimated that HB2 cost the state over $\$ 500$ million due to canceled business expansion plans, concerts, and sporting events - and that figure was calculated only two months after the bill was signed (Doran 2016). Analysis from the Associated Press in 2017 estimated that the North Carolina economy had lost $\$ 2.66$ billion in the first year HB2 was in effect (AP 2017). A report by the Williams Institute suggested that HB2 threatened to remove a further \$200 million a year from the North Carolina economy had the state not rescinded the bill (Mallory \& Sears 2017). Governor McCrory and his Administration, which insisted that HB2 had no effect on the state's economy, disputed these figures.

Speaking on the economic effect of HB2, North Carolina Commerce Secretary John Skvarla told the press that the bill had not "moved the needle one iota" (Peralta 2016), suggesting that the economic losses outlined above were balanced out by the gains the law provided. The gains that Skvarla hinted at, however, were never substantiated by the Administration. For example, one economic measure of a bill's success is job creation. Had HB2 truly been economically neutral, the bill would have generated just as much job investment in North Carolina as it lost. While the loss of investment by Deutch Bank, PayPal, CoStar Group, and others cost the state over 4,000 jobs, however, not one corporation announced that they decided to invest in North Carolina due to HB2 (KFTC 2017). The argument used by the McCrory Administration that HB2 was economically neutral, then, does not appear to hold up to scrutiny.

Governor McCrory attempted to relieve criticism of the law by signing an executive order that protects LGBTQ+ individuals in state public employment (Executive Order 93), but this action was too little, too late. McCrory, whose first term as governor ended in 2016, lost his bid for reelection to Democrat Ray Cooper in November. Many in the media expressed their belief that HB2 was the cause of McCrory's loss of a second term as governor (Long 2016; Stern 2016; Charlotte Observer 2016). There is reason to 
believe this is the case; first, Ray Cooper made HB2 a central issue in his campaign and promised to work to repeal the law (Stern 2016). HB2 also appeared to be overwhelmingly unpopular in the state: only $34 \%$ of North Carolinians supported HB2 according to a 2016 Public Policy Poll survey. Lastly, McCrory lost his seat in a year in which North Carolinians gave their support to Republicans in other statewide elections: Donald Trump won the state in his bid to be President, and Richard Burr defeated Democrat Deborah Ross to secure reelection in the U.S. Senate (New York Times 2016).

Though Ray Cooper became the Governor of North Carolina, Republicans still overwhelmingly controlled the state legislature, making the repeal of HB2 difficult. On February 21, 2017, the North Carolina House of Representatives introduced House Bill 142 to the floor (North Carolina General Assembly 2017). HB142 would revoke HB2 from the North Carolina Code, including the provisions regarding bathroom access, though it also prevented local governments from granting nondiscrimination ordinances regarding restroom access (HB142 2017). Essentially, private organizations in the state would gain the authority to decide their public bathroom policies, which was outlawed under HB2. Notably, HB142 also banned local governments in the state from amending their employment ordinances until the year 2020 (HB142 2017), meaning Charlotte's LGBTQ+ nondiscrimination law would still be unenforceable for several years.

The North Carolina General Assembly passed HB142 on March 30, and Governor Cooper signed the bill that day (NCGA 2017). Governor Cooper called the bill a "well thought out compromise." but both LGBTQ+ activists and the local press accused the Governor of going back on his campaign promise to repeal HB2 in its entirety (McLaughlin 2017). The Editorial Board of the Charlotte Observer (2017) stated that the Governor had "failed spectacularly" on his campaign promises and accused him of "turning his back on the LGBT community.” Despite these concerns, HB142 appeared to quiet some of the corporate criticisms of the government of North Carolina, with the NCAA revoking its ban on the state (NCAA 2017) and the NBA announcing that Charlotte will host the 2019 NBA All Stars Game (Mallony 2017). Still, corporations such as IBM and the McKinney Advertising Agency have continued to criticize the North Carolina government, and the governments of Minnesota, Washington, California, and twenty-two municipalities have continued their boycotts (Martin 2017). 
The goal of this chapter was to present evidence that discrimination against LGBTQ+ individuals not only has an adverse impact on sexual and gendered minorities, but on the entire community. Scholars such as Richard Florida have theorized that allowing persistent discrimination in a community deters the creative class and creative industries from relocating to the area. Further, allowing discrimination to occur may also reduce public budgets and increase expenditures through the lowered incomes and spending powers LGBTQ+ residents have due to discrimination. Recent events in Indiana and North Carolina have demonstrated that even the appearance of being unfriendly to LGBTQ+ residents can result in a severe economic backlash from individuals, corporations, and other governments.

Overall, the previous three chapters have demonstrated that there are serious individual and economic costs associated with LGBTQ+ discrimination in the United States. For these reasons, economists, policy analysts, psychologists, and medical professionals have noted that local nondiscrimination laws are beneficial to a community. In fact, while reading the literature on this subject, I did not come across one peer-reviewed article that indicated such policies are detrimental to an individual, an organization, or the economy. Furthermore, surveys analyzed in Chapter II demonstrated that a majority of Kentuckians are in favor of such policies. Despite these realities, Fairness Ordinances remain rare in Kentucky. The lack of LGBTQ+ nondiscrimination laws in the state suggests that political forces work to prevent such policies from being enacted. The next chapter will provide case studies on recent attempts at bringing a Fairness Ordinance to Berea and Bowling Green, both of which failed. This discussion will provide some context as to why some Kentuckians - including local government officials - are hesitant to support Fairness in their communities. 


\section{CHAPTER VII:}

\section{CRITICISMS OF LGBTQ+ INCLUSION IN KENTUCKY}

Up until this point, this thesis has explored the literature on LGBTQ+ nondiscrimination laws in the hopes of demonstrating that these policies are overwhelmingly seen as beneficial to the communities that possess them. Chapter III highlighted the fact that such laws are needed, as LGBTQ+ persons are often the target of workplace discrimination in the United States. Subsequent chapters explored the literature on the harm LGBTQ+ employment discrimination causes to residents, organizations, and local economic development in communities that allow such actions to occur. Furthermore, surveys have suggested that most Kentuckians support the enactment of fairness laws. Given overwhelming evidence that these policies benefit all residents, as well as the high level of support these ordinances receive from Kentucky residents, one might expect public officials in the Commonwealth to be clamoring to enact such policies. And yet, the fact remains that most Kentuckians are not protected by a Fairness Ordinance, leaving many residents with no legal recourse to challenge this form of discrimination.

This chapter attempts to explain this paradox in Kentucky. As noted in Chapter II, the Fairness Coalition and its allies have been increasingly aggressive in recent years in their effort to expand the number of Kentucky municipalities with a Fairness Ordinance. Not all their attempts, however, have been successful. Two sites of such failed attempts are the cities of Berea and Bowling Green, which occurred in 2014 and 2017 respectively. Using archives from local sources, video evidence of local town hall meetings, and first-hand accounts of these debates from those directly involved in the fight for Fairness in Berea and Bowling Green, this chapter details the reservations some in Kentucky have about Fairness Ordinances. This exploration provides an interesting opportunity to examine why some local governments in Kentucky have been hesitant to adopt a Fairness Ordinance for their residents. 


\section{Berea's Fight for Fairness}

The city of Berea, located fifteen miles south of Richmond in Central Kentucky, has a long and notable history of social tolerance. The abolitionist minister John Fee established Berea in 1850, and the community soon became populated by spirited opponents of slavery, often at great risk to their personal safety (Burnside 2017). The local college in Berea, aptly named Berea College, began admitting both women and African Americans at its founding in 1855, becoming the first institute of higher education in the South to possess a policy of racial and sex integration (Burnside 2017). Fee and other Bereans are still remembered today for their work during the Civil War aiding freed slaves brought to nearby Camp Nelson, where they built houses, schools, and medical facilities for those at the camp, including former slaves (Burnside 2017).

Despite being founded on the concept of tolerance, however, the local government of Berea has not yet enacted a Fairness Ordinance to protect its LGBTQ+ residents from discrimination in public accommodations, housing, or employment. In fact, the Berea Council holds the distinction of being the first local government in Kentucky to vote against the enactment of a Fairness Ordinance since the Louisville Board of Aldermen voted against Fairness in 1997 (Aldridge, PC 2016). The lack of a Fairness Ordinance in Berea is not the result of apathy among its residents, however. The public debate on a Fairness Ordinance in Berea has divided the community for over six years now (McDonald 2014).

The controversy over a citywide Fairness Ordinance dates to 2011 when the Berea City Council began debating the creation of a local human rights commission (HRC). The proposed HRC would be responsible for educating Berean businesses and property owners on the various civil rights laws, as well as assisting the Kentucky Commission on Human Rights in its goal of ensuring compliance with state employment, housing, and public accommodation laws (Ord. 09-2011, 2011). The establishment of a local HRC appeared not to be controversial in the small town. Based on video evidence from a public forum and several city council meetings held throughout the summer of 2011, several dozen residents expressed their 
support for a local HRC while only one spoke against its formation (Berea Council, 19 April - 20

September 2011). ${ }^{18}$

What did cause a backlash from some in the community was a proposed amendment to Ord. 092011. Seeing an opportunity to expand the number of municipalities that possess a Fairness Ordinance in Kentucky, the pro-civil rights groups Kentuckians for the Commonwealth and the ACLU of Kentucky, in addition to the newly formed Bereans for Fairness, strove to include sexual orientation and gender identity among the protected classes under the purview of the proposed HRC (Grigg 2014). From the start of the HRC debate, representatives from these groups began lobbying the Council to amend the ordinance to give LGBTQ+ residents equal treatment under the law (Berea Council 19 April - 20 September 2011).

In response to the increasing pressure from many Bereans to expand the scope of the proposed HRC to include protections for sexual and gender minorities, the Berea Council announced on May 3, 2011, that a public forum would be held on June 14 of that year (Berea Council, 3 May 2011). This forum would focus on three questions: should Berea possess its own local human rights commission?, should Berea enact a Fairness Ordinance?, and had any members of the public witnessed discrimination of any kind? The goal of the forum was to give Bereans an opportunity to answer these questions and state their opinions on the creation of both a local HRC and a Fairness Ordinance.

The public forum was originally scheduled to be located inside the Berea City Hall (Berea Council, 3 May 2011). Soon after the forum was announced, however, it became apparent that this room would be far too small to hold what was expected to be a large crowd (Berea Council, 17 May 2011). This high level of interest was likely due to the combined efforts of the ACLU of Kentucky, Kentuckians for the Commonwealth, and Bereans for Fairness. Soon after the forum was announced, these organizations began rallying the community to attend the event to show their support for Fairness (Aldridge, PC 2016). To ensure all Bereans had an opportunity to speak at the forum, the Council decided to move the meeting to the Berea Community Gym. Just as public officials do for all council meetings, the June 6 public forum was recorded and uploaded onto the government's Vimeo account.

18 These videos can be accessed here: https://vimeo.com/user7396497 
Of those that spoke that night, eight Bereans stated their opposition to the proposed Fairness Ordinance and one individual stated his opposition to both Fairness and the creation of a Berea HRC (Fairness Meeting, 6 June 2011). The most common objection to Fairness was the lack of necessity for such an ordinance. Kenneth Carol raised this question of whether discrimination in Berea exists, stating: "I've lived here for over thirty-five years and I never not once seen anybody discriminated against" (Fairness Meeting, 6 June 2011). Pastor Mickey Bowling went as far as to ask for a show of hands from the audience to see if anyone had witnessed discrimination against an LGBTQ+ Berean, emphasizing his request for proof that discrimination is common in the town (Fairness Meeting, 6 June 2011). ${ }^{19}$ Pastor Bill Woods suggested simply being LGBTQ+ was not cause for discrimination in Berea, but acting in a way that goes against traditional norms may be the cause of employment discrimination:

"I have talked to some different employers, and those employers have stated to me that as long as the individual doesn't flaunt their lifestyle, it doesn't matter if they were gay, lesbian, transgender, whatever, they wouldn't fire them” (Fairness Meeting, 6 June 2011).

On the surface, these objections did appear to have some merit. During these early years of the Berea Fairness debate, no tangible evidence existed that demonstrated that Bereans had been discriminated against due to their sexual orientation or gender identity. As stated in Chapter III, however, discrimination complaints are a poor instrument for determining the level of discrimination that occurs within a municipality, especially if there is no legal recourse for the discriminated individual to utilize. Further, no governmental body existed at that time that would accept claims of discrimination stemming from one's sexual orientation or gender identity. In June 2011, Berea did not possess an HRC of its own, the Kentucky Commission on Human Rights did not - and still does not - accept complaints of this kind, and the EEOC had yet to make its landmark rulings in Macy and Baldwin.

There was anecdotal support to the claim that LGBTQ+ discrimination existed in Berea. During the forum, many Bereans - both LGBTQ+ and not - admitted to either witnessing or being subjected to LGBTQ+ discrimination while in Berea. This evidence was unsubstantiated, largely due to the fault of the

\footnotetext{
19 The camera was facing away from the audience, so it could not be determined how many people raised their hand. Berea Councilman Fields also rebuked this question, telling the audience not to answer, and stating that back-and-forth discussions with the audience would delay the proceedings.
} 
government. To collect, investigate, and prosecute discrimination claims made by LGBTQ+ residents, a city must have a Fairness Ordinance in place. How are Bereans subjected to this form of discrimination expected to prove their case when they receive no legal support from their government? How safe should they feel to come forward with such a complaint? The argument made by Fairness opponents that the city needed to prove LGBTQ+ discrimination existed in Berea before a Fairness Ordinance should be enacted, then, was not practical.

Several opponents of Fairness also stated their belief that federal and state laws protecting LGBTQ+ individuals from discrimination already exist, adding to the argument that the proposed ordinance was unnecessary. Steven Taylor, a self-proclaimed "proud evangelical” told the audience: "The LGBT population are already protected by federal laws for these grievances. I don't understand why this ordinance is necessary" (Fairness Meeting, 6 June 2011). One local business person - who did not identify himself during the meeting - noted his own experience with the government bureaucracy when it came to workplace discrimination:

"I employ twenty-six, twenty-seven people and every month I get a deal from the federal government and the state saying that I can't discriminate 'cause of gays, lesbians, age, weight... So why do we need this Fairness law?” (Fairness Meeting, 6 June 2011). ${ }^{20}$

Some residents also feared that, if enacted, the Fairness Ordinance would interfere with their Constitutional rights, specifically the Free Exercise and Free Speech Clauses of the First Amendment. Deborah Keane expressed her belief that "the Constitution gives me the right to hire and fire whoever I want," though she did assure the public that she would never let an individual's sexual orientation dictate her business practices (Fairness Meeting, 6 June 2011). Pastor Woods expressed a similar concern that the proposed ordinance would "command a new morality" and "hamper people's freedom of expression and religion by forcing them to hire people they would not choose for the business they own" (Fairness Meeting, 6 June 2011). Pastor Bowling also questioned the constitutionality and fairness of the Fairness

\footnotetext{
${ }^{20}$ Weight, in addition to sexual orientation and gender identity, is not a protected characteristic at the federal
} level, nor is it in the state of Kentucky. 
Ordinance: "Is it legal and is it fair that, as a born-again believer, someone should force people into my business against my beliefs? I just don't think it is" (Fairness Meeting, 6 June 2011).

Many opponents also objected to giving members of the LGBTQ+ community "special rights" not afforded to straight, cisgender residents. Ingrained in this argument was the idea that both sexuality and gender identity are lifestyle choices, not innate traits. Kent Ostrander, Director of the conservative Family Foundation of Kentucky, complained to the Council: “I don't believe it's at all necessary. This is a political push to expand recognition of special rights. It's foolishness to codify into law some kind of identity for gays that suffer from sexual confusion" (Fairness Meeting, 6 June 2011). Donald Valley also questioned the concept of giving "special rights" to the LGBTQ+ community, stating: "Homosexuality is a learned behavior that can be changed through counseling. It does not qualify for special status" (Fairness Meeting, 6 June 2011). An unidentified man who traveled from Nicholasville to attend the meeting told the media after the forum, "They have the same rights as everyone, they're asking for more" (Howard 2011).

The strong showing of support from pro-Fairness Bereans, however, largely drowned out these few objections to the ordinance. While nine individuals spoke out against the proposed Fairness Ordinance during the June 6 forum, thirty-three Bereans spoke in favor of Fairness. By far the most common argument made in favor of the ordinance was Berea's history of social tolerance. In all, twenty-five Fairness advocates used Berea's history of equality as one of their motives for supporting Fairness. Nancy Pickle, a "longtime resident" of Berea, noted: "Passing this ordinance is just continuing the legacy of openness and acceptance that Berea is known for and is why I call Berea home" (Fairness Meeting, 6 June 2011). Meagan Oban also used the small town's long history of tolerance as justification for the ordinance:

"I moved to Berea because I do not know any other community that is so rooted to its past, yet so embracing of progress. It is this appreciation for this tradition of a uniquely brave stance on equality that made me choose Berea as my home" (Fairness, 6 June 2011).

Many supporters of Fairness also used their speaking time to address some of the concerns espoused by critics of the ordinance. Thirty Bereans - including one opponent of Fairness - stated that they either had seen firsthand or had been the victim of discrimination stemming from sexual orientation or gender identity while in Berea. Billy Woone noted that he was evicted from his residence after his landlord 
learned that his roommate was his partner. The property owner told the couple that the neighborhood was "family friendly" and that their presence would tarnish this image (Fairness Meeting, 6 June 2011). Mattel Menderlous told her story about how a former coworker was fired from their place of employment after their manager discovered that she was gay, causing her to move away from the city (Fairness Meeting, 6 June 2011). Patricia Martinez, a teacher in the Madison County public school system, admitted having faced harassment from another staff member for several years once her sexual orientation became public (Fairness Meeting, 6 June 2011).

The next public discussion of the proposed Fairness Ordinance took place during a regularly scheduled council meeting on July 19, during which the non-LGBTQ+ inclusive Ord. 09-2011 received its first reading. The Fairness Ordinance was not on the agenda, and its proponents packed City Hall to express their displeasure that Ord. 09-2011 was not amended to include sexual orientation or gender identity protections (Berea Council, 19 July 2011). David Seroyer, who also spoke in favor of Fairness during the June 6 forum, expressed his wholehearted support for the creation of a local HRC but noted that Ord. 092011 contained a "gaping hole due to its omission of sexual orientation as a protected category" (Berea Council, 19 July 2011). Another resident noted that she was "protected because she is a woman, because she is Jewish, because she is old, but not because she is a lesbian" and pleaded with the Council to fix this omission (Berea Council, 19 July 2011)

Several Fairness advocates also utilized the July 19 meeting to accuse the Council of stalling on Fairness. Resident Jason Trent accused the Council of wanting the "issue to go away by not voting on the Fairness Ordinance" (Berea Council, 19 July 2011). Lisa Vaughn also accused the Council of purposefully delaying the Fairness vote, but noted: "No amount of pigeonholing will prevent Bereans for Fairness from attending all meetings until this issue is resolved" (Berea Council, 19 July 2011). In response to these growing accusations, Mayor Connelly assured residents that a Fairness Ordinance would be placed on the Council's agenda sometime in August (Berea Council, 19 July 2011). No critics of either the proposed HRC or the Fairness Ordinance spoke at the July 19 meeting.

Despite Mayor Connelly's pledge for further discussion of Fairness, video evidence of the council meetings of August 2, August 16, and September 6 reveal that the ordinance was never on the agenda as 
promised. ${ }^{21}$ While these videos provide no explanation for this lack, several news articles have shed some light on why the Council chose to table this discussion. Councilwoman Farmer told a reporter from the Lexington Herald-Leader that she believed the time was not right to pass a Fairness Ordinance in Berea, stating: "We must focus first on establishing the [Human Rights] Commission. Without the Commission, such ordinances would be unenforceable" (Kocher 2011). She did express, however, her "deepest sympathies" to Berea's LGBTQ+ community (Kocher 2011).

Councilman Fields told a reporter for The Berea Citizen that he, like Councilwoman Farmer, felt sympathetic to LGBTQ+ Bereans (McDonald 2011). Councilman Fields noted his concern, however, that a Fairness Ordinance might discourage the growth of the proposed HRC. During several meetings (City Council, 26 April 2011; 5 July 2011; 16 August 2011), the Council stated that their goal for the Berea HRC was for it to merge with the Richmond $\mathrm{HRC}$ in the hopes of creating a single commission for Madison County. Had Berea passed a Fairness Ordinance and the merger occurred, Councilman Fields feared "administrative chaos" would occur, as the countywide HRC would have different regulations to enforce based on the address where the discrimination occurred (McDonald 2011).

In response to growing criticism against the Council (Kocher 2011), Mayor Connelly issued a press statement explaining why he believed it was not appropriate for Berea to enact a Fairness Ordinance. Connelly stated that he and some in the Council were concerned about the administrative cost of a Fairness Ordinance (Connelly 2011). As the regulations for the proposed local HRC would not differ from that of the state, costs stemming from this new commission was expected to be minimal. The proposed HRC would be staffed primarily by volunteers, and administrative expenses would be covered by the state, as Berea would be essentially educating Bereans on state law. If the Council enacted a Fairness Ordinance, however, local funding would be required to implement the law, as the state does not protect sexual or gendered minorities. Mayor Connelly and the Council, then, expressed their concern over whether Berea can afford to protect LGBTQ+ Bereans against discrimination (Connelly 2011).

${ }^{21}$ While not on the official agenda, the Fairness Ordinance was discussed by several residents during the open discussion forum - an allotted timeslot of every meeting when concerned citizens are allowed to address the Council on topics that not on the agenda. 
Representatives from Kentuckians for the Commonwealth and Bereans for Fairness tried to relieve the Council of this concern by providing evidence that extending these protections to the LGBTQ+ community would not be a financial or administrative burden to the city. At the August 16 meeting, Lisa Vaughn provided the Council with a fiscal impact statement made by the Kentucky Commission on Human Rights that outlined the predicted costs of expanding the city's civil rights protections to include sexual and gendered minorities. According to this analysis, extending protections to include these groups would cost the city approximately $\$ 750$ a year, far below what many opponents of the ordinance claimed (Berea Council, 16 August 2011). The report also stated that no additional staff would be needed to enforce the ordinance and expected the city attorney to have to defend only one additional case every ten years (Berea Council, 16 August 2011). ${ }^{22}$ Additionally, at the September 6 meeting, a representative from the Lexington Fair Housing Council notified the Council that her organization was willing to burden the cost of investigating LGBTQ+ housing discrimination complaints in Berea, further lowering these costs (Berea Council, 6 September 2011).

Despite reassurances that a Fairness Ordinance would not fiscally bankrupt the city, the Council continued to pursue the creation of a local HRC without the Fairness amendment. On September 20, the Council voted unanimously to approve the non-amended Ord. 09-2011, thereby creating the Berea HRC (Berea Council, 20 September 2011). At the same time the Council was deliberating the ordinance, Kentuckians for the Commonwealth and Bereans for Fairness held a fairness rally outside City Hall. Over 400 protesters attended the rally (Cornelison 2011), and their displeasure could be heard following the passage of the non-amended Ord. 09-2011 (Berea Council, 20 September 2011).

In October 2016, I had the opportunity to interview Michael Aldridge of the ACLU of Kentucky, who has been directly involved in the Berean Fairness debate. The interview brought forth a firsthand account of what occurred in Berea and shed light on other possible reasons for the Council's unwillingness to vote on the proposed Fairness Ordinance: a lack of political will. Aldridge noted that, in his opinion, the

${ }^{22}$ This is not to say that only one case of discrimination would occur in Berea every decade, but the KCHR predicted that only one case would go to Court. 
Council - including Mayor Connelly - were personally in favor of amending Ord. 09-2011 to include protections for sexual and gendered minorities, but were politically scared to act:

"The Council... were not fully convinced that the residents supported the Fairness Ordinance and so they tried to do their best to not give their personal views on the ordinance one way or another. We see that a lot in Kentucky, that a Board or a Council will deliberately not vote on these ordinances, they just kick the can down the road and don't let their position be known." (Michael Aldridge, PC 2016).

This lack of political will would become the nail in the coffin to the proposed ordinance. As noted above, opposition to Fairness was relatively small compared to the amount of support the ordinance received from the community. Most residents at the forum were in favor of Fairness, and no opponent came to criticize expanding the scope of the $\mathrm{HRC}$ at any of the council meetings during the summer of 2011. As will become evident, delaying the vote allowed those who opposed Fairness to begin building an opposition movement. In the interview with Director Aldridge, he noted that:

"If they would have just passed it, there would probably not have been much outcry in Berea. Because the Council and the Mayor kept delaying the vote on the ordinance, you know, that gives time for opposition to build... The opposition didn't even get organized until, like, year three and a half." (Aldridge, PC 2016).

This opposition would primarily come from the conservative, "pro-family" Family Foundation of Kentucky (FFK) (Aldridge, PC 2016). Aldridge noted that representatives from the FFK began visiting churches in the Madison County area to build opposition to Fairness if the Council ever placed a Fairness Ordinance on the City Agenda. This coalition mainly focused on two arguments in their attempt to build an anti-Fairness base (Aldridge, PC 2016). First, the coalition questioned the "fairness" of the ordinance, arguing that these ordinances give special rights to the minority while harming the majority. Second, the coalition described pro-Fairness advocates as being "outsiders" from Louisville and Lexington, who were attempting to impose their liberal ideals down the throats of Bereans. This latter point is particularly ironic, as the FFK is headquartered in Lexington.

As Aldridge noted, this anti-Fairness coalition was slow to build, and video evidence of council meetings demonstrates that all individuals that spoke on Fairness in Berea continued to be supporters of the ordinance. At the October 4 meeting, David Shroyer challenged the Council to hold a vote on the Fairness 
Ordinance, demanding, "the Council...show its colors, to declare its positions, to come to a vote" (Berea Council, 4 October 2011). Bereans continued to come to meetings to implore the Council to act on fourteen separate occasions between the enactment of Ord. 09-2011 and the end of 2012 (Berea Council 18 October 2011 - 04 December 2012). Not once did any member of the public speak out against a possible Fairness Ordinance during this time (Berea Council, 18 October 2011 - 4 December 2012).

Through the relentless determination of Bereans for Fairness, Fairness advocates scored a major victory in early 2014: Fairness was placed on the Berea City Council Meeting Agenda for the first time since the 2011 public forum (Berea Council, 18 February 2014). On February 18 the Berea HRC - which publicly supported Fairness since its inception - requested four members of the council volunteer to form a committee to begin drafting a Fairness Ordinance (Berea Council, 18 February 2014). The Council unanimously voted to approve the request, thereby creating the Fairness Committee.

The Berea HRC announced that the process of drafting an ordinance would take some time (Berea Council, 18 February 2014). Several groups, including the Kentucky Commission on Human Rights and the ACLU of Kentucky, held training sessions for the Committee, explaining the various legal and financial obstacles the Council would have to consider while debating the Fairness Ordinance (Berea Council, 17 June 2014; Aldridge PC, 2016). After months of training, drafting, and revising, the final draft of Ord. 182014 was given its first reading on September 02 (Berea Council, 2 September 2014). The proposed ordinance expressly forbade discrimination against individuals based on their actual or perceived sexual orientation or gender identity (Ord. 18-2014). Like other Fairness Ordinances in the state, the ordinance granted religious exemptions and made businesses with less than fifteen employees immune from the ordinance. Following the first reading, the Council voted in favor of holding another public forum on the subject (Berea Council, 2 September 2014). This forum was similar in structure to the 2011 forum and was scheduled for September 12.

It is striking how different the 2014 forum was compared to the one that took place in 2011. Although most speakers still spoke in favor of Fairness, the proportion was more even than it had been previously. Of the thirty-nine individuals that spoke on September 12, twenty-three were in favor of the ordinance, fifteen were against it, and one resident announced his neutrality (Fairness Meeting, 12 
September 2014). Perhaps stemming from the greater balance between the support and opposition, Bereans were more willing to express their agitation toward speakers who did not share their position on the ordinance. While the audience at the first forum remained quite respectful of differing positions, individuals on both sides of the debate at the 2014 forum frequently jeered those who spoke contrary to their beliefs (Fairness Meeting, 12 September 2014). The environment became so hostile that on four separate occasions during the two-hour meeting the Council had to step in and threaten to cancel the forum if the heckling continued (Fairness Meeting, 12 September 2014).

It is also evident that both sides of the debate were more organized than was the case in 2011. Many of those in favor of the ordinance wore blue t-shirts with "Another Kentuckian for Fairness," while the opposition sported red shirts that read "JUST SAY NO TO FAVORITISM" (Fairness Meeting, 12 September 2014). These slogans turned out to be more than a mere sign of a Berean's position on the proposed ordinance; they were symbols of a philosophical debate that took place at the hearing. That is, does a Fairness Ordinance lead to greater equality for all or unfair favoritism for some? Opponents of Fairness believed that the ordinance would promote favoritism, not fairness, and this argument became the most common objection of the ordinance at the forum.

Those residents that took the position that fairness laws provide "special rights" to LGBTQ+ persons used many of the arguments that were made at the 2011 forum. Hank Kennedy, a local pastor at Wayside Christian Church, stated: “I think it's bull to make an ordinance for one special group. You should make the ordinance for all groups. That would be real fairness" (Fairness Meeting, 12 September 2014). Shane Morris, who spoke at the June 2011 forum, reiterated this position: "Not only is it apparent to me that the homosexual community is not being discriminated against, they are being overly accommodated... this ordinance is not about fairness, but favoritism" (Fairness Meeting, 12 September 2014). In a passionate speech that received by far the most applause and jeers from the audience, Berea resident Carl Roberts seemed to imply that a Fairness Ordinance would lead to discrimination against non-LGBTQ+ Bereans. Roberts told his story to the audience: 
"When I was twenty, I tried to apply for a job in a bank and they wouldn't even give me an application. Yet, behind me were two black boys who also asked for an application and guess what? The bank manager gave them an application. These laws do nothing but harm the majority. This is not fairness; this is reverse discrimination" (Fairness Meeting, 12 September 2014).

Roberts' comments and the subsequent reaction to his speech indicates that many white Bereans, who are the vast majority of local residents, had issues with the notion of civil rights legislation in general, not just the Fairness Ordinance. This displayed a remarkable turnaround from 2011 when most Fairness opponents spoke in favor of the then-proposed HRC, and no one spoke out against civil rights for groups such as African Americans or women.

There were, however, some speakers who made it known that they were not against the protections given by the federal and state Civil Rights Acts, but did oppose extending these protections for LGBTQ+ Bereans. These residents claimed that the purpose of these laws is to protect against discrimination due to some innate trait, not "lifestyle choices." Berea resident Jeff Osborne made this argument:

"Of course we shouldn't discriminate against black people. Color is something we are born with, I can't help being white and therefore I should not be discriminated against because of it. Same goes for women. But homosexuality is a choice... Of course it is a choice, homosexuals cannot reproduce, so how is it genetic? These laws are meant to protect people from discrimination for characteristics they cannot help, not a perverse lifestyle." (Fairness Meeting, 12 September 2014).

While the "favoritism, not fairness" argument was the most common objection of the proposed ordinance at the 2014 forum, it was not the only argument made against Fairness. Some of the opposition spoke out against the ordinance on the grounds of religious objections, the apparent lack of discrimination occurring in Berea, and individual rights (Fairness Meeting, 12 September 2014). Suffice to say that many of these arguments mirrored those of 2011. What was striking, though, was the sudden rise of anti-urban undertones attached to these opinions.

Shane Morrison received a loud cheer from the Fairness opposition when he pleaded with the Council "not to be intimidated by outsiders from Louisville or Lexington" (Fairness Meeting, 12 September 2014). Jeff Osborne feared that the proposed ordinance would not only trample on his rights as a Christian man but also that the ordinance would attract "radical activities that plague larger cities across the country" (Fairness Meeting, 12 September 2014). With great disdain, one woman directly 
attacked the ACLU, stating that the organization was only in Berea because "they already killed the rights of Christians in Louisville and Lexington, and now they are after the rest of the state" (Fairness Meeting, 12 September 2014).

Fairness supporters appeared to offer little resistance to these claims during the public forum, apart from the fact that most proponents were not "outsiders" but longtime residents of Berea. Rather than argue that the ordinance was neither unfair nor radical, proponents continued to champion Fairness on the grounds of Berea's history of tolerance and their own experiences with discrimination, mirroring the arguments made in 2011. This may have been an error on their part, as opponents of Fairness were quick to counter these arguments. After listening to several residents claim that what brought them to live in Berea was the town's history of tolerance, Dale Holeman noted that these individuals "came to Berea knowing that the ordinance was not in place" and stated "if you don't like our laws, you can leave" (Fairness Meeting, 12 September 2014). Another resident, Marsha Hawkins, cited demographic data that Berea was growing at a fast pace, even without a Fairness Ordinance (Fairness Meeting, 12 September 2014).

While many Fairness supporters claimed to either be a victim of or witness to LGBTQ+ discrimination in Berea, several opponents countered such claims by citing statistics garnered by the Berea HRC (Fairness Meeting, 12 September 2014). When the HRC formed, it was instructed by the Council to collect claims of discrimination stemming from one's sexual orientation or gender identity, though the HRC had no power to investigate or act against the offenders. In the thirty-three months that the HRC was active, the Commission received five complaints of such discrimination, a number that did not impress opponents of Fairness (Fairness Meeting, 12 September 2014).

Again, it is unwise to use the number of claims filed against discriminating individuals to gauge the overall level of discrimination in a community, particularly seeing that the Berea HRC had no power to prosecute the discrimination claims it received, so making a claim would bring little personal benefit to those discriminated against. It should also be noted that for a city of Berea's size, five discrimination complaints in less than three years is not an insignificant number. Finally, the amount of disdain shown toward the LGBTQ+ community by many opponents of Fairness during the 
meeting suggests that it is likely that discrimination occurs in the city. In an interview with local radio station WFPL, Chris Hartman, Director of the Fairness Campaign, made this point:

"If there were no intolerance in Berea, anyone who says that was not at the meeting last night because there was plenty of hate, vitriol, and intolerance being spewed in that meeting. We are not looking for special rights...we're looking for equal rights, we're looking for fairness.” (Quote taken from WFPL 2014)

The September 12 forum was the final opportunity for the public to weigh in on Fairness, as the ordinance was to be voted on during the next council meeting. In a packed City Hall filled with the blue "Another Kentuckian for Fairness" and red "JUST SAY NO TO FAVORITISM" shirts, the Council voted 5-3 against the Fairness Ordinance (Berea Council, 7 October 2014). Councilpersons Diane Kerby, Virgil Burnside, and Billy Wagers voted in favor of the proposal, while Jerry Little, Violet Farmer, Chester Powell, Chad Hembree, and Ronnie Terrill voted against it. Unlike the public forum a month earlier, the audience at this meeting remained quite composed, even after the votes were read - neither opponents nor supporters of Fairness cheered nor jeered the vote (Berea Council, 7 October 2014).

Before voting took place, several Councilpersons explained why they could not support the ordinance. Councilman Little expressed his sympathies with anyone who faced discrimination in Berea but noted that he did not believe it was within the jurisdiction of the Council to extend protections beyond what Frankfort deemed appropriate (Berea Council, 7 October 2014). This objection was shared by Councilman Terrill who, while choosing not to speak at the October 7 meeting, explained his position on the ordinance during a 2013 interview with the local radio program All About Berea. In the interview, Terrill explained the following to Chad Hembree:

"The General Assembly has introduced bills like [the Fairness Ordinance] for years and nothing has come of it. If the State doesn't think the gay community needs protections, you know, I do not think Berea is in any position to disagree... I don't support discrimination, but the Council has its limits as to what it can do." (All About Berea, 6 September 2013).

Councilwoman Farmer expressed her sympathy for any person that faced discrimination before she cast her no vote, stating: "I fully believe in, and support fair treatment and equal opportunity for all people... in every aspect of life." (Berea Council, 7 October 2014). Despite her empathy, 
Farmer noted that she could not support the ordinance. Unlike Terrill and Little, Councilwoman Farmer had not expressed concern about the legality of the ordinance, but rather the financial cost of enforcing such a policy. Apparently, assurances from the Kentucky Commission on Human Rights that the ordinance would not bankrupt the city did not convince her. She read the following statement before casting her no vote:

"Creating another protected class without state or federal laws to support enforcement causes me great concern. I question the potential liability to the city. The additional personnel dictated by the ordinance, the investigator and Hearing Officer have the potential to be very costly. The expenses associated with extended legal and court battles could drain city financial resources.” (Berea Council Meeting, 7 October 2014)

Councilman Powell, whom many considered to have been the deciding vote on the ordinance (McDonald 2014), ${ }^{23}$ emphasized his commitment to exploring the issue of Fairness, stating: "I have looked at both sides. I have rode the fence for so long I'm sore" (Berea Council, 7 October 2014). Despite years of debate that had already taken place, however, Powell felt that the ordinance was being rushed. After suggesting that the Council wait a few months for the Berea HRC to continue gathering data, Powell declared, "I will vote on it if we decide to vote... but I just do not see any reason to vote on it yet" (Berea Council, 7 October 2014). Ultimately, Powell voted against the ordinance. After the council meeting, Andy McDonald of the Richmond Register asked Powell why he voted against the ordinance. Powell reiterated that he had "not [seen] any reason for the ordinance" (McDonald 2014), suggesting that the HRC did not produce sufficient evidence to justify enacting the ordinance.

While being dealt with the first official defeat of a Fairness Ordinance in almost two decades was certainly a blow to Fairness advocates in Berea and all around Kentucky, Bereans for Fairness has continued to educate the city on the harms of LGBTQ+ discrimination. Their target, however, appears to have changed. Based on video evidence and Meeting Minutes, between the October 7 council meeting and the writing of this thesis, Bereans for Fairness have only spoken to the Council once on LGBT issues in the city (Berea Council, 21 October 2014 - 20 June 2017). This occurred on April 19,

${ }^{23}$ In the event that Councilperson Powell voted "yes" on the Fairness Ordinance, Mayor Connelly would have broken the 4-4 tie. Mayor Connelly, who announced his support for the ordinance in 2012, would have almost certainly voted "yes", breaking the tie in the ordinance's favor. 
2017, when several Bereans spoke in favor of a resolution denouncing discrimination, which passed unanimously. ${ }^{24}$ Rather, members of Beareans for Fairness and Kentuckians for the Commonwealth have been very attentive at various Berea HRC meetings, where they discuss methods of educating community businesses and property owners of the harms of LGBTQ+ discrimination (Berea HRC, 12 January 2015; 2 July 2015; 7 December 2015; 4 January 2016; 7 March 2015; 4 April 2016; 5 July 2016; 3 October 2016; 6 February 2017; 1 May 2017). It appears, then, that the Bereans for Fairness and Berea HRC are working to change the hearts of the community, rather than the council, in the hopes of eliminating LGBTQ+ discrimination in the city.

\section{Bowling Green's Fight for Fairness}

With a population of 59,103 according to the 2010 Census, Bowling Green is the most populous city in Kentucky that does not currently possess a Fairness Ordinance. The large population of Bowling Green, combined with its lack of LGBTQ+ protections, has made the city a high priority for Kentucky LGBTQ+ activists (Kentuckians for the Commonwealth 2017). It is not surprising, then, that Bowling Green also happened to be the site of the most contentious battle for the enactment of Fairness during the early months of 2017, with activists on both sides pleading their case to the Bowling Green Board of Commissioners. Like in Berea, the residents of Bowling Green have been divided on whether the city should adopt a Fairness Ordinance for several years, and historical evidence suggests the ordinance had long been unpopular in the city (Bennett 2011). In 2017, however, the ordinance was supported by the majority of those who attended a special working session on Fairness, as well as receiving the support of several local media outlets. Despite the appeals of the more than sixty residents who turned out in favor of Fairness, the Commission chose not to hold an official vote on the ordinance.

The Fairness movement has a long history in Bowling Green. In 1999, the Bowling Green HRC held several public hearings on whether the organization should recommend the Bowling Green Board of Commissioners add sexual orientation to the list of protected classes under Chapters 2, 14, and 17 of the

${ }^{24}$ This resolution does not carry any legal effect, but simply denounces all forms of discrimination in Berea. 
city's ordinance code (Bennett 2011). If approved, this would not create policy, but act as a suggestion for further action on the part of the Commission. Most residents who attended the HRC meetings, however, were against extending these protections to LGBTQ+ residents (Bennett 2011). Ultimately, the HRC did recommend adding the words sexual orientation to the list of classes protected by the organization (Bennett 2011; KFTC 2017; Sisk 2017). The Board of Commissioners, however, ignored this recommendation, and in doing so chose not to hold further debate on Fairness in Bowling Green.

Bowling Green commissioners continued to ignore those in the local Fairness movement for well over a decade following the HRC's recommendation (KFTC 2017). The apathetic attitude of the Board, however, transformed in early 2017. Due in large part to the local LGBTQ+ advocacy group Bowling Green Fairness, the debate on a Fairness Ordinance for Bowling Green became a central campaign issue during the 2016 local elections (Baute 2016; Collins 2016; King 2016; Sisk 2017). During a candidate forum hosted by the International Communities Advisory Council, eleven candidates were asked if they supported Fairness in Bowling Green. Six of the candidates stated their belief that there was no need for such an ordinance in the city. Incumbent Commissioner Denning was among these candidates, expressing his belief that a Fairness Ordinance was unnecessary due to existing federal and state laws that protect LGBTQ+ residents (ICAC 2016). The other two incumbents - Commissioners Parrigin and Williams stated that the Commission does not have jurisdiction over such civil rights matters and suggested activists focus on the state government for such changes (ICAC 2016). Three candidates, however, disagreed with these sentiments and pledged to introduce Fairness if elected.

One candidate, former Commissioner Brian "Slim" Nash, stated that he was unsure if a Fairness Ordinance was necessary, but promised to consider the issue (ICAC 2016). Nash, who re-entered Bowling Green politics in 2016 after losing a reelection bid in 2012, waited late into the campaign before making his position known. Nonetheless, Nash did eventually state his support for a Fairness Ordinance, vowing to introduce the ordinance within sixty days of taking office (Sisk 2017). Despite this show of support, Fairness advocates remained hesitant on Nash, as the candidate had previously taken part in the Board's custom of ignoring Fairness (KFTC 2017). This hesitation is evident by the actions of Bowling Green Fairness, which did not endorse Nash's reelection campaign (Bowling Green Fairness Facebook 2017). 
Slim Nash, however, did not need Bowling Green Fairness' endorsement to achieve victory. On November 8, 2016, Bowling Green residents voted to reelect Nash into the Commission, replacing Melinda Hill who unsuccessfully ran for a seat in the Kentucky House of Representatives. The other three incumbent candidates - Sue Parrigin, Rick Williams, and Joe Denning - and Mayor Wilkerson also won reelection, making Nash the only pro-Fairness candidate elected onto the Board. Even with Nash's election victory, Dr. Patti Minter, a professor of history at Western Kentucky University who has been involved in Bowling Green's Fairness movement for over two decades, referred to Fairness advocates as only “cautiously optimistic," largely due to Nash's previous apathy on Fairness (KFTC 2017).

It would not take long for Fairness advocates to know where Commissioner Nash truly stood on Fairness. During the first board meeting of 2017, Bowling Green Fairness representative Jennifer Morlan spoke to the Commission on the need for the city to have a Fairness Ordinance (BG Commission, 3 January 2017). This was not unusual: representatives from Bowling Green Fairness had advocated for the ordinance at every board meeting since 2015 (BG Commission, 5 January 2015 - 13 December 2016). ${ }^{25}$ What was surprising, however, was that a commissioner agreed with Morlan's position. Newly sworn-in, Commissioner Nash re-announced his intent to draft a Fairness Ordinance, pledging to do so sometime in February (BG Commission, 3 January 2017). This proclamation made Nash the first Commissioner in Bowling Green's history to publicly support Fairness (Sisk 2017).

Energized by this victory, Fairness advocates began attending board meetings en masse to educate the Commission on the need for Fairness in Bowling Green (BG Commission, 17 January - 21 February 2017). Video evidence from these meetings makes it evident that Bowling Green Fairness leaders decided to justify their position from an economic standpoint, rather than making a moral case. This approach departs from the strategy used in Berea, where most pro-Fairness advocates justified their position on the basis of city's history of tolerance. At the February 7 meeting, six members of Bowling Green Fairness spoke to the Board during Public Comments about the economic benefits of a Fairness Ordinance ( $B G$ Commission, 7 February 2017). ${ }^{26}$ Each representative cited a different study that suggested localities with

${ }^{25}$ Minutes, Agendas and videos of the various board meetings: http:/www.bgky.org/city-commission. ${ }^{26}$ Public Comments is designated time in which members of the public can communicate to the Board about issues not on the official agenda. The City Code requires this time to be held at the start of every meeting. 
an ordinance protecting their LGBTQ+ residents are at an economic advantage (BG Commission, 7 February 2017). Among these advocates was Dr. Minter, who lectured the Board on studies that suggest young professionals are increasingly moving to cities that are LGBTQ+-friendly. Following her speech, Minter noted: "We're seeing some of our best and brightest students [at WKU] decide they want to move to a place where they can be who they are" (BG Commission, 7 February 2017). To reiterate their point that Fairness is good for business, each representative also took turns in reading the names of local businesses that had announced their support for Fairness - eighty-one in all (BG Commission 7 February 2017). No Commissioner made any comments about these presentations, nor did any member of the public speak against the proposed ordinance during this meeting.

At the February 14 meeting, the city administrator announced that Ord. BG2017-5 - the Bowling Green Fairness Ordinance - had been placed on the February 21 Agenda (BG Commission, 14 February 2017). Bowling Green Fairness and Kentuckians for the Commonwealth began an online campaign to pack City Hall with Fairness supporters (Bowling Green Fairness Facebook), and their efforts were not in vain. Kathryn Ziesig of the WKU Herald (2017) wrote that most board meetings see only a couple dozen residents in attendance. At the February 21 meeting, however, the number of residents in attendance outnumbered the seating available, leaving a large crowd outside City Hall (Ziesig 2017; BG Commission, 21 February 2017).

Bowling Green's City Code mandates that before open debate can be held on an ordinance, a Commissioner must second the motion for discussion (BG Ord. 2-2-12). This means neither the Board nor members of the public would be able to discuss the ordinance if Commissioner Nash could not get one of his colleagues to second his motion for discussion. Furthermore, the Bowling Green Code mandates that the public cannot comment on ordinances placed on the Agenda during Public Comments, as this time is reserved for matters not on the Agenda (BG Ord. 2-2.16). Essentially, then, if no Commissioner seconded Nash's motion for discussion, there would be no dialogue on the ordinance at this meeting. Ultimately, that is what occurred. After the city manager had read the title and summary of the ordinance, Commissioner Nash motioned for discussion, and Mayor Wilkerson asked the Board for a second. After a few seconds of 
deafening silence, Wilkerson announced that the motion for discussion had failed (BG Commission, 21 February 2017), killing the ordinance.

While the crowd inside the Chamber remained reserved up to that point - the Fairness Ordinance was the last item on the agenda - the meeting quickly turned chaotic after the ordinance was scrapped ( $B G$ Commission, 21 February 2017). Fairness advocates inside the chamber began chanting "shame" at the Commission, and those who had to wait outside could be heard voicing their displeasure as well ( $B G$ Commission, 21 February 2017). Nash issued a point of order, asking to place a working session for the ordinance for the March 7 board meeting. Mayor Wilkerson asked if someone would second Commissioner Nash's point of order, to which none responded. Mayor Wilkerson announced that the point of order was defeated and quickly called an end to the meeting in the midst of vast public disapproval (BG Commission, 21 February 2017). Local media reports indicate that most Commissioners quickly exited City Hall through the back door to avoid their angry constituents (Austin 2017).

Following the February 21 meeting, it was noted that a second is not required for a commissioner to create a working session (Agenda, 21 February 2017). On February 23, the city announced that a working session for the Fairness Ordinance was placed on the March 7 Agenda, thereby allowing members of the public an opportunity to speak on the ordinance. Bowling Green Fairness and Kentuckians for the Commonwealth began rallying residents to attend the March 7 working session as they had done for the February 21 meeting (KFTC 2017). This time, though, various conservative groups, including The Family Foundation of Kentucky, joined their efforts (KFTC 2017). Up until the February 14 board meeting, Fairness opponents had been largely absent from this debate, as no resident voiced their opposition to the ordinance during any of the previous meetings (BG Commission, 3 January - 14 February 2017). There was also no video evidence to indicate that Fairness opponents were at the February 21 meeting, though the procedural gag order makes confirming their absence difficult (BG Commission, 21 February 2017).

The operations made by pro- and anti-Fairness groups appeared to have been fruitful, though one campaign certainly received a bigger response. Hundreds of supporters of the Fairness Ordinance attended the March 7meeting, joined by dozens of opponents, again leaving many residents outside City Hall (Line 2017). After concluding the other items on the Agenda, Mayor Wilkerson opened the working session. The 
session began with Commissioner Nash reading the Fairness Ordinance - during which he emphasized its religious exemptions - and Mayor Wilkerson stressing the need for civility during the debate ( $B G$ Commission, 7 March 2017). Residents were allotted three minutes each to explain their positions on Fairness.

Thirteen individuals voiced their disapproval of the ordinance during the three-hour working session (BG Commission, 7 March 2017). Many of their objections mirrored those made at the 2014 forum in Berea, perhaps due to the influence of the FFK on both debates. Several residents protested the idea of giving legal protections to the LGBTQ+ community, viewing these ordinances as giving social approval to individuals whom they view as immoral. Retired police officer David Gordon told the Board: "I oppose the Fairness Ordinance because the Holy Scripture condemns the practice of homosexuality...I believe and accept there can be no justification in attempting to legalize that which is morally wrong" (BG Commission, 7 March 2017). Deborah Herston expressed concern about the "immoral society" her grandchildren were growing up in and suggested that the ordinance would "further move the boundary of morality in our community" (BG Commission, 7 March 2017). Of the thirteen opponents of the ordinance, eleven expressed the concern that passing Fairness would result in sexuality and gender identity becoming an amoral issue, which runs counter to their religious beliefs (BG Commission, 7 March 2017).

Opponents also questioned the legality of granting civil rights protections to LGBTQ+ individuals. Again, the main concern appeared to be granting protections to individuals based on "behaviors," not innate characteristics. Channel Yule, a retired teacher, expressed his opposition to Fairness: "It makes conduct a protected status. This is very different from our other laws which protect race, sex, and religion; all of which are benign, inborn characteristics" (BG Commission, 7 March 2017). David Gifford appeared to be insulted at the comparison of race and sexual orientation: "Let us be clear, race is unchangeable, sexual orientation can be changed. I do not think it is fair or equitable to compare the two" (BG Commission, 7 March 2017).

Also similar to the debate in Berea, many Fairness opponents in Bowling Green opted to express their disapproval with wordplay by questioning the "fairness" of the Fairness Ordinance. Several residents feared that the proposed ordinance would overly burden the freedoms guaranteed to them by the 
Constitution, particularly their freedom of religion. Richard Nelson expressed his concern that the rights of a small minority group would endanger the rights of the majority if the Board passed the ordinance. During the working session, Nelson stated: "What this ordinance does is that it elevates the rights of sexual expression over the rights of religious freedom guaranteed by the First Amendment" (BG Commission, 7 March 2017). Ben Simpson, a local pastor, expressed a similar viewpoint, stating that the First Amendment "expressly forbids the government from passing laws that limit the free exercise of religion" and that the proposed ordinance would violate this right by "forcing Christians to participate in same-sex marriages" (BG Commission, 7 March 2017).

Several Fairness opponents also attempted to negate the arguments made by Fairness supporters by espousing fears that the ordinance would wreak havoc on local businesses. Pastor Robert Tart listed several small businesses in New York, Colorado, and New Mexico that were fined after either refusing to perform their services at a same-gender wedding or for insisting that transgender persons wear the uniform that matches their birth-assigned sex, ultimately causing these businesses to fail (BG Commission, 7 March 2017). Pastor Tart was not the only individual who brought examples of businesses that have been fined for failing to comply with their local or state nondiscrimination law: Franklin Wood, Richard Nelson, Jack Mitton, and Mike Salzman all mentioned a recent ruling by the Lexington HRC as well (BG Commission, 7 March 2017). In 2012, the Lexington-based t-shirt printing company Hands on Originals was fined by the HRC for refusing to print t-shirts for the 2012 Lexington Pride Parade. The owner of Hands on Originals, Blaine Adamson, defended his actions by citing his First Amendment right to freedom of religion, stating printing t-shirts that "promote homosexuality would violate my Christian beliefs" (Cheves 2017). Though this ruling would later be overturned by a Circuit Court, some residents feared that lengthy court battles might ruin local businesses if Fairness were enacted.

One argument that was common in Berea that was conspicuously absent in Bowling Green was that a Fairness Ordinance was not needed due to the lack of discriminatory practices in the city $(B G$ Commission, 7 March 2017). There were perhaps two reasons for this omission. For one, the Bowling Green HRC had testified during the meeting that they had received twenty-one claims of discrimination from LGBTQ+ residents in 2016, a higher figure than that in Berea (BG Commission, 3 January 2017). 
This difference was also perhaps due to the overwhelming number of Bowling Green residents who came forward at the working session to acknowledge being the victim of discrimination stemming from their sexual orientation or gender identity. Contrasting with the thirteen opponents of the ordinance, fifty-four individuals spoke in favor of extending protections to the Bowling Green LGBTQ+ community, and fortyseven stated that they had either witnessed or experienced this form of discrimination in Bowling Green (BG Commission, 7 March 2017).

While most members of the Board had no comments for those who opposed the ordinance, ${ }^{27}$ Commissioner Denning repeatedly questioned the testimony of those who claimed to have been the victim of discrimination (BG Commission 7 March 2017). Drew Earnhardt told the Board about his experiences with anti-gay harassment at his former workplace, stating that a new manager would refer to him as a "sissy", "girl", and "rainbow" in front of other employees and customers, resulting in a "hostile atmosphere" (BG Commission, 7 March 2017). Earnhardt also stated that his performance reviews began to decline after the manager was hired, though his on-the-job performance did not change. Eventually, the harassment became too much, he said, and he decided to leave the company (BG Commission, 7 March 2017).

Commissioner Denning asked Earnhardt if he could present the Board with evidence of this discrimination (BG Commission, 7 March 2017). Such proof, of course, would have been extremely difficult since the Bowling Green HRC is only instructed to collect claims, not investigate them. Commissioner Denning also suggested that Mr. Earnhardt could have sought employment in a larger corporation, one that had internal LGBTQ+ protections (BG Commission, 7 March 2017). To this latter point, Mr. Earnhardt asked Denning, "Why should it matter if I work for a corporation or a 'Ma-N-Pa shop'? This behavior should not occur anywhere" (BG Commission, 7 March 2017).

Commissioner Denning also took issue with several proponents of Fairness who claimed that discrimination against LGBTQ+ persons was as unjust as other forms of discrimination. Pam Morland made this argument in front of the Board. After Morland announced that she in no way equates the

${ }^{27}$ Commissioner Nash did frequently correct Fairness opponents who claimed that a Fairness Ordinance would force churches into performing same-sex marriages. 
injustices of African Americans in the mid- $20^{\text {th }}$ century to that of the Bowling Green LGBTQ+ community in 2017, she stated her belief that "any and all discrimination should be banned, no matter the cause." (BG Commission, 7 March 2017). After her speech, Denning objected to her line of reasoning, arguing:

"I am well versed on the civil rights programming and lack of programming that has gone on for years and it is my opinion that there is no comparison of any kind between what we as blacks have gone through and what members of the LGBT community have gone through" (BG Commission, 7 March 2017).

The tension between Denning and Fairness advocates came to a climax halfway through the working session. Grayson Hunt, a transgender man, attempted to clarify Morland's statement to the Board: "Historically, the leaders of the gay rights movements were trans-women of color, so to talk about these things as two separate issues is an erasure of history" (BG Commission, 7 March 2017). In an incredibly tense moment, Commissioner Denning interrupted Hunt's speech, using the pronoun "her" to refer to Hunt (BG Commission, 7 March 2017). Many in the crowd objected to this misused pronoun, and Hunt stated that he was determined to have his "full three minutes" (BG Commission, 7 March 2017). After twenty seconds of passionate back-and-forth between Denning and Hunt over the matter of speaking time, Mayor Wilkerson stepped in and allowed Hunt to continue his speech.

It was never on the Agenda for the Board to hold a vote on a Fairness Ordinance following the working session, yet many Fairness proponents hoped that the great showing of support would convince the Board to reconsider the motion in the future (KFTC 2017). It became quickly apparent, however, that this shift was not going to happen. After closing the working session, Mayor Wilkerson thanked the public for their feedback on this issue but stated that the decision on the Fairness Ordinance had already been made:

"The fact that this ordinance was on the Commission before, means, in essence, it was voted down four-to-one. So unless a member of this Commission chooses to change their opinion, this ordinance would not be on the Agenda again" (BG Commission, 7 March 2017).

Following the March 7 working session, Commissioner Denning was asked by local reporters why he opposed Fairness in Bowling Green. Denning reiterated his longstanding view that a Fairness Ordinance in Bowling Green was unnecessary, as these protections are already given to sexual and gendered minorities by the state and federal governments (Bennett 2011). In an interview with local news station 
$W B K O$, Denning incorrectly stated: “There are already state and national laws that exist for this... I don't see the need to adding more to the code" (WBKO 2017). Denning also brought this opinion to the March 7 meeting, asking Brandon Nelsey - who told the Board he was fired after he came out as gay - why he did not go to the Kentucky Commission on Human Rights to receive justice. Nelsey responded by telling the Board that he did discuss his options with an attorney, but the lawyer informed him that his former employer did not break any law. Denning then suggested Nelsey get a second opinion on the matter $(B G$ Commission, 7 March 2017).

Mayor Wilkerson and Commissioner Williams were also asked why they continued to oppose the Fairness Ordinance. Like Berea Councilpersons Little and Terrill, these Bowling Green officials stated their belief that it would have been inappropriate for a local government to redefine protected classes and that the law would be better managed at the state level (Austin 2017). This was not the first time Mayor Wilkerson used this line of reasoning to dismiss Fairness in Bowling Green. In 2013, Wilkerson had told a reporter for Bowling Green Daily News that: “This is a state's issue. I don't like discrimination, but we just don't have jurisdiction over these matters" (Brandenburg 2013).

Commissioner Parrigin appeared to concur with Mayor Wilkerson and Commissioner Williams, asking a reporter at $W B K O$ : "Is it appropriate for a local city government to decide protected classes? I just don't believe it is" (Nie 2017). More than any other Commissioner, however, Parrigin received the largest criticism from the local press (Austin 2017; Dods 2017; Line 2017; Herald Editorial Board 2017). Parrigin, a former employee at Western Kentucky University, sued the school on the grounds that she was denied a promotion due to her gender. In two separate articles, the Bowling Green Daily News criticized Parrigin for refusing to grant the LGBTQ+ community the same rights that have protected her (Dods 2017; Line 2017). The Editorial Board of the WKU Herald (2017) wrote a scathing article against Parrigin, painting the Commissioner as greedy for failing to extend protections she has utilized to LGBTQ+ residents. In another article from the WKU Herald, Emma Austin referred to Parrigin as "hypocritical” (Austin 2017).

Commissioner Parrigin and the rest of the Board would continue to receive criticism from the press in the weeks following the failed Fairness vote. On March 08, the day after the working session, Parrigin asked the city manager to draft what would become Ord. BG2017-8. This ordinance would amend 
the Bowling Green Code of Ordinances, revising the order of business during board meetings. Specifically, the ordinance would move Public Comments from the start of the meeting to the last item on the agenda. Many viewed BG2017-8 as a way for the Board to silence Fairness advocates, as it would make the starting time of Public Comments later and unpredictable, thereby making it more difficult for residents to speak to the Board. Parrigin was heavily criticized by the Bowling Green Daily News (Dods 2017), LeoWeekly (Sisk 2017), the Lexington Herald (Minter 2017), and the WKU Herald (Austin 2017) for her ordinance.

During the March 21 board meeting, Commissioner Parrigin motioned for a first reading of this new ordinance, which was seconded by Commissioner Williams (BG Commission 21 March 2017). After the first reading, Parrigin explained why she believed BG2017-8 would be beneficial to board meetings. Parrigin argued that public servants often have to sit through " a dozen or so" testimonies from residents during Public Comments before they are allowed to address the Board, extending the amount of time these employees have to wait to be heard (BG Commission, 21 March 2017). Under the proposed order of business, city officials would have the opportunity to address the Board early in the meeting. After giving their reports, these public servants could then leave, allowing them more time at home while also increasing the number of seats available for Public Comments.

Commissioner Nash made it known that he opposed BG2017-8. By moving Public Comments toward the end of the meeting, Nash noted that its starting time would be unpredictable, lowering public attendance and participation at commission meetings (BG Commission, 21 March 2017). Nash also stated that public officials should be present for Public Comments, as it is vital for city officials to have a thorough understanding of residents' concerns. After Commissioner Williams defended Parrigin's ordinance by stating it was not aimed at lowering public participation but prioritizing the items on the agenda, Nash responded that the Board's "business should come last" and that "citizens should always come first." (BG Commission, 21 March 2017). This last retort received an enormous amount of applause from those in attendance.

Similar to the Fairness debate, Nash was unable to convince a second Commissioner to side with him, and the Board approved BG2017-8 by a vote of four-to-one (BG Commission, 4 April 2017). While proponents of Fairness were never mentioned during the discussion of the ordinance, Commissioner 
Denning's subsequent comments suggested that the Board was growing weary of the presence of these residents. After the Board approved the new ordinance, Denning asked the Mayor if they could further curtail public participation by allowing representatives to speak on specific issues only on designated nights. Denning noted that the Board "hears from the same individuals saying the same things" and argued that it would be more logistical to limit these speeches to certain meetings (BG Commission, 4 April 2017). Mayor Wilkerson indicated that the matter might be considered at a later meeting, though as of this writing, no such ordinance has been introduced.

If the goal of BG2017-8 was to prevent members of Bowling Green Fairness from speaking, then the ordinance has not been successful. At the April 18 meeting, eight Fairness advocates - who had to wait two hours and thirty-seven minutes before Public Comments could begin - pleaded with the Board to reconsider the Fairness Ordinance (BG Commission 18 April 2017). In the five board meetings that have occurred between April 18 and the writing of this thesis, at least three representatives from Bowling Green Fairness have addressed the Board (BG Commission 5 May - 20 June 2017). During this time, all Bowling Green residents - whether they came to speak on Fairness or some other issue - had to wait an average of just over eighty-one minutes for Public Comments to commence (BG Commission 5 May - 20 June 2017).

Moving forward, LGBTQ+ activists' persistent lobbying in Bowling Green may prove vital if the Commission ever decides to reintroduce a fairness ordinance. Just weeks following the Fairness working session, Dr. Minter gave an interview for the Kentuckians for the Commonwealth's podcast Power to the People, in which she discussed the Fairness Movement in Bowling Green. ${ }^{28}$ In the interview, Minter blamed the political culture of Bowling Green as the likely culprit behind the city's lack of protections (KFTC 2017). In the podcast, Minter noted that:

"Bowling Green, historically, is a city that doesn't like to shake things up... The cultural aspect of all this is that people in power, people who have a lot of privilege, tend to act in ways that they don't think will be challenged by marginalized groups in the city, and that has historically been true. And there has not been an attempt to challenge the lack of LGBT rights until the movement was rejuvenated in 2011." (Dr. Patricia Minter on the Power to the People Podcast entitled "To Be Fair" 2017).

${ }^{28}$ The full podcast, To be Fair, can be heard here: http://kftc.org/powertothepeople 
The birth of Bowling Green Fairness in 2011 was the first step in "shaking things up" for local LGBTQ+ advocates, and by continually adding pressure to residents and public officials to support Fairness, they are hoping to demonstrate that they will continue to challenge the city's political elite. While the Fairness vote indicates they have yet to be successful in completing their primary goal of an enacted Bowling Green Fairness Ordinance, they nonetheless have had several victories. As stated at the February 7 meeting, Bowling Green Fairness collected over eighty signatures from local businesses stating their support for a Fairness Ordinance (BG Commission, 7 February 2017). These advocates also created a petition to present to the commission in support of Fairness, in which over 1,100 Bowling Green residents signed (BG Commission, 7 February 2017). Perhaps their most notable accomplishment, however, was the evolution of Commissioner Nash on this issue. Nash has stated that discussions with activists from Bowling Green Fairness were the reason he became a Fairness supporter (Nie 2017). By convincing a public official who had an apathetic history with LGBTQ+ rights to support and even to introduce a Fairness Ordinance, Bowling Green Fairness is proving that local political culture can be changed.

\section{Addressing the Misconceptions and Fears of Fairness}

The two case studies provided in this chapter demonstrate that many residents and public officials in Kentucky have reservations about Fairness laws. A closer examination, however, reveals that many of the misgivings espoused by residents often do not match with those of their elected representatives, even when both groups oppose the Fairness Ordinance. In both Berea and Bowling Green, public officials appeared to be more concerned with the administrative questions on Fairness, such as enforcement costs and jurisdiction restrictions on local governments. While a few residents shared these officials' concerns, most residents who opposed Fairness argued their case with either religious vindication or by suggesting LGBTQ+ persons are attempting to receive special rights. In both Berea and Bowling Green, no public official denounced the LGBTQ+ community on moral grounds or suggested that Fairness would grant sexual and gendered minorities privileges that would harm the Christian, heterosexual, and cisgender majority. 
This section will briefly explore the five common arguments made against Fairness in Berea and Bowling Green. It is important to note that these five arguments were not the only misgivings residents had on Fairness. Some of these fears were explored in earlier chapters. The myth that LGBTQ + discrimination does not occur in Kentucky, for example, has already been addressed in Chapter III, as well as in this chapter, so this misconception will not be explored again here. In addition, Chapter II established that neither the Commonwealth of Kentucky nor the federal government protects LGBTQ+ persons, so I will also not reexamine this misbelief either. Finally, the aim of this thesis is not to debate moral issues related to sexuality and gender identity, so justifications on those bases for denying LGBTQ+ protections will also not be discussed.

\section{Religious Freedom}

One of the common complaints offered by opponents of Fairness in Kentucky is that these ordinances are unconstitutional. The main concern here is that by forcing businesses, nonprofit organizations, and religious institutions into giving equal treatment to sexual and gendered minorities, local human rights commissions are violating the Free Exercise Clause of the First Amendment to the United States Constitution. In other words, opponents of Fairness fear that individuals and organizations who possess sincerely held religious beliefs against sexual and gendered minorities will be forced to violate their moral code by hiring and promoting members of the LGBTQ+ community.

Despite the concerns of many Kentuckians that a Fairness Ordinance would violate their First Amendment rights, a closer examination reveals that these claims are unfounded. In the 1971 SCOTUS Case Lemon v. Kurtzman, the High Court established the following criteria for determining if a law violates the First Amendment:

"First, the statute must have a secular legislative purpose; second its principal or primary effect must be one that neither advances nor inhibits religion; finally, the statute must not foster 'an excessive government entanglement with religion"” (Lemon v. Kurtzman, 1971).

It has been well established that prohibiting discrimination in employment, housing, and public accommodations is a legitimate secular purpose of a government (MDoCR 2013). Fairness Ordinances also do not promote one religion over another, nor do they "foster 'an excessive 
government entanglement with religion'," as every Fairness bill and ordinance introduced in Kentucky has included exemptions for religious institutions. The final test Fairness legislation must pass, then, is whether the ordinance "inhibits religion."

The Supreme Court of the United States has settled this question. SCOTUS has ruled on several occasions that the First Amendment does not give blanket protections to individuals and organizations from discriminating against individuals that might violate their religious beliefs. In the 1968 case Newman $v$. Piggie Park Enterprises (390 U.S. 400), SCOTUS ruled that privately-held businesses could not discriminate against African Americans - or any other minority covered by Title VII - simply because the business owner's "religious beliefs compel him to oppose any integration of the races." Similarly, SCOTUS appeared to expand this philosophy to religiously-based organizations in the 1983 case Bob Jones University v. United States (461 U.S. 574), in which the Court ruled that the First Amendment did not protect the Christian university from having its tax-exempt status revoked by the Internal Revenue Service for its refusal to accept African American students.

While some conservatives might point to Bob Jones University v. the United States as evidence that Fairness Ordinances will force churches and religiously based institutions into hiring LGBTQ+ persons, local and state political actors have taken steps to ensure that these entities are protected from such actions. As noted in Chapter II, the retracted Fairness Ordinance of Henderson, the proposed ordinances in Bowling Green and Berea, and every Fairness Bill that has entered the state legislature or become law in Kentucky municipalities has had generous exemptions for religious organizations. Under these ordinances, no religious institution or any organization that is directly associated with a religious institution - such as a private school - is forced into hiring a member of the LGBTQ+ community.

\section{"Special Rights"}

Beyond religious opposition, secular objections are also common among opponents, though many of these have a religious undertone to them. One such argument is that granting protections for members of the LGBTQ+ community gives these individuals not civil rights but "special rights" that straight, cisgender residents would not possess, thereby giving sexual and gendered minorities an unfair advantage in employment and housing opportunities. Berea resident Carl Roberts made this case when he stated his 
belief that Fairness Ordinances do not promote fairness, but rather "reverse discrimination" (Fairness Meeting, 12 September 2014).

The rhetoric of LGBTQ+ rights as "special rights" is not a new phenomenon in Kentucky. In her historical overview of LGBTQ+ Kentuckians, Fosl (2016) notes that the Religious Right began to use such language in the 1990s to dismiss LGBTQ+ activists' claim that they were seeking equal treatment under the law. The Religious Right were particularly prone to use this rhetoric at African American churches, which they hoped would drive a wedge between LGBTQ+ activists and black activists by insinuating gays were equating the historic and contemporary struggles of African Americans with their own (Fosl 2016). This rhetoric became and remains quite popular in Kentucky, as evident by its frequent use in Louisville, Lexington, and Henderson in 1999 (Bennett 2011), and in Berea (Fairness Meeting, 12 September 2014) and Bowling Green (BG Commission, 7 March 2017) this decade. Commissioner Denning of Bowling Green appears to have bought this argument, as he passionately dismissed any Fairness proponent's use of using "civil rights" in discussing LGBTQ+ rights (BG Commission, 7 March 2017). Denning, however, appears to be the exception to this rule today. Though the vast majority of Fairness advocates in both Berea and Bowling Green where white, all black members of the public that showed up to the Fairness meetings spoke in favor of the ordinances (Fairness Meeting, 12 September 2014 \& 6 June 2011; BG Commission, 7 March 2017).

While the archival evidence shows that giving special rights to the LGBTQ+ community is a concern for many Kentuckians, a closer look at the proposed and enacted ordinances in the state shows that these fears are unwarranted. Every Fairness ordinance and bill introduced in the Commonwealth has had the same definitions of both sexual orientation - "an individual's actual or imputed heterosexuality, homosexuality or bisexuality" - and gender identity - "manifesting an identity not traditionally associated with one's biological maleness or femaleness." Rather than creating "special rights" for some minority group, these ordinances enact civil rights by protecting all residents of a locale from discrimination due to their sexual orientation or gender identity, including heterosexual and cisgender residents. As noted in Chapter III, documentation from Louisville and Lexington's human rights commissions demonstrate that discrimination against employees due to their heterosexuality does occur. These protections can be and 
have been utilized by Kentuckians of all sexualities and gender identities. Therefore, when Hank Kennedy told the Berea Board: "I think it's bull to make an ordinance for one special group. You should make the ordinance for all groups. That would be real fairness," (Fairness Meeting, 6 June 2011) he was, unknowingly perhaps, providing support to Fairness in Berea.

Applicability

Several Fairness opponents have claimed that LGBTQ+ persons are not eligible for workplace protections. The argument here stems from the belief that individuals are capable of choosing their sexual orientation or gender identity, which makes them ineligible for such protections. Civil rights laws, these opponents argue, are intended to protect against discrimination stemming from some innate and benign trait, such as skin color. Berea resident Donald Valley made this argument: "Homosexuality is a learned behavior that can be changed through counseling. It does not qualify for special status" (Fairness Meeting, 6 June 2011).

The scientific community, however, does not support the argument that sexual orientation or gender identity is a choice. It is true that there is no scientific consensus on what exactly causes a person's sexual orientation or gender identity (American Psychological Association 2008). Psychologists and biologists have long noted that a myriad of genetic, hormonal, developmental, social and cultural factors may be the cause of an individual's sexual orientation (APA 2008). Further, recent research has given increasing evidence that prenatal hormonal conditions may be the cause of having a gender identity that does not match one's biological sex (American Psychiatric Association 2016). Whatever the cause of LGBTQ+ identity, however, there is an overwhelming consensus from the scientific community that one does not have control over their sexual orientation or gender identity (APA 2008, American Psychiatric Association 2016). In other words, being LGBTQ+ is not a choice.

Even if one still believes that sexuality or gender identity is a choice, however, that "choice" would not disqualify such individuals from state protections. The state government of Kentucky has set precedent in protecting classes of individuals whose behavior is certainly a choice. KRS 344.040, passed during the 1994 General Assembly Session, gives tobacco users the same employment protections as 
women, racial minorities, or those with disabilities. Under KRS 344.040, it is an unlawful practice for an employer to:

"Fail or refuse to hire, or to discharge any individual, or otherwise to discriminate against an individual with respect to compensation, terms, conditions, or privileges of employment

... because the individual is a smoker or nonsmoker." (KRS 344.04)

Certainly, the choice to be a smoker - or a non-smoker - is just that: a choice. Therefore, the claim that nondiscrimination laws are designed to only apply to certain innate traits does not hold in the state.

\section{Business and Government Costs}

Critics of Fairness Ordinances have also voiced concerns over the additional costs these

ordinances may bring to a number of entities. Several business owners during the Berea and Bowling Green Fairness debates assured residents that they would never discriminate in hiring or services due to an employee's sexual orientation or gender identity. Yet, these Fairness opponents also espoused their fear that a disgruntled employee might accuse them of discrimination when no such actions occurred. In other words, many Fairness opponents believe that Fairness Ordinances increase the number of frivolous lawsuits against employers, forcing business owners to spend income they might not have on legal fees. It is not just concerns of added costs to business owners that are worrying opponents of fairness ordinances; many are also concerned about the added cost to an already stretched local government budget. Councilwoman Farmer in Berea voiced this concern, telling Fairness supporters she was worried that adding protections not covered by the state would result in the city having to hire an attorney and an investigator to enforce the policy, which would be a financial burden to the city (Berea Council, 7 October 2014).

Scholarly investigations into the frequency of lawsuits made by LGBTQ+ employees who claim to be the victim of discrimination at their workplace, however, should alleviate these fears. Mallory and Sears (2011b) analyzed employment discrimination complaints made by LGB + individuals in twenty states that offered LGB + workplace protections and found that sexual minorities make discrimination claims at the same rate as other minorities. Their report stated that states with LGBTQ+ protections could expect 4.0 complaints for every 10,000 LGB+ employees (Mallory \& Sears 2011). This rate is similar to that of racial discrimination (3.9 complaints for every 10,000 non-white employees) and slightly lower than that of gender discrimination (5.0 complaints for every 10,000 female employees) (Mallory \& Sears 2011). 
The Government Accountability Office (GAO) issued a report on the frequency of workplace discrimination claims that stem from an employee's sexual orientation and gender identity between 2007 and 2012 in states that possessed such protections. In their report, the GAO found that discrimination claims from sexual minorities accounted for anywhere between $2.4 \%$ to $6.8 \%$ of all discrimination claims made to state human rights agencies, with the mean being $4.4 \%$. Gendered minorities made even fewer discrimination complaints, accounting for less than $1 \%$ in all states and all years in which the GAO examined the data. The GAO finalized their report by stating that LGBTQ+ complaints appear to be "proportionate" to the estimated LGBTQ+ population in these states (GAO 2013), suggesting LGBTQ+ persons are not overburdening businesses with frivolous lawsuits.

The KCHR also regularly releases data for local politicians to consider when debating fairness ordinances and bills, including estimated complaint figures. In Berea, for example, the KCHR estimated that extending protections for sexual and gendered minorities would result in an additional three employment complaints per year (Berea Council, 16 August 2011). Moreover, the KCHR expected that the majority of these cases could be settled without a trial. In fact, the Commission estimated that granting LGBTQ+ protections would result in the Berea government needing to defend an LGBTQ+ resident in court once every ten years (Berea Council, 16 August 2011). The KCHR also stated that the city would not need to hire additional public servants for enforcement and estimated that the ordinance would increase the Berea HRC's budget by just \$750 a year (Berea Council, 16 August 2011). This increase in expenditures amounts to just $0.00003 \%$ of the entire Berea City Budget for 2017 (City of Berea 2016). These reports make it overwhelmingly likely that protecting LGBTQ+ employees from discrimination will not result in employers and governments being overly burdened by discrimination claims.

Not within the Jurisdiction of Local Governments

By far the most common reason given by public officials in Berea and Bowling Green as to why they do not support Fairness is their belief that local governments do not have the jurisdiction to do so. In other words, it is the opinion of these officials that local governments do not or should not possess the ability to enact human rights legislation that differs from that of the State. This was the reason given by Berea Councilmembers Terrill and Little, Bowling Green Commissioners Parrigin and Williams, and 
Bowling Green Mayor Wilkerson as to why they did not support their respective Fairness Ordinances. In fact, Councilmember Little, Commissioner Parrigin, and Mayor Wilkerson indicated that they support LGBTQ+ nondiscrimination laws in theory, but desire for these protections to be made by the Kentucky General Assembly or U.S. Congress (Berea Council, 7 October 2014; Nie 2017; Austin 2017).

When examining the Kentucky Revised Statutes, however, one discovers that these justifications appear to be mere excuses to put the blame on Frankfort for their LGBTQ+ residents' lack of protections. KRS Chapter 82.082 states that:

A city may exercise any power and perform any function within its boundaries... that is in furtherance of a public purpose of the city and not in conflict with a constitutional provision or statute. (KRS Ch. 82.082)

As already stated, it has been well established that protecting the civil rights of residents is a public purpose that a government may pursue, as the federal government, the State of Kentucky, and several municipalities have created various human rights commissions and enacted laws and ordinances that aim to grant certain individuals protections in employment, housing, and public accommodations. Further, nowhere in KRS Chapter 344 - the section of Kentucky's body of laws that pertains to civil rights - does it state that local governments do not possess the authority to grant protections that are beyond the scope of what the KRS details. In fact, KRS Chapter 344.330, entitled "Powers of Local Commissions", appears to give this authority to local governments and human rights commissions:

"A local commission may be authorized to... receive, initiate, investigate, hear, and determine charges of violations of ordinances, orders, or resolutions forbidding discrimination adopted by the city or county (emphasis mine)." (KRS Ch. 344.330)

Finally, if local governments do not have the authority to protect LGBTQ+ residents from discrimination in employment, housing, or public accommodations, one would expect the eight local fairness ordinances in effect throughout the state to have been overturned by the Courts. Yet, this has not occurred, suggesting opponents of Fairness have no grounds to imply that local governments lack the jurisdiction to create such policies. Kentucky is a home rule state, meaning local governments are allowed to enact any policy that is not explicitly forbidden by the state or federal constitution (Kelly, PC 2017). The argument utilized by many local officials in Bowling Green and Berea that they are powerless to act, therefore, cannot be supported by evidence. 


\section{CHAPTER VIII:}

\section{EXPLAINING FAIRNESS ORDINANCES IN KENTUCKY}

Though the earliest local nondiscrimination ordinances for LGBTQ+ Americans can be traced

back to the early 1970 s, the cities issuing these ordinances were few in numbers and primarily located in liberal college towns throughout the United States, such as Ann Arbor, Michigan; Amherst, Massachusetts; and Austin, Texas (Johnson 2004). It was not until the mid-1990s that larger cities in the United States began implementing these ordinances in greater numbers: by 1995, sixteen of the twenty largest cities in the United States protected their LGBTQ+ residents from workplace discrimination (Johnson 2004). These laws were not just limited to large metropolitan areas, however, as many smaller cities as diverse as Spokane, Washington; Fort Wayne, Indiana; Yellow Springs, Ohio; and Orlando, Florida issued similar protections by the mid-1990s as well.

The diversity of locales issuing nondiscrimination ordinances motivated several political scientists to begin studying this trend. Wald, Button, and Rienzo published one of the more widely cited studies in 1996, entitled "The Politics of Gay Rights in American Communities: Explaining Antidiscrimination Ordinances and Policies." This study remains the first and most prominent national survey analyzing what attributes of a city are correlated to that community's enactment of a nondiscrimination ordinance for their LGBTQ+ residents (Dixon, Kane, \& DiGrazia 2017). Wald et al. (1996) surveyed 251 U.S. cities (126 of which possessed LGBTQ+ nondiscrimination ordinances) and utilized logistic regression to conclude what variables belonging to a city help determine if their residents are most likely to be protected by an LGBTQ+ non-discrimination ordinance.

Their findings suggested that the greater the population size, ethnic diversity, resident wealth (measured in income per capita), and average educational attainment, the more likely a city was to possess a nondiscrimination law (Wald et al. 1996). Wald et al.'s (1996) study also suggested that both the 
religious composition and the presence of an LGBTQ+ political organization in the locale were also correlated with the likelihood that an LGBTQ+ protection ordinance is present within a city. ${ }^{29}$ Meanwhile, the proportion of registered Democrats, average college enrollment, the presence of LGBTQ+ elected officials, and the average age of a city or town, factors one might expect to correlate with the presence of a fairness ordinance, were found not to be significant in their regressions. Several other studies conducted since the article was published give support to Wald et al.'s findings (see Dixon et al. 2017; Ying 2016; Negro, Perretti, Carroll 2013; Rimmerman, Wald, Wilcox 2000). While these works suggest that the presence or absence of a Fairness Ordinance can be reduced to a few demographic or institutional factors, it is important to note that these studies were conducted at a national rather than state-specific level. The question remains, then, if and to what extent these findings are applicable to the communities of Kentucky.

This chapter will attempt to investigate if the current understandings of which attributes of an American city tend to be favorable to LGBTQ+ employment nondiscrimination laws are germane to the state of Kentucky. Using data from the American Community Survey (attained by the Minnesota Population Center), information provided by the Fairness Coalition, political party data from the Kentucky State Board of Elections, and religious data from the Association of Religious Data Archives, I conduct a logistic regression similar to that of Wald et al. to examine if the attributes found to be significant in their 1996 study are also significant for modern-day Kentucky municipalities. The proportion of registered Democrats in a municipality, which was found to be not significant in Wald et al.'s national study, will also be tested for Kentucky cities. One could make the argument that this omission was largely the result of the year the study was conducted, as Democrats were not as open to LGBTQ+ rights as they are today. Therefore, it may be beneficial to retest this variable considering the party's growing acceptance of LGBTQ+ rights. The analysis suggests that many of the factors Wald et al. found to be significant predictors of the presence of LGBTQ+ nondiscrimination laws in the United States during the 1990s do not hold true for modern-day Kentucky cities, as only population size and educational attainment were found to be statistically significant predictors in the state.

\footnotetext{
${ }^{29}$ The presence of a state non-discrimination law was also found to be positively correlated with the existence of local nondiscrimination laws. Since I will only be examining Kentucky in my regression, however, I cannot add this variable to either Models.
} 


\section{$\underline{\text { Descriptive Statistics }}$}

\section{Dependent Variable}

The binary dependent variable for the logistic regression is cities in Kentucky. Locales that possess a Fairness Ordinance were coded with a value of 1 and the locales without a Fairness Ordinance were coded with a value of 0 . In all, only eight Kentucky municipalities - Louisville-Jefferson County Metro, Lexington-Fayette County Metro, Covington, Vicco, Frankfort, Morehead, Danville, and Midway possess a Fairness Ordinance for their LGBTQ+ populations (Table 8.01) and thus were coded as 1 . This is in sharp contrast to the 417 cities and towns in Kentucky that have yet to pass such workplace protections, which were coded as 0 .

Table 8.01: Local Nondiscrimination Laws in Kentucky

\begin{tabular}{|c|c|c|c|c|}
\hline & \multicolumn{2}{|c|}{ All Cities } & \multicolumn{2}{|c|}{ Cities with 5000+ Residents } \\
\hline & $\underline{\text { Frequency }}$ & $\underline{\text { Percent }}$ & Frequency & Percent \\
\hline Ordinance & 8 & 1.88 & 6 & 8.11 \\
\hline No Ordinance & 417 & 98.12 & 68 & 91.89 \\
\hline Total & 425 & 100 & 74 & 100 \\
\hline
\end{tabular}

Table 8.01: The frequency of the "successes" and "failures" of the dependent variable, cities/towns. Source: Minnesota Population Center.

It may be disadvantageous to have such unbalanced data, as this may reduce the statistical power of the analysis. To help balance the data, this analysis will only examine Kentucky cities with a population of 5,000 persons or greater according to the 2006-2010 American Community Survey population estimates. At first glance, this appears not to be too large of a problem, as the eliminated towns account for only $11.3 \%$ of Kentucky’s population according to the 2006-2010 ACS (Minnesota Population Center 2017). By doing this, however, two Kentucky towns that possess a Fairness Ordinance - Midway (population 1,645) and Vicco (334) - are removed from the dataset. Despite this limitation, limiting the number of cases in this 
regression to those cities with a population of 5,000 residents or greater is necessary to have a robust result. Therefore, this study will examine only the 74 largest population centers in Kentucky (Table 8.01).

Another potential problem with the data is the overall lack of $1 \mathrm{~s}$ in the dataset $(\mathrm{N}=6)$. Ideally, a binary regression would have more than six l's, as having too few cities in the sample may lead to the regression possessing small-sample bias (Allison 2012). Small-sample bias lowers the statistical power of the regression, producing potentially false results. Having too small of a sample size for one of the groups also limits the number of independent variables one can test with; it is rather easy to over-specify a limiteddependent variable regression with so few cases in one of the groups. This was not an issue for Wald et al. (1996), as they were able to find many more cases due to the wider-scope of their study. Therefore, it is important to keep these limitations of my analysis in mind throughout the chapter.

\section{Independent Variables}

The explanatory variables used in the regression conducted for this thesis mirror the six independent variables found to be significant in Wald et al.'s (1996) study: population size, ethnic diversity, wealth, average education attainment, the religious composition of a municipality; and the presence of an $L G B T Q+$ political organization in the city. In addition to these variables, percent Democrat will also be tested. Though this variable was not statistically significant in Wald et al.'s national study, it is possible that the proportion of Democrats in Kentucky cities will be a strong predictor of whether that municipality possesses a Fairness Ordinance. Table 8.02 displays the descriptive statistics for each explanatory variable in both cities with and without a Fairness Ordinance.

A glance at Table 8.02 might suggest that much of Wald et al.'s (1996) findings do apply to Kentucky municipalities. It is important, however, not to rely on simple observation of the data when assessing these means. To compare the mean values of each independent variable between cities with a Fairness Ordinance and cities without a Fairness Ordinance, I utilized Welch's t-test. Welch's t-test is useful in this situation, as the sample size between the two groups is extremely uneven, as shown in Table 8.02. The results of these t-tests will suggest whether municipalities with a Fairness Ordinance differ 


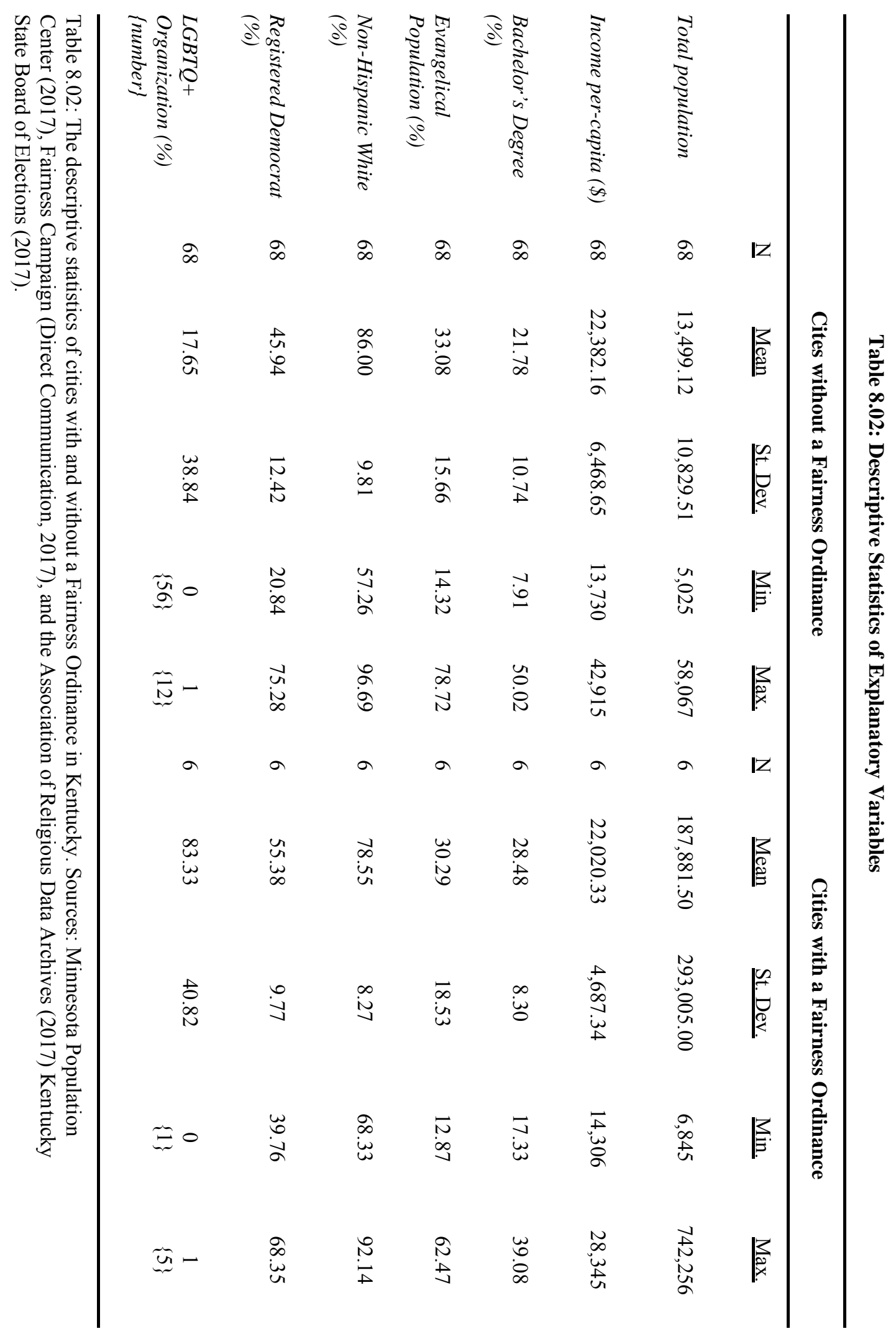


significantly from those without, thereby giving some indication of whether these variables might make good predictors of a Fairness Ordinance.

Total Population. In Wald et al.'s study, an increase of 10,000 residents in a location raised the odds ratio of that town or city of having an LGBTQ+ nondiscrimination law by 1.57 , which was significant (Wald et al. 1996). This finding suggests that larger cities are more likely to possess these ordinances when compared to smaller municipalities. ${ }^{30}$ To test this hypothesis in Kentucky, data from the 2006-2010 ACS was utilized, which provides demographic information - including population size - on every city in the state. In conducting the t-test, the natural $\log$ of each municipal population was taken to reduce the skew of the data, which is evident by the standard deviation of the mean of Cities with Fairness Ordinance being larger than the mean itself (Table 8.02). This skew is likely due to the presence of Louisville and Lexington in this group, each of which has a population that is much greater than the average in Kentucky.

At first glance of Table 8.02, it appears that Wald et al.'s findings do apply to Kentucky municipalities, as cities with a Fairness Ordinance have an average population that is about fourteen times greater than that of cities without these ordinances. To compare each of the group's means, a Welch's t-test was conducted comparing the average natural log of the population of municipalities with a Fairness Ordinance $(\overline{\mathrm{x}}=10.90)$ with the mean natural $\log$ of the population of those cities without such ordinances $(\overline{\mathrm{x}}=9.30)$. The resulting test indicates that there is a significant difference between these two means at a confidence level of $95 \%(p=0.040)$, suggesting municipalities with a Fairness Ordinance do have a larger population than those without (Table 8.03). Therefore, it remains possible that a municipality's population size is a predictor of whether that community possesses a Fairness Ordinance.

\footnotetext{
${ }^{30}$ Wald et al (1996) published their figures in logistic regression coefficients, not odds ratios. These coefficients can easily be converted to odds ratios, however, by taking the natural log of the coefficients.
} 
Table 8.03: $t$-test Results Comparing Population Means

Cities without a Fairness Ordinance

$\mathrm{N}$

Mean

(Std. Error)
68

9.30

$(0.073)$
Cities with a Fairness Ordinance

6

10.90

$(0.733)$

$$
\text { Welch's d.f }=5.14 \quad \text { t-score }=-2.17 \quad p=0.040
$$

Table 8.03: Results from the Welch's t-test comparing the means of the (natural log of the) population between Kentucky cities with and without a Fairness Ordinance.

Income Per-Capita. Wald et al. (1996) also demonstrate that the average wealth of residents in a city influences the odds of that locale having a nondiscrimination ordinance. According to their findings, a $\$ 1000$ increase in the average income per-capita increases the odds of that city having these ordinances by a ratio of 1.14 (Wald et al. 1996). Their findings suggest that cities with wealthier residents are more likely to have employment protection laws for their LGBTQ+ population than that of less-wealthy cities. To test this idea, information from the 2006-2010 ACS was again used, which provided income per capita data on Kentucky cities.

Looking at Table 8.02, one can already tell that Wald et al.'s findings might not be fully applicable in Kentucky, as cities that do not possess these antidiscrimination laws have a mean income per capita $(\overline{\mathrm{x}}=$ $\$ 22,382)$ that is $\$ 362$ higher than cities with these protections $(\bar{x}=\$ 22,020)$. It is important to note that the standard deviation of cities with Fairness Laws is much smaller than the cities without these protections, suggesting that some cities without Fairness Ordinances may be wealthy outliers in the data. Results from the Welch's t-test suggest that the two means are not significantly different from one another $(p=0.55)$ (Table 8.04). This lack of significance suggests that it is unlikely that residential income in Kentucky is a significant predictor of whether a municipality possesses a Fairness Ordinance. Therefore, this variable will not be included in the logistic model. 
Table 8.04: $t$-test Results Comparing Income per capita Means

\section{Cities without a Fairness Ordinance $\quad$ Cities with a Fairness Ordinance}

$\mathrm{N}$

Mean

(Std. Error)
68

$22,382.16$

(784.44)
6

$22,020.33$

(1913.6)

Welch's d.f $=7.52 \quad$ t-score $=0.175 \quad p=0.567$

Table 8.04: Results from the Welch's t-test comparing the income per capita means between Kentucky cities with and without a Fairness Ordinance. Mean figures are in dollars.

Bachelor's Degree. Average educational attainment was also significant in Wald et al.'s study.

According to their analysis, for every one-year increase in the average educational attainment of residents, the odds ratio of the city possessing an LGBTQ+ nondiscrimination law increased by 1.78 (Wald et al. 1996). Unfortunately, the ACS does not provide data on the average number of years of education for a municipality. Rather, the ACS provides educational data based on specific categories of attainment, such as "No High School Diploma," "High School Diploma," "Some College," “Associate Degree," etc. As a substitute for Wald et al.'s use of years of education, I generated a variable that shows the percent of residents in a locale that possesses a bachelor's degree. Though the specific odds ratios might not be comparable, it is still possible to test if municipalities with more educated residents have higher odds of possessing a Fairness Ordinance.

The descriptive statistics table above shows that cities in Kentucky that possess a Fairness Ordinance do have a higher percentage of residents with at least a bachelor's degree $(\overline{\mathrm{x}}=28.48 \%)$ when compared to those cities without such protections $(\bar{x}=21.78 \%)$. Again, this difference in means was tested for significance using Welch's t-test. The results indicate that the mean educational attainment between municipalities with and without a Fairness Ordinance are statistically different from one another $(p=0.04)$ at a confidence level of $95 \%$ (Table 8.05 ), suggesting there may be a relationship between educational attainment in a Kentucky municipality and that municipality's enactment of a Fairness Ordinance. 
Table 8.05: $t$-test Results Comparing Educational Attainment Means

\begin{tabular}{|c|c|c|}
\hline & Cities without a Fairness Ordinance & Cities with a Fairness Ordinance \\
\hline $\mathrm{N}$ & 68 & 6 \\
\hline \multirow[t]{2}{*}{$\begin{array}{c}\text { Mean } \\
\text { (Std. Error) }\end{array}$} & $\begin{array}{l}21.78 \\
(1.30)\end{array}$ & $\begin{array}{l}28.48 \\
(3.39)\end{array}$ \\
\hline & d.f $=7.20 \quad$ t-score $=-2.03$ & $\mathrm{p}=0.042$ \\
\hline
\end{tabular}

Table 8.05: Results from the Welch's t-test comparing the mean educational attainment between Kentucky cities with and without a Fairness Ordinance. Means figures are in percent of residents with at least a bachelor's degree.

Non-Hispanic White. Wald et al.'s study suggests that racial diversity also influences the presence of LGBTQ+ employment nondiscrimination laws in the United States. According to their analysis, a 1\% decrease in the Non-Hispanic white population resulted in a slight increase in the odds ratio of 1.04, suggesting that racially diverse communities are more likely to possess nondiscrimination laws for LGBTQ+ residents (Wald et al. 1996). To test this hypothesis in Kentucky cities, 2006-2010 ACS data on the number of non-Hispanic white residents in a municipality was utilized.

Table 8.02 shows that looking at the descriptive statistics alone, Kentucky cities that possess a Fairness Ordinance have a smaller percentage of non-Hispanic whites $(\overline{\mathrm{x}}=78.55 \%)$ compared to those locales without such ordinances $(\overline{\mathrm{x}}=86.00 \%)$. The results from the Welch's t-test also suggest that these two means are significantly different from one another $(\mathrm{p}=0.039)$ at a confidence level of $95 \%$ (Table 8.06), indicating that the racial makeup of a municipality might be a predictor of whether a city has a Fairness Ordinance. 
Table 8.06: $t$-test Results Comparing Percent Non-Hispanic White Means

Cities without a Fairness Ordinance

$\mathrm{N}$

Mean

(Std. Error)
68

85.97

(1.19)
Cities with a Fairness Ordinance

6

78.55

(3.38)

Welch's d.f $=6.83 \quad$ t-score $=2.07 \quad \mathrm{p}=0.039$

Table 8.06: Results from the Welch's t-test comparing the mean percent of Non-Hispanic White residents in Kentucky cities with and without a Fairness Ordinance.

Evangelical Population. Wald et al. (1996) suggest that evangelicals, who tend to be more conservative on social issues such as gay rights, would act as a group to protest the passage of LGBTQ+ employment nondiscrimination laws. Thus, they hypothesized that the presence of evangelicals would decrease the likelihood of cities possessing these laws. Their analysis seemed to support this hypothesis, as a $1 \%$ increase in the proportion of evangelical Christians in a city decreased the likelihood that a nondiscrimination law was present by an odds ratio of 0.93 (Wald et al. 1996). Unfortunately, city-based data on the religious beliefs of residents do not exist, as the United States government does not collect such data. What data is available comes from the Association of Religious Data Archives, an online database that reports religious surveys at the international, national, and county levels. While it is not ideal to use countylevel data as a substitute for city-level data, Wald et al. also used county-level data to run their logistic regression (Wald et al. 1996), suggesting that our analyses may be comparable. ${ }^{31}$

Table 8.02 reports that cities with a Fairness Ordinance on average possess a lower proportion of evangelical residents $(\overline{\mathrm{x}}=30.20 \%)$ compared to cities without such workplace protections $(\overline{\mathrm{x}}=33.08 \%)$. However, the resulting Welch's t-test indicates that this difference is not statistically significant $(p=0.36)$.

${ }^{31}$ Wald et al (1996) used a publication by Bradley Martin, Churches and Church membership in the United States 1990 : an enumeration by region, state and county based on data reported for 133 Church groupings to estimate city-level religious data in their study. 
This lack of significance suggests that percent of evangelical residents within a municipality might be a poor indicator of whether that city possesses a Fairness Ordinance. Therefore, this variable will not be included in the logistic model.

Table 8.07: $t$-test Results Comparing Percent Evangelical Means

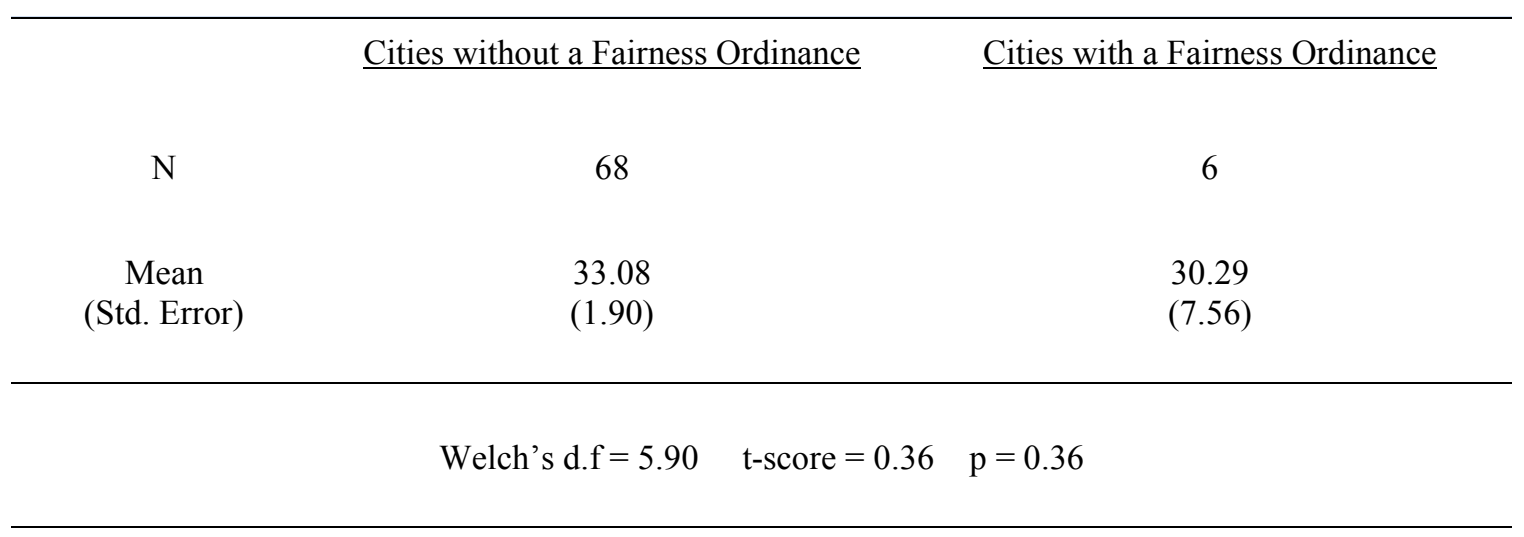

Table 8.7: Results from the Welch's t-test comparing the mean percent of evangelical residents in Kentucky cities with and without a Fairness Ordinance.

Percent Democrat. Unlike the other variables in this analysis, the proportion of registered Democrats to Republicans was not a significant indicator in Wald et al.'s (1996) study, but the evolution of the Democrat Party's views on gay rights have been significant since the mid-1990s. Because of this development, this variable will be included in this analysis. Unfortunately, the state of Kentucky collects voter registration information at the county-level, meaning county-level data will again be used. This data comes from the Kentucky State Board of Elections, which provides the number of registered voters for each political party in all 120 Kentucky counties. Using this data, the variable Percent Democrat was generated by taking the total number of registered Democrats in each county and dividing that number by the total number of registered voters.

The mean of the percent of registered Democrats in cities with a Fairness Ordinance ( $\bar{X}=55.38 \%)$ appears to be much greater than that of cities without similar LGBTQ+ protections $(\overline{\mathrm{X}}=45.94 \%)$ (Table 8.02). This finding is supported by the Welch's t-test (Table 8.08), which suggests that these two means are 
significantly different from one another $(\mathrm{p}=0.03)$ at a confidence level of $95 \%$. Therefore, this analysis indicates that percentage of registered Democratic voters might be a significant predictor of whether or not a municipality possess a Fairness Ordinance.

Table 8.08: $t$-test Results Comparing Percent Democrat Means

\begin{tabular}{|c|c|c|}
\hline & Cities without a Fairness Ordinance & Cities with a Fairness Ordinance \\
\hline $\mathrm{N}$ & 68 & 6 \\
\hline \multirow[t]{2}{*}{$\begin{array}{c}\text { Mean } \\
\text { (Std. Error) }\end{array}$} & $\begin{array}{l}45.94 \\
(1.51)\end{array}$ & $\begin{array}{l}55.38 \\
(3.99)\end{array}$ \\
\hline & Welch's d.f $=7.12 \quad$ t-score $=-2.21$ & $\mathrm{p}=0.031$ \\
\hline
\end{tabular}

Table 8.08: Results from the Welch's t-test comparing the mean percent of registered Democrats in Kentucky cities with and without a Fairness Ordinance.

$L G B T Q+$ Organizations. Wald et al. (1996) examined the political opportunity structure of the 251 cities in their survey to determine if the presence of an LGBTQ+ organization (referred by them as "gay service providers") influenced the likelihood that a city possesses an LGBTQ+ nondiscrimination ordinance. They found that cities that possessed such organizations increased their odds ratio of having a nondiscrimination law for LGBTQ+ residents by 1.35 (Wald et al. 1996).

To test this theory in Kentucky, I contacted the Fairness Campaign to gather information on local Fairness organizations in the state. The binary variable, $L G B T Q+$ Organizations, was then generated using this information. Cities that possess a Fairness chapter were coded 1 and cities without such organizations were coded $O$ (Table 8.02). Five of these local Fairness organizations in Kentucky are in a city that possesses a Fairness Ordinance, while twelve are located in a city that does not possess such protections.

Unlike the other independent variables in this analysis, the presence of an active LGBTQ+ rights organization is not a continuous variable, but a categorical one. One of the assumptions of the Welch's t- 
test is that variables are continuous, meaning the issue of $L G B T Q+$ Organizations cannot be tested using this method. Instead, both the Pearson's Chi-Square test and the Fisher's Exact test were utilized to determine if there is a relationship between a city being home to a Fairness organization and that city possessing a Fairness Ordinance. Both tests require that the variables be categorical, which fits the available data.

While Pearson's Chi-Square test is by far the most popular inferential statistical test for comparing two categorical variables, I chose also to include Fisher's Exact test because the data may produce unreliable results from the Chi-Square test alone. Pearson's Chi-Square test works best when there are at least five observations for each cell, and this assumption is violated in this data as the number of cities with a fairness ordinance but without a Fairness organization is just one (Table 8.09). Fisher's Exact test, however, does not possess the same requirements as the Chi-Square test and is much more equipped to handle data with smaller sample sizes. Therefore, both tests will be included in the analysis.

The Pearson's Chi-Square test (Table 8.10) produced a critical value of 13.44, which is statistically significant $(\mathrm{p}<0.001)$, suggesting that a relationship does exist between cities that are home to a Fairness organization and cities that possess a Fairness Ordinance. This result is supported by the Fisher's Exact test (Table 8.10), which also produced a statistically significant result $(\mathrm{p}=0.02)$, giving further evidence that a relationship exists. Furthermore, this relationship appears to be strong, as the value of Cramer's V - a measure of association test for categorical variables - is high at 0.426 (Table 8.10). 
Table 8.09: Fairness Ordinance * LGBT Organization Crosstabulation

\begin{tabular}{c|ccc|c}
\hline & Count & $\begin{array}{c}\text { Cities without an } \\
\text { LGBT Organization }\end{array}$ & $\begin{array}{c}\text { Cities with an LGBT } \\
\text { Organization }\end{array}$ & Total \\
\hline $\begin{array}{c}\text { Cities without } \\
\text { a Fairness } \\
\text { Ordinance }\end{array}$ & Actual & 56 & 12 & 68 \\
\hline $\begin{array}{c}\text { Cities with a } \\
\text { Fairness } \\
\text { Ordinance }\end{array}$ & Actual & 52.4 & 15.6 & 68.0 \\
\hline & Expected & 4.6 & 5 & 6 \\
\hline Total & Actual & 57 & 1.4 & 6.0 \\
\hline
\end{tabular}

Table 8.09: Crosstabulation of Kentucky municipalities with a Fairness Ordinance and Kentucky municipalities with an active Fairness Campaign.

Table 8.10: Pearson's Chi2 and Fisher's Exact Tests

\begin{tabular}{cccc}
\hline & $\underline{\text { Value }}$ & $\underline{\text { Df }}$ & $\underline{\text { Significance }}$ \\
N & 74 & - & - \\
Pearson Chi2 & 13.44 & 1 & 0.00 \\
Cramer's V & 0.426 & 1 & - \\
Fisher's Exact & - & 1 & 0.02 \\
\hline
\end{tabular}

Table 8.10: Results from the Pearson's Chi-Sq. and Fisher's Exact Tests from the crosstabulation shown in Table 8.09.

\section{$\underline{\text { Regression Analysis }}$}

To test if Wald et al.’s findings apply to Kentucky municipalities, a robust logistical regression was conducted using the statistical software STATA. The database utilized in this regression features the binary dependent variable (cities) and all the independent variables that were significant in the t-tests: total 
population, Bachelor's degree, non-Hispanic white population, percent Democrat, and LGBTQ+

organizations. In the first model run (Model I), all five explanatory variables were included. The results from this regression are found in Table 8.11.

Table 8.11: Logistic Regression, Model I

\begin{tabular}{|c|c|c|c|}
\hline$\underline{\text { Explanatory Variable }}$ & $\underline{\text { Odds-Ratio }}$ & Confidence & Interval \\
\hline In. Total population & $\begin{array}{l}2.46^{* *} \\
(0.999)\end{array}$ & {$[1.13$} & $5.42]$ \\
\hline Bachelor's degree & $\begin{array}{l}1.10^{* *} \\
(0.071)\end{array}$ & {$[0.981$} & $1.26]$ \\
\hline Non-Hispanic white population & $\begin{array}{c}0.966 \\
(0.035)\end{array}$ & {$[0.899$} & $1.038]$ \\
\hline Percent Democrat & $\begin{array}{c}1.28 \\
(0.103)\end{array}$ & {$[1.02$} & $1.57]$ \\
\hline$L G B T Q+$ Organization & $\begin{array}{c}10.56 \\
(12.53)\end{array}$ & {$[1.11$} & $100.3]$ \\
\hline constant & $\begin{array}{c}5.23 * 10-12 \\
(3.04 * 10-11)\end{array}$ & {$[5.89 * 10-17$} & $3.04 * 10-7]$ \\
\hline $\begin{array}{l}\text { Wald Chi2 } \\
\text { Prob }>\text { Chi2 } \\
\text { Pseudo R2 }\end{array}$ & $\begin{array}{l}28.01 \\
0.000 \\
0.4078\end{array}$ & & \\
\hline
\end{tabular}

The results from Model I demonstrate that most odd ratios in this study's regression show identical directional-results as Wald et al.’s (1996) study (Table 8.11). Despite this congruence, several 
variables that were significant in Wald et al.'s study were not found to be significant in Kentucky: nonHispanic white population, percent Democrat, and LGBTQ+ organizations, were found not to be statistically significant at a confidence level of $90 \%$. This indicates that the racial diversity and political partisanship of a city, as well as the presence of an LGBTQ + organization, are not significant predictors of a municipality possessing a Fairness Ordinance.

The variables Total Population $(\mathrm{p}=0.026)$ and Bachelor's degree $(\mathrm{p}=0.045)$ were found to be statistically significant at a confidence level of $95 \%$. As these variables are structurally different from those of Wald et al's study, ${ }^{32}$ it is inadvisable to compare the specific odds ratios. Table 8.11 does indicate, however, that Wald et al.'s (1996) findings on the relationship between these variables might be pertinent in Kentucky. This model indicates that cities with larger total populations and greater proportions of college-educated residents have a greater chance of possessing a Fairness Ordinance.

Still, only two of the six variables that Wald et al.'s study found to be significant predictors of an LGBTQ+ nondiscrimination law were significant in this study of Kentucky. One possible explanation for the lack of evidence supporting Wald et al.'s claim is due to the presence of multicollinearity in Model I. If some of the explanatory variables are correlated with one another, the resulting odds ratios and z-scores might be unstable and inaccurate. To test for multicollinearity, I generated a correlation matrix in STATA for all the independent variables in Model I. A correlation matrix tests each variable against one another to determine how related variables are to one another. Any two variables with a correlation greater than 0.400 or less than -0.400 are collinear and are indicated by asterisks in Table 8.12 .

\footnotetext{
${ }^{32}$ Wald et al used whole population figures and average years of education as measurements for the variable population and education, while this study uses the log of population and percent of residents with at least a bachelor's degree.
} 
Table 8.12: Multicollinearity Matrix

\begin{tabular}{|c|c|c|c|c|c|}
\hline & $\begin{array}{l}\text { Total } \\
\text { population }\end{array}$ & Percent Democrat & $\begin{array}{l}\text { Bachelor's } \\
\text { degree }\end{array}$ & $\begin{array}{l}\text { Non-Hispanic } \\
\text { White }\end{array}$ & $\begin{array}{l}L G B T Q+ \\
\text { Organizations }\end{array}$ \\
\hline $\begin{array}{l}\text { Total } \\
\text { population }\end{array}$ & 1.000 & & & & \\
\hline $\begin{array}{l}\text { Percent } \\
\text { Democrat }\end{array}$ & 0.181 & 1.000 & & & \\
\hline $\begin{array}{l}\text { Bachelor's } \\
\text { degree }\end{array}$ & 0.073 & -.0163 & 1.000 & & \\
\hline $\begin{array}{l}\text { Non-Hispanic } \\
\text { White }\end{array}$ & $-0.471 *$ & $-.492 *$ & 0.241 & 1.000 & \\
\hline $\begin{array}{l}\text { LGBTQ+ } \\
\text { Organizations }\end{array}$ & $0.560^{*}$ & 0.220 & 0.062 & $-0.473 *$ & 1.000 \\
\hline
\end{tabular}

Table 8.12: Results from the multicollinearity matrix ran using STATA for all six explanatory variables. Any two variables with a correlation greater than 0.400 are considered collinear. These correlated variables are indicated by asterisks.

The outcome of this correlation matrix demonstrates that four sets of independent variables correlate with one another: 1) Total population and non-Hispanic white, 2) Percent Democrat and nonHispanic white, 3) Total population and LGBTQ+ organizations, and 4) non-Hispanic white and LGBTQ+ organizations (Table 8.12). It is not surprising that the non-Hispanic white population is negatively correlated with population size and percent Democrat, as rural areas tend to be much whiter and conservative compared to the urban centers of Kentucky. Furthermore, LGBTQ+ organizations are more likely to exist in more populated cities, as these are the areas that are likely to have more LGBTQ+ residents. Because of these findings, $L G B T Q+$ organizations and non-Hispanic white were removed as explanatory variables in Logistic Regression Model II. Table 8.13 displays the result from the second logistic regression. 


\section{Explanatory Variable}

ln. Total population

Bachelor's degree

Percent Democrat

Constant

Wald Chi2

Prob $>$ Chi2

Pseudo R2 $\underline{\text { Odds-Ratio }}$

$1.29 * * *$

$(0.027)$

$1.11^{*}$

$(0.071)$

1.12

$(0.086)$

$5.23 * 10-12$

$(3.04 * 10-11)$
Confidence Interval

$\left[\begin{array}{ll}0.981 & 1.26\end{array}\right]$

$[0.964$ 1.30]

$[5.89 * 10-17 \quad 3.04 * 10-7]$
25.39

0.000

0.4323

Table 8.13: Results from the robust logistic regression using all six explanatory variables. Robust standard errors are in parentheses. Probabilities were calculated using Z-scores: ${ }^{*} P<.10,{ }^{* *} P<.05,{ }^{*} * * P<.01$. Sources: Minnesota Population Center (2017) and the Kentucky State Board of Elections (2017). Regression ran using STATA.

As was the case in Model I, the odds-ratios for both total population and bachelor's degree were statistically significant in Model II (Table 8.13). Total population - which was significant at a 99\% confidence level in Model II - was more significant in the second model $(p=0.003)$ than in the first $(p=$ 0.026). Though more significant, the odds ratio for total population was noticeably lower in Model II (1.29) than in Model II (2.46). Model II suggests that increasing the total population of a municipality by ten percent increases the odds of that city possessing a Fairness Ordinance by a ratio of 1.29. Total population also possessed a much lower robust standard error in the second model $(0.027)$ than in the first (0.99). These changes probably stem from the removal of the collinear variables in Model II. Nonetheless, in both models a city's population was shown to be a significant predictor of whether a Kentucky municipality possesses a Fairness Ordinance, with more populated cities being more likely to have such employment protections. 
The percentage of residents with a bachelor's degree was also statistically significant in both models, though this significance decreased to the $90 \%$ confidence level in Model II $(p=0.078)$. Table 8.13 suggests that the variable bachelor's degree is a marginally significant predictor of whether a Kentucky municipality possesses a Fairness Ordinance, with a one percent increase in residents with a bachelor's degree increasing the odds of that municipality possessing a Fairness Ordinance by a ratio of 1.11. Unlike the variable total population, neither the odds-ratios nor the robust standard errors differed much between Model I and Model II, likely because no variable was found to be collinear to bachelor's degree in the correlation matrix (Table 8.12).

The third variable in Model II, Percent Democrat, was not statistically significant at even the $90 \%$ confidence level in this model, mirroring the results from Model I. Therefore, it seems as if Wald et al. (1996) may have been correct in their assessment that the percent of registered Democrats in a city bears no relationship to whether that municipal government enacts a Fairness Ordinance. This finding could be because many rural counties in Kentucky have relatively high numbers of conservative Democrats living within them. In Breathitt County, for example, $87.9 \%$ of registered voters are registered as Democrats, yet no municipality within this county possesses a Fairness Ordinance (Kentucky State Board of Elections 2017).

This analysis suggest that a Kentucky municipality’s population size and educational attainment are significant predictors of that city possessing a Fairness Ordinance, with municipalities with a greater number of residents and higher average educational attainment levels more likely to possess a Fairness Ordinance. This conclusion was also made in Wald et al.'s 1996 study. In addition to these findings, I was also able to give further evidence to Wald et al.'s conclusion that the presence of a strong Democratic-base does not predict whether a municipality possesses such ordinances, at least in Kentucky municipalities. Importantly, however, not all variables found to be significant in Wald et al.'s national study were significant in Kentucky: racial diversity, income per capita, the presence of a strong LGBTQ+ service provider, and the presence of a strong evangelical population were not found to be significant predictors of whether a Kentucky municipality possessed a Fairness Ordinance or not. 
Though Model II provides interesting insight into what residential characteristics help promote Fairness in a Kentucky municipality, it is also important to remember that the model is not perfect. Of the 425 cities in Kentucky, only eight possess a Fairness Ordinance. This imbalance reduces the statiscal power of any model. To help correct this, the models in this analysis only examined the 74 Kentucky municipalites with a population over 5,000 according to the 2010 U.S. Census. Not only did this cut out most Kentucky cities, but it also reduced the number of Fairness communities in the dataset to six, leaving out Midway and Vicco. Further, having only six 1 s also risks over-specifying the model and small-sample bias. 


\section{CHAPTER IX:}

\section{CONCLUSION}

This thesis provided a literature review on the personal, organizational, and economic benefits Fairness can provide to communities in the Commonwealth, as well as aimed to uncover the demographic and political challenges facing the movement in Kentucky. This topic is especially critical to the economic, social, and physical health of the Commonwealth, as the state is currently undergoing several crises. The average Kentucky household has the fifth lowest median income in the Union at $\$ 45,215$, which is more than $\$ 10,000$ less than the average American household income in $2016(\$ 56,657)$ (American FactFinder 2016). In addition, the Commonwealth has the fifth highest unemployment rate in the country at $5.3 \%$ (Bureau of Labor Statistics 2017). The state is also the fourth least developed according to the American Human Development Index (Social Science Research Council 2017a). The average life expectancy of a Kentucky resident is 76.0 years, almost three years less than the American average and higher than only six other states (SSRC 2017b). In their annual Well-Being Index - a subjective measure that estimates the overall "happiness" of residents - Gallup (2017) ranked Kentucky as the second least well-being state in the Union. These are just a few of the many measures that highlight the poor quality of life experienced by many Kentuckians compared to the rest of the country (Gallup-Sharecare 2016).

There are many policies state and local officials can initiate to improve the lives of Kentuckians, and one such policy is Fairness. The various studies surveyed in Chapter III demonstrate that workplace discrimination against LGBTQ+ Kentuckians is not a myth, and the literature on discrimination in the workplace examined in Chapters IV, V, and VI suggest that such harassment can result in severe costs to the individual, organization, and entire local economic health when these acts occur. This research suggests that Fairness is not only a civil rights issue, but an economic and public health concern as well. Recent

events in other states demonstrate that laws that permit LGBTQ+ discrimination to occur under the guise of "religious liberty" - acts frequently promoted by both Democrat and Republican lawmakers in the General 
Assembly - often results in further economic and social harms to the communities that possess such policies. Furthermore, surveys taken in Kentucky on Fairness suggests this policy is politically popular in the state, and these findings were supported by the greater overall numbers of residents in both Berea and Bowling Green who came out to support a Fairness Ordinance compared to those who were against the policy. Fairness, then, appears to be a popular and credible method of improving the lives of all Kentuckians, not just the state's LGBTQ+ population.

Despite the support LGBTQ+ nondiscrimination policies continue to receive from both academics and Kentucky residents, only nine municipalities have enacted a Fairness Ordinance in the Commonwealth, and the ordinance in Henderson was retracted just two years after being enacted. To uncover the political resistance to Fairness in Kentucky, Chapter VII provided two case studies on the Fairness movements in Berea and Bowling Green, two cities in which a Fairness Ordinance was introduced into the local governments. Based on video evidence of town hall meetings in which Fairness was debated, the ordinances received a great amount of support from residents, though opposition to the ordinance was present in both cities as well. Residents who were opposed to granting LGBTQ+ employment protections often did so under the guise of morality, the constitutionality of Fairness, and "special rights" arguments, though a few residents did make secular concerns over added business costs. It appears from these two case studies that mobilizing both support and opposition are significant forces in the outcome of a Fairness Ordinance, as well as the positions held by powerful local officials (which was especially evident in the Bowling Green example).

The public officials who ultimately blocked Fairness from being enacted in Berea and Bowling Green, however, justified their actions not by attacking the morality of LGBTQ+ persons or by arguing religious freedoms are more important than employment rights, but instead by stating administrative concerns they have with Fairness. The most popular concern made by Berean and Bowling Green officials was that local governments cannot - or should not - create additional protected classes not covered by the state government. Other concerns include that of Councilwoman Farmer of Berea, who noted her worry that protecting sexual and gendered minorities may result in the need of additional government staff, which she feared would overburden the Berean taxpayer. Additionally, Commissioner Dennings of Bowling 
Green expressed his belief that nondiscrimination laws already exist at the state level that protects LGBTQ+ Kentuckians from discrimination in employment, public accommodations, and housing.

Chapter VII also indicated that the justifications given by local residents and officials in Bowling Green and Berea on why they could not support Fairness in their communities - whether intrinsically secular or religious - do not hold up to scrutiny. The Supreme Court, for example, has repeatedly ruled that the First Amendment does not give Americans the right to engage in discriminatory actions based on their religious beliefs, so the belief that Fairness violates the Free Exercise Clause is simply not true. Similarly, every Fairness Law introduced and enacted in the Commonwealth protects against discrimination stemming from one's sexuality and gender identity, which includes heterosexual, cisgender residents. The claim, then, that these laws promote "special" rights is also false: Fairness protects every resident from sexual orientation or gender identity discrimination. Studies conducted by government entities such as the Government Accountability Office and the Kentucky Commission on Human Rights also have concluded that LGBTQ+ nondiscrimination laws are an economic burden to neither local governments nor businesses. In fact, evidence from Chapters V and VI indicated that these laws might bring economic growth to the organizations and communities that enact Fairness. Furthermore, the KRS plainly states that local governments do have the authority to enact Fairness, so the claim made by public officials in Berea and Bowling Green that the ordinance is outside their jurisdiction is false as well.

Chapter VIII explored how and to what extent certain demographic characteristics of Kentucky communities increase the likelihood of that municipality possessing a Fairness Ordinance. To this aim, a robust logistic regression model was utilized, as this model allows researchers to predict the probability of an event occurring (such as Fairness) based on the chosen independent variables. The predictor variables chosen in my study were largely based on Wald et al.'s 1996 national study, which used a similar logistic regression model to uncover if and which residential characteristics predicted the existence of an LGBTQ+ nondiscrimination ordinance in cities across the United States. The variables for my analysis, as adapted from Wald et al were municipal population size, income per-capita, education attainment (as a percent of residents with a bachelor's degree), percent evangelical, percent non-Hispanic white, percent registered Democrats, and the existence of an $L G B T Q+$ organization in the community. After reducing the number of 
independent variables based on the results of the Welch's t-tests and a multicollinearity matrix, only the variables percent Democrat, (natural log of) total population, and educational attainment. Of these, only the latter two were statistically significant. In other words, this analysis suggested that Kentucky communities with a large population size and high educational attainment are more likely to possess a Fairness Ordinance than areas that are less populated and educated.

The Effects of Population Size and Residential Educational Attainment on LGBTQ+ Rights

Wald et al. (1996) stated in their study that a municipality's population size is the strongest indicator of whether or not a city possesses an LGBTQ+ nondiscrimination ordinance. Models I and II of this study confirmed that conclusion, as population size was the most significant indicator in both models. This is hardly surprising. Of the thirty most populous cities in the United States (according to the 2010 U.S. Census), twenty-four possess a comprehensive LGBTQ+ nondiscrimination ordinance. Further, three of these cities without such protections are prohibited by state law from enacting nondiscrimination policies (Charlotte in North Carolina, and Memphis and Nashville in Tennessee). ${ }^{33}$ Of the 187 non-county municipalities with an LGBTQ+ nondiscrimination law, only 34.8\% have a population less than 100,000, despite the fact that the vast majority of American municipalities do possess small populations. ${ }^{34}$

Wald et al. (1996) note that a cyclical and self-reinforcing relationship exists between urban areas and LGBTQ+-friendly policies. First, LGBTQ+ individuals tend to be more numerous (in both absolute numbers and in proportion) in urban areas than in rural communities (Wald et al. 1996). The LGBTQ+ community has long been attracted to the city as a space of refuge against a more stigmatizing rural society. This reality is perhaps best exemplified by the early work of George Chauncey in Gay New York: Gender, Urban Culture, and the Making of the Gay Male World, 1890-1940. Channeling the work of the German sociologist Gerog Simmel, Chauncey notes how the city has long acted as a space of relative invisibility from the non-LGBT society - and individual freedom for gay persons. In the mass of people that

\footnotetext{
33 The three municipal governments that are legally permitted to implement LGBTQ nondiscrimination ordinances but have chosen not to do so are Houston, El Paso, and Oklahoma City.

${ }^{34}$ The average local jurisdictional population in the U.S. is 6,200 (Cox 2008).
} 
constitutes the urban, LGBTQ+ individuals are allowed to express themselves in ways that might not be possible for rural queer persons, where anonymity is less possible and strict moral conformity is often enforced (Chauncey 1994, 62). In New York City, for example, gay enclaves and neighborhoods began developing in the late $19^{\text {th }}$ century, exposing the myth that gays had not formed a community prior to the 1960s (Chauncey 1994, 11). These neighborhoods quickly developed into a magnet for gay rural residents, who came to the city "by the thousands" to participate in the gay world Chauncey described (Chauncey, 1994, 11).

Though Chauncey's work focused exclusively on New York's gay (and male) enclaves of the late $19^{\text {th }}$ and early $20^{\text {th }}$ centuries, his claim that LGBTQ+ persons view the city as a place of refuge continues to have merit to this day. Charles Kaiser (2007), Robert Bailey (1999), Lillian Faderman (2015), Christina Hanhardt (2014), and dozens of other scholars have written extensively on how cities provide LGBTQ+ persons with a strong sense of community, which continues to attract out-of-city gay migrants. This reality is also seen in empirical data: the 2010 U.S. Census reported that there were 4.2 same-sex couples per 1000 households in Kentucky. In the Commonwealth's two metropolitan areas - Jefferson and Fayette counties these figures enlarge to 6.23 and 7.31 respectively (Williams Institute 2010). Further, the Williams Institute estimates that while 3.04\% of Kentucky adults are LGBTQ+ (Mallory \& Sears 2015), in Metro Louisville this figure is $4.50 \%$ (Gallup Daily Tracking Poll 2015). In fact, the proportion of LGBTQ+ residents in Louisville is the $11^{\text {th }}$ highest in the United States, rivaling that of Los Angeles (4.6\%) and beating New York City $(4.0 \%)$, cities noted for their history of gay tolerance. These figures suggest that many among Kentucky's rural LGBTQ+ population may be relocating to the state's urban centers, and an enormous body of scholarly work (Wimark \& Östh 2013; Wimark 2014; Annes \& Redlin 2012) suggests that this could be occurring due to the more hospitable atmosphere found in cities for LGBTQ+ persons.

Wald et al. (1996) assert that as the concentration of LGBTQ+ individuals in cities increase, a community becomes better able to mobilize their collective resources to lobby for pro-LGBTQ+ policies. Prior to the 1980s, local politicians were hesitant to meet publicly with LGBTQ groups and persons, as doing so was politically damaging (Faderman 2015). In 1970, for example, the activist group Gay Activists Alliance made several requests that the Mayor of New York, John Lindsay, a liberal Republican who 
supported the Civil Rights Act as a congressional representative, make a public statement opposing gay and lesbian discrimination in the city. Mayor Lindsay, who had Presidential ambitions, did not even respond to the GAA's several requests, despite his apartment private sympathies with the LGBTQ+ community (Faderman 2015, 218). ${ }^{35}$ Americans' attitudes on gays and lesbians at this time is evident by a 1969 Harris poll, which found that $63 \%$ of Americans believed gays were "harmful to American life" (Fosl 2012). The political costs of publicly meeting with - let alone announcing his support of - the LGBTQ+ community did not outweigh the benefits, as most Americans at that time saw LGBTQ+ persons as sick and morally bankrupt.

Beginning in the 1980s, however, Faderman (2015) has noted an apparent shift in some politicians' attitudes toward the LGBTQ+ community. More politicians began not only meeting with LGBTQ+ groups, but actively attempting to gain their favor by advocating for pro-LGBTQ+ policies, such as nondiscrimination ordinances. In New York City, for example, Mayor Ed Koch not only publicly supported the city's LGBTQ+ community, but also strongly advocated for and signed a nondiscrimination ordinance in 1986 that protected LGBTQ+ persons (Faderman 2015). This trend was not limited to local politics either - though it certainly had the greatest effect on the local, as then-candidate Bill Clinton publicly met with gay activists and announced his support for several pro-gay policies - such as ending the gay ban in the military - throughout his 1992 campaign (Faderman 2015), something that would have been inconceivable a decade earlier. ${ }^{36}$

Wald et al. (1996) notes that resource mobilization theory may be a useful concept to explain this sudden change in government attitudes toward the LGBTQ+ community. According to this theory, as the concentration - in terms of sheer population size and resources - of a certain group or identity increases, social movements are better able to gather and utilize their resources to promote a unified goal. In the context of gay rights, this theory suggests that during the 1980s the growing concentration of LGBTQ+

\footnotetext{
${ }^{35}$ Lindsay did enact some reform for the city's LGBTQ+ residents, such as ending the police raids on gay bars and police entrapments (Faderman 2015).

${ }^{36}$ Obviously, Clinton was not able to keep his promise to end the gay ban in the military. Nonetheless, the fact that a candidate was able to publicly support the LGBTQ+ community and win a presidential election is significant.
} 
individuals in American cities, in addition to the growing resources (time, wealth, etc.) of this community, allowed LGBTQ+ organizations the capacity to mobilize LGBTQ+ persons and their resources into effective political tools. Politicians, whom mobilization theorists describe as rational agents, understood that if they did not support gay rights they would lose this critical voting bloc and its political donations, which may even go toward their political opponents. Acting with their self-interest in mind, politicians, according to mobilization theory, began engaging with LGBTQ+ persons and supporting their policies to entice this community's political support.

Mobilization theory is certainly a useful concept in thinking about how higher concentrations of LGBTQ+ individuals in urban areas influence these communities' receptiveness to pro-LGBTQ+ policies, but it is incomplete. According to mobilization theory, politicians will only act upon a social movement's grievances if it is politically sensible to do so; otherwise, the politician will be acting in an irrational manner. This dynamic is seen in Faderman's account of Mayor Lindsay's refusal to support gay rights in 1970: it was not politically expedient to associate with queer individuals in the 1970s, so he maintained distance between himself and the Gay Activists Alliance. If the urban public saw LGBTQ+ residents as pariahs during the 1980s the way it did during the early 1970s, resources and population size alone likely would not have been enough to draw political support from local politicians. What mobilization theory misses, then, is the effect of population size on cultural attitudes.

As the LGBTQ+ community grew in urban areas, they also became more visible. In 1979, less than a fifth of Americans knew an openly gay individual (Gallup 2016). By 1986, this figure rose to 26\%, and by 2003 most Americans knew at least one openly gay person (Gallup 2016). This visibility is crucial: research has suggested that knowing an LGBTQ+ individual makes one significantly more likely to both be comfortable around LGBTQ+ persons and to support LGBTQ+ rights (Morales 2009; Montopoli 2015; Gallup 2016). In my interview with ACLU Director Aldridge, he noted that getting people to know an LGBTQ+ person and hear their grievances is the "single most effective tool we [the Fairness Coalition] have in promoting Fairness in Kentucky" (Aldridge, PC 2016). As the number of LGBTQ+ individuals in cities increased, then, their visibility allowed cisgender, straight urban residents the opportunity to get to know them on a personal level, which has been empirically shown to lessen homophobia and encourage the 
support of gay rights. Without this visibility, politicians may not have been able to capitalize on the resource mobilization that was also occurring during this time, as LGBTQ+ individuals still would have been considered politically toxic.

A city's population size, then, works in a number of ways to influence that municipality's odds of possessing an LGBTQ+ nondiscrimination ordinance. LGBTQ+ individuals have historically been attracted to cities, as they provide a space for this community to live authentically with less societal interference than would have been possible in smaller communities. This increase in population works to promote LGBTQ+ rights in two ways: by providing a space for resource mobilization to influence local decision makers' opinions of the LGBTQ+ community and by normalizing LGBTQ+ persons to other urban residents, thereby allowing politicians to act on these resources in a politically saleable way. Furthermore, this process is cyclical. As urban residents and politicians have grown more accepting of their LGBTQ+ neighbors and as local governments have begun implementing pro-LGBTQ+ policies, more LGBTQ+ individuals are attracted to these cities. The presence of these new LGBTQ+ residents only further normalizes LGBTQ+ persons and adds to the resource mobilization of LGBTQ+ groups, thereby reinforcing the process.

This cycle of visibility and acceptance is paramount to the ability of Kentucky's LGBTQ+ rights movement in gaining support for Fairness. Michael Aldridge noted that, "the single greatest tool [the Fairness movement] have in getting these ordinances passed is to put a familiar face on the issue" (Aldridge, PC 2016). Greater concentrations of LGBTQ+ persons in Kentucky cities, then, works to normalize straight and cisgender residents to the LGBTQ+ community. This, in turn, makes these nonLGBTQ+ residents less hostile to LGBTQ+ rights, paving the way for local politicians to support ordinances such as Fairness more easily. Importantly, though, this does not suggest that rural areas are immune to this process. Rural LGBTQ+ Kentuckians have long been a fabric of the Commonwealth (Fosl 2016), and many queer Kentuckians continue to reside in areas outside of Louisville and Lexington. Similar to that of cities, rural residents are also normalized to LGBTQ+ persons through their - albeit more limited - interactions with them. This cycle was evident in Vicco, where the presence of an openly gay mayor and a lesbian couple in the town normalized the city council to the LGBTQ+ community. Aldridge, who was 
involved in the Vicco's drafting of its Fairness Ordinance, described the following exchange between himself and a councilmember:

"One city council member... comes in and says 'I haven't had time to read this...but let me just get this straight. You know how we can't, like, deny housing to Ethel, the black lady on Third Street?... Well is this the same thing for that lesbian couple on the Ridge?' And I was like, 'Yeah, pretty much the same thing.'... And so he was like 'Okay' and voted for it." (Aldridge, PC 2016)

In other words, the urban has a greater predisposition for this familiarity by virtue of their greater proportions of LGBTQ+ residents, but that does not mean that rural areas are entirely incapable of knowing and supporting their local LGBTQ+ community.

In addition to population size, education attainment was also a significant predictor of whether Kentucky municipalities possess a Fairness Ordinance in both Wald et al.'s study and in Models I and II of this thesis, though this relationship was more significant in the former's model. Certainly, educational attainment has been shown to be positively correlated with greater critical thinking skills (Adorno, FrenkelBrunswick, Levinson, \& Sanford 1950), suggesting that highly educated residents may possess a greater ability to critically analyze Fairness opponents' claims, which, as discussed in Chapter VII, were largely inaccurate scare tactics. Perhaps more importantly, though, is the effect higher education has on an individual's convictions. Sociological research has repeatedly demonstrated that higher educational attainment is positively correlated with higher levels of social liberalism (Schoon, Cheng, Gale, Batty, Deary 2010). In other words, educational attainment is an instrumental variable for social liberalism, with highly educated individuals typically being more socially liberal than those with less education (Marshall 2014).$^{37}$ This instrumental variable has proven to be fruitful: research has repeatedly demonstrated that

\footnotetext{
${ }^{37}$ Another possible instrument for this "ideology" variable is political party strength - with Democrats being "liberal" and Republicans "conservative", which does exist at the municipal (county) level and was included in both Models I and II, though it was not found to be significant. How can we explain this disjuncture between educational attainment and political party strength in terms of predicting a city's possession of Fairness? I argue that, in Kentucky at least, political party affiliation is a poor indicator of "social liberalism." Though never officially considered among the "Solid South", Kentucky has a long history with Democratic politics, dating back to the Civil War. Even in 2017, Democrats hold a slight edge over Republicans in terms of registered residents $(1,681,092$ vs. 1,368,271) (State Board of Election 2017). These Democrats, however, have historically been "Blue-Dog Democrats", that is, socially conservative. This type of Democrat is still dominant to this day in the Commonwealth, as evident by the 2016 U.S. Presidential Election: In Bracken County, Democrats outnumber Republicans more than two-to-one $(4,418$ vs. 1,643) (State Board of Election 2016), yet then-candidate Trump won the county by a margin of 56.9\% (Politico 2016).
} 
individuals with higher degrees of educational attainment are significantly more likely to support social justice movements, including those for women (Cherlin \& Barnhouse 1985), racial and ethnic minorities (Schoon, Cheng, Gale, Batty, Deary 2010), religious minorities (Weil 1985), the homeless (Phelan, Link, Stueve, Moore 1995), and LGBTQ+ rights (Wald et al. 1994; Kozloski 2010; Ohlander et al. 2005.

While there is a consensus among sociologists that higher education is positively correlated with support for social justice movements, the process through which education produces these "liberal" individuals is still being debated (Surridge 2016). In general, the literature details three models used by sociologists to explain the effects education has on social liberalism: the developmental model, the socialization model, and the ideological refinement model. The developmental model was conceptualized in 1950 by sociologists Adorno, Frenkel-Brunswick, Levinson, and Sanford as a way of explaining the effects education has on tolerance toward African Americans and Jewish Americans in the United States. According to this model, higher education improves the cognitive skills of those who engage in it, which in turn produces a lasting good in terms of social values. According to Hyman and Wright (1979) education produces personal (cognitive) growth which results in a greater appreciation of values such as diversity, democratic governance, and egalitarianism, all values that influence an individual's favorable predisposition toward social justice movements such as LGBTQ+ rights . Schwartz (2010) also notes that increased cognitive abilities augment reasoning skills, allowing individuals to become more adaptable to new ideas. The developmental model, then, understands the relationship between education and social values rather linearly: knowledge produces cognitive growth, which produces tolerance.

The developmental model, which became hegemonic in sociology in the latter half of the twentieth century, started to receive criticism during the 1980s (Phelan et al. 1995). Though sociologists found many errors with the model, one common criticism was that Adorno's formulation largely ignored the social effects of higher education (Phelen et al. 1995). American post-secondary educational institutions often transport students away from their rather homogenous upbringings into a more diverse and global culture. The university setting encourages students to make connections with a diverse network of cultures and traits, a phenomenon that might have been impossible in the student's hometown (Weil 1985). This exposure to a vast array of cultures at universities, then, works in a similar fashion to that of cities: it 
normalizes the "other," generating familiarity and empathy. Further, Phelen et al. (1995) note that university professors, who often have an enormous socialization role in university culture, transfer their socially liberal attitudes to their students, which further solidifies this socialization process. The socialization model, then, distinguishes itself from the developmental model by promoting complex relationships - as opposed to the linear individual growth - within university culture as the process that explains highly educated individual's liberal attitudes to social issues.

Alongside the socialization model, the ideological refinement model began attracting the attention of sociologists in the mid-1980s (Phelen et al. 1995; Surridge 2016). Jackman and Huma, who developed the model, criticized both the developmental and socialization models for ignoring the institutional effects higher education has on the individual's behavior (Phelen et al. 1995). Drawing on Foucault's "Power/Knowledge" concept, Jackman and Huma stated that higher education institutions work continually to reproduce the neoliberal ideal of individualism in university settings through the curriculum, which has historically been used to justify liberal (in the classical, not the modern political, sense) economics and politics. This results in highly educated individuals being supportive of some social policies, but not all. According to this framework, social policies that work against the "neoliberal agenda" - a redistribution of wealth, for example - are not academically produced (or promoted) by the educational institution (Surridge 2016). Importantly, though, social policies that do not interfere with this agenda - such as equal access to jobs among those equally qualified, women's rights, etc. - are promoted at the university setting. In this way, universities use "biopolitics" to discipline individual bodies into supporting the neoliberal agenda.

Though the developmental model, socialization model, and ideological refinement model have been tested and debated by sociologists for decades, Surridge (2016) notes that we are still no closer to answering why education has such a profound impact on an individual's liberal attitudes. And while this is certainly a very important question for sociologists, the specific means behind education's influence on social values has little importance here. Rather, the crucial point is that, whatever the mechanisms may be, research has demonstrated that education does influence an individual's perception of minority rights, including LGBTQ+ rights. Model II of this study, as well as the works of Wald et al. (1996), Kozloski (2010), and Ohlander et al. (2005) attests to this hypothesis. 
Ohlander, Batalova, and Treas (2005) constructed a regression model using data from the 19881994 General Social Survey to understand the effects that educational attainment has on an individual's attitudes toward gay rights. The descriptive statistics alone suggested that a positive relationship exists between educational attainment and being LGB-friendly. When asked, "Should a homosexual be allowed to teach?" $49.1 \%$ of respondents without a high school degree (in 1994) answered "no" to this question (Ohlander et al. 2005). This figure dropped to 14.6\% among those with a bachelor's degree and $11.7 \%$ among those with a graduate degree (Ohlander et al. 2005). In their regression model, Ohlander et al. found that educational attainment was the most significant predictor of whether an individual supported gay rights - more than age, race, geographic location, or religious affiliation. ${ }^{38}$ Further, this research has demonstrated that higher education can even increase an individual's support of LGB rights in situations where that individual's background might suggest they would be hostile toward gay rights, such as individuals raised in a Fundamentalist church (Ohlander et al. 2005).

Michael Kozloski (2010) also used General Social Survey data in his analysis of the relationship between educational attainment and LGBTQ+ attitudes, though he focused his study on American tolerance and moral attitudes toward the LGBTQ+ community rather than individual rights. His data was also more temporally extensive than Ohlander et al.'s, dating back to 1973 and continuing until 2006. Unsurprisingly, much of Kolzoski’s conclusions mirrored that of Ohlander et al. In 1998, for example, $52.3 \%$ of Americans surveyed who did not have a high school diploma believed that sexuality was a choice Kozloski 2010). Those with a graduate degree, however, were much less likely to believe one chooses their sexuality (18.7\%). Also similar to Ohlander et al.'s analysis, Kozloski found educational attainment to be a significant indicator of whether an individual is tolerant of LGBTQ+ persons. $^{39}$

This relationship, however, appears to be weakening over time (Kozloski 2010). Prior to 1994, Kozloski found that the relationship between higher education and greater tolerance for the LGBTQ+

\footnotetext{
38 "Geographic location" referred to the region of the United States the individual is residing in (North, South, East or West), not whether the individual is in an "urban area" or not. This variable "urban/rural" was not included in Ohlander et al.'s analysis.

${ }^{39}$ Kozloski's study did include variables for different settlement types ("Large City", "Medium City", "Suburb", "Town", and "Farm." Similar to this study, the settlement type (which can be seen as a substitute for municipal population) was more significant than educational attainment, with larger cities being more likely to possess these ordinances.
} 
community was extremely significant. In the decades since 1994, however, this relationship has been slowly weakening, though it remained significant at the time of Kozloski's study. Kozloski attributes this weakening of causality to the increased visibility of LGBTQ+ persons in American society, which has resulted in a greater tolerance for the LGBTQ+ community across all educational levels. This weakening relationship between educational attainment and pro-LGBTQ+ rights may explain why in Wald et al.'s 1996 study, average years of residential education was a very significant predictor of whether a municipality possessed an LGBTQ+ nondiscrimination ordinance, while this relationship was only marginally significant for Kentucky municipalities in 2017 (using 2010 data).

\section{$\underline{\text { Future Research }}$}

Model II of this thesis has suggested that average educational attainment and municipal population size are significant predictors of whether a Kentucky municipality possesses Fairness, with more populated and educated communities being more likely to implement this LGBTQ+-friendly policy. It is important to note, however, that population size and educational attainment alone do not appear to tell the whole story. Chapter VII detailed the local political debates on Fairness in Bowling Green and Berea, two cities that have failed to pass Fairness in their communities. In hindsight, these municipalities were excellent choices for this study: not only is the historical account of these cities among the best in the state, these cities also represent the limits of the logistic models. Bowling Green, for example, is the third most populous city in Kentucky, and both Bowling Green and Berea residents are among the most educated in the state, with each possessing an institution of higher learning within their boundaries. According to the logistical regression model - through which one can calculate the probability of a city possessing Fairness by entering the data into the regression ${ }^{40}$ - both Berea and Bowling Green have extremely (greater than 99.3\%) high probabilities of possessing a Fairness Ordinance.

${ }^{40}$ The equation for this probability calculation is: $\hat{\mathrm{p}}=\left[\mathrm{e}^{\wedge}\left(\beta \mathrm{x}_{0}+\beta \mathrm{x}_{1}+\beta \mathrm{x}_{2} \ldots\right)\right] /\left[1+\mathrm{e}^{\wedge}\left(\beta \mathrm{x}_{0}+\beta \mathrm{x}_{1}+\beta \mathrm{x}_{2} \ldots\right)\right]$, where $\hat{\mathrm{p}}$ is the probability, e is the exponential function, $\beta \mathrm{x}_{0}$ is the constant, and each subsequent $\beta \mathrm{x}$ is the odds ratio of the variable multiplied the value for that variable in that particular city. For example, in Model II the odds ratio for total population is 1.29 , so that figure would be multiplied by the (log) total population of Bowling Green to get $\beta \times 1$ for Bowling Green. 
Future research should attempt explain this disjuncture. One possible avenue for addressing it could be adding new variables to the logistical regression. There are certainly other possible explanatory variables that were missed in this research but could help explain why some Kentucky municipalities possess a Fairness Ordinance. Determining and testing those variables should be a priority. The resources available also limited this study: lacking the financial means to collect new data, this research used data made available through third-party sources, such as the American Community Survey. This was not a problem for many of the variables used in this study; institutions such as the ACS or the U.S. Census provide very accurate city-level demographic data. Some sources, however, were more problematic. For example, religious demographic data is currently only available at the county-level, which may have skewed the results of the t-tests. If city-level religious data is gathered and made public through a thirdparty source, or if one has the means to collect this data themselves, these new variables should be used and retested.

Another possible avenue for future research is to use a qualitative methodology - such as a case study or ethnography - to provide an in-depth analysis of one or more political debates on Fairness in a Kentucky municipality. In conducting research for this study, several political actors stated that Kentucky's political culture is a major hindrance to the Fairness movement in the state (Aldridge, PC 2016; Marzian PC 2016; Minter 2017). According to these Fairness advocates, politicians in Kentucky attempt to make as few waves as possible, which inherently promotes the status quo. In the two case studies provided in Chapter VII, this resistant political culture certainly was visible in Bowling Green and Berea, though the nature of those case studies prevented in depth analysis of this phenomenon on my part. "Political culture" is extremely difficult to quantify, suggesting that regressions alone may be inadequate to explaining Fairness in Kentucky. Qualitative research might be fruitful for attempting to explain what tactics made by LGBTQ+ advocates are most successful in their work to expand the number of Fairness communities in the state. Aldridge noted that familiarity with LGBTQ+ persons, followed by educating the public on the lack of protections LGBTQ+ Kentuckians have, are the most useful tools the Fairness Coalition has. How, then might the resources of the Fairness Coalition - or other LGBTQ+ civil rights groups - be utilized in a way that maximizes their effectiveness in rural Kentucky? 
Finally, qualitative research might also be more apt at understanding rurality and Fairness in the Commonwealth. The two smaller Fairness cities in Kentucky - Midway and Vicco - were not included in either Model I or II due to the inherent imbalance of data that results from studying Fairness in Kentucky. Issues such as sample size are not as critical in some qualitative research methods, suggesting this limitation may be overcome. Further, qualitative research might also be an excellent choice for studying the effects of rurality and Fairness. Kentucky is very much a rural state, meaning studying its urban centers will provide an incomplete picture of the realities LGBTQ+ Kentuckians face. Understanding the effects of the rural on Fairness, then, is crucial for understanding Fairness in the Commonwealth as a whole. 


\section{REFERENCES}

Adorno T., Brunswick E., Levinson D., \& Sanford R. 1950. The Authoritarian Personality. New York: Harper

Aldridge M. Personal interview. 15 September 2016.

Alesia S. "NCAA: 'Religious freedom' law creates concern for future events” Indianapolis Star 25 March 2015.

Alexander C. “ACC, NBA, NHL to monitor, assess North Carolina's controversial HB2” Charlotte Observer 30 March 2016.

Allison P. 2012. Logistic Regression for Rare Events. Statistical Horizons Blog.

(ACLU) American Civil Liberties Union-a. "Anti-LGBT Forces in Congress Are Giving Trump Very Bad Advice."

(ACLU) American Civil Liberties Union-b. “Anti-LGBT SB180 Passes Senate, House Unlikely to Hear Bill."

(ACLU) American Civil Liberties Union of Ohio. “ACLU Drops Support For 1993 RFRA 25 August 2015."

(AHA) American Heart Association. 2015. Stress and Heart Health. Report.

American Psychiatric Association. 2016. What Is Gender Dysphoria?. Report.

(APA) American Psychological Association. 2015. Stress in America: The Impact of Discrimination. Report.

(APA) American Psychological Association. 2008. Answers to your questions: For a better understanding of sexual orientation and homosexuality. Report.

Annes, A. \& Redlin, M. 2012. Coming out and coming back: Rural gay migration and the city. Journal of Rural Studies 28:1, 56-68.

Anonymous. Complaint filed to the LMHRC. 13 May 2012.

(AP) Associated Press. “Obama to Sign Protections for Contractors' Gay Employees.” The New York Times 16 June 2014.

(AP) Associated Press. “'Bathroom bill' to cost North Carolina \$3.76 billion” CNBC 27 March 2017.

Austin, E. “A review of voices: fight for fairness” WKU Herald 03 May 2017

Ayoko O., Callan V., \& Hartel C. 2003. Workplace Conflict, Bullying, and Counter-productive Behaviors. International Journal of Organizational Analysis Vol. 11(4). 283-301. 
Badgett M., Nezhead S., Waaldijk K., \& Rodgers Y. 2014. The Relationship Between LGBT Inclusion and Economic Development. Report by The Williams Institute and USAid.

Badgett M., Durso L., \& Schneebaum A. 2013. New Patterns of Poverty in the Lesbian, Gay, and Bisexual Community. Report by The Williams Institute.

Bailey R.W. 1999. Gay Politics, Urban Politics: Identity and Economics in the Urban Setting. Columbia University Press: New York. Print.

Bares A. 2015 Turnover Rates by Industry. Report for Compensation Force.

Barskey A., Bradley J., Brief A., Chan S., \& Dietch F. 2003. Subtle Yet Significant: The Existence and Impact of Everyday Racial Discrimination in the Workplace. Human Relations Vol. 56(11): 1299-1324.

Belonsky J. 2010. On The U.S. Army's First Gay Discharge. The Bileraco Project.

Bennedsen M. \& Wolfenzon D. 2000. The Balance of Power in Closely-Held Businesses. The Copenhagen Business School.

Bennett M. 2011. Fighting for Fairness: The History of Kentucky's Local Movements to Enact Fairness Ordinances in 1999. Thesis. Western Kentucky University.

Berry P., Gates D., \& Gillespie G. 2012. Novice Nurse Productivity Following Workplace Bullying. Journal of Nursing Scholarship Vol. 44(1) 80-87.

Bimbi D., Nanin J., Parsons J., Vicioso K., Missildine W., \& Frost D. 2006. Assessing gay and bisexual men's outcome expectancies for sexual risk under the influence of alcohol and drugs. Substance Use \& Misuse, 41. 643-652.

Binker M. "McCrory expresses displeasure with NC 'religious freedom' law proposals" WRAL News 30 March 2015.

Blumberg A. “Critics Say Kentucky’s New ‘Religious Freedom’ Bill Targets LGBTQ Students.” Huffington Post. 22 March 2017.

Boushey H. \& Glynn S. 2012. There are Significant Business Cost to Replacing Employees. Center for American Progress.

Boyle J. "HB2 costs Asheville \$1.5M conference” Citizen Times 25 April 2016.

Bracken D. 2016. "Economic impact of HB2 mushrooms in the Triangle." The News and Observer.

Bradley J. "Unpopular Law Only Strengthens Resolve” The Gleaner August 14, 1999.

Brammer J. \& Blackford L. "Republicans take the Kentucky House after 95 years of Democratic control." Kentucky 08 November 2016.

Brammer J. \& Desrochers D. "Bevin calls transgender bathroom legislation unnecessary and silly." The Lexington Herald. 09 December 2016. 
Brandenburg K. “Group eyes fairness ordinance” Bowling Green Daily News 22 December 2013.

Briggs J. “A year after RFRA, Angie's List's east-side expansion is still off.” Indy Star 08 July 2016.

Broverman N. 2016. “Indiana Took \$60 Million Hit After Passing Antigay Law.” The Advocate.

Brown D. "Governor Beshear Restores Employment Fairness Protection to State Government." Governor Steve Beshear's Communications Office. June 02, 2008.

Burns C. 2012. The Costly Business of Discrimination. Report. The Center for American Progress.

Burt R. 2004. Structural Holes and Good Ideas. American Journal of Sociology, Vol. 110(2). 349-399.

Burwell v. Hobby Lobby Stores. 573 US _ (2014).

Caiazza T. 2015. Scientific Opinion Poll: Small Business Owners Oppose Denying Services to LGBT Customers Based on Religious Beliefs. Center for American Progress.

Campbell C. 2016. Obama administration won't cut funds to North Carolina as House Bill 2 lawsuit proceeds. The News and Observer.

Carter J. Executive Order 12107. Signed on 28 December 1978.

Center for American Progress. 2011. Small Businesses Support Fairness. Report.

CERS. 2017. The Average Employee Lawsuit costs \$250,000. Report.

Chauncy, G. 1994. Gay New York: Gender, Urban Culture, and the Making of the Gay Male World 18901940. BasicBooks: New York.

The Charlotte Observer Editorial Board."McCrory, fittingly, leaves office with a whimper." The Charlotte Observer 22 December 2016.

The Charlotte Observer Editorial Board. "HB2 repeal: Cooper turns back on LGBT community" The Charlotte Observer 30 March 2017.

Charter and Code of Ordinances Ch. 2, Art. 2, Sec. 33. Lexington-Feyette County Urban Government.

Cherlin, A., \& Walters, P. (1981). Trends in United States Men's and Women's Sex-Role Attitudes: 1972 to 1978. American Sociological Review, 46(4), 453-460.

Cheves J. 2014. "After 15 years, lawmakers hold hearing on bill to ban discrimination based on sexual orientation." The Lexington Herald.

City of Berea Council Meeting, "Fairness Meeting \#2".

City of Berea Council Meeting, 19 April 2011 - 22 October 2014.

Civil Rights Act of 1964. Title VII. 1964. 42 U.S. Code $\S 2000 \mathrm{e}-4$.

City of Charlotte, North Carolina. Ordinance 7056. 
Clark T. 2004. The City as an Entertainment Machine. Research in Urban Policy. Camberly, UK: Elsevier.

Cochran S., Mays V., \& Sullivan J. 2003. Prevalence of mental disorders, psychological distress, and mental health services use among lesbian, gay and bisexual adults in the United States. Journal of Consulting and Clinical Psychology, 71. 53-61.

Cole v. Young. 351 US $536(1956)$.

Commonwealth of Kentucky State Board of Elections. 2017. Voter Registration Statistics - Report.

Commonwealth of Kentucky State Board of Elections. 2016. Voter Registration Statistics - Report.

Community Marketing Inc. 2010. Gay and Lesbian Tourism. Report.

Congressional Archives. 2017. HR 1308 - Religious Freedom Restoration Act.

Congressional Archives. 2016a. H.R.14752 - Equality Act.

Congressional Archives. 2016b. H.R.14752 - Equality Act.

Congressional Archives. 2016c. H.R.4636 - Employment Non-Discrimination Act of 1994.

Congressional Archives. 2016d. H.R.811: Employment Non-Discrimination Act of 2011.

Congressional Archives. 2016e. Employment Non-Discrimination Act of 2013.

Congressional Archives. 2016f. 10 U.S.C. section 654.

Congressional Archives. 2016g. H.R.2965 - Don’t Ask, Don’t Tell Repeal Act of 2010.

Congressional Archives. 2016h. S.4023 - Don't Ask, Don't Tell Repeal Act of 2010

Cook T. "Indiana House OKs controversial religious freedom bill” The Indy Star 23 March 2015.

Cooper C. 2011. "Organizational Effects of Workplace Bulling”. In Bulling and Harassment in the Workplace. CRC Press: New York. Print

Cornelison M. "Fairness rally in Berea." Lexington Herald-Leader. 20 September 2011.

Cortina J. \& King E. 2010. The Social and Economic Imperative of Lesbian, Gay, Bisexual, and Transgendered Supportive Organizational Policies. Industrial and Organizational Psychology Vol. 69(2). 74.

Cox, W. 2008. “America is more small town than we think.” New Geography 09 October 2008.

Council J. "Cities still wrestling with including sexual orientation in anti-discrimination ordinances." Courier Press 08 April 2012.

Desrochers D. "Hoover declares transgender bathroom bills 'dead'”. The Lexington Herald, 09 February 2017. 
Diversity Taskforce. 2012. Gay, Lesbian, Bisexual, and Transgender Marketing Guide. Report.

Dods C. “Parrigin can’t have it both ways” Bowling Green Daily News. 24 February 2017.

Doran W. 2016. "How much money has HB2 cost North Carolina?" Charlotte Observer.

Don't Ask, Don't Tell. 10 U.S.C. section 654. Added 30 November 1993.

Dressler W., Oths K., \& Gravlee C. 2005. Race and ethnicity in public health research: Models to explain health disparities. Annual Review of Anthropology, 34. 231-252.

Duffy N. "Kentucky Governor signs law to permit anti-LGBT discrimination in schools." PinkNews. 20 March 2017.

Durso E., Mirza S., \& McBride S. 2016. North Carolina's Discriminatory H.B. 2 Threatens More Than Half Billion Dollars in Economic Activity. Center for American Progress.

Earle H. 2003. Building a workplace of choice: Using the work environment to attract and retain top talent. Journal of Facilities Management, Vol. 2(3). 244-257.

Einarsen S., Hauge L., \& Skogstad A. 2010. The relative impact of workplace bullying as a social stressor at work. Scandinavian Journal of Psychology 51(5). 426-433.

Eisenhower G. Executive Order 10450. Signed on 27 April 1953.

EEOC. 2016a. What You Should Know About EEOC and the Enforcement Protections for LGBT Workers. Report.

EEOC. 2016b. “IFCO Systems Will Pay \$202,200 In Landmark Settlement of One of EEOC's First Sexual Orientation Discrimination Lawsuits". Press Release.

EEOC. 2016c. Examples of Court Decisions Supporting Coverage of LGBT-Related Discrimination Under Title VII.

EEOC. 2016d. Fact Sheet: Recent EEOC Litigation Regarding Title VII \& LGBT-Related Discrimination.

EEOC. 2016e. IFCO Systems Will Pay \$202,200 In Landmark Settlement of One of EEOC's First Sexual Orientation Discrimination Lawsuits.

EEOC. 2015a. "What You Should Know About EEOC and the Enforcement Protections for LGBT Workers". Report.

EEOC. 2015b. Baldwin v. Foxx, Appeal No. 0120133080 (15 July 2015).

EEOC. 2012. Macy v. Holder, Appeal No. 0120120821 (20 April 2012).

Elbin T. "Berea should again be a leader, enact fairness law." The Lexington Herald-Leader. 22 June 2011.

Evans T. 2015. Angie's List canceling Eastside expansion over RFRA. Indianapolis Star. 
EqualDex. 2017. LGBT Rights in Kentucky.

Faderman L. 2015. The Gay Revolution. Simon \& Shuster: New York. Print.

Feinstein B., Goldfried R., \& Davila J. 2012. The relationship between experiences of discrimination and mental health among lesbians and gay men: An examination of internalized homonegativity and rejection sensitivity as potential mechanisms. Journal of Consulting and Clinical Psychology, Vol 80(5): 917-927.

Florida R. 2002. The Rise of the Creative Class. Basic Books: New York.

Florida R. 2012. The Rise of the Creative Class: Revisited. Basic Books: New York.

Florida R., Mellander C., \& Stolarick K. 2008. Inside the Black Box of Regional Development: Human Capital, the Creative Class and Tolerance. Journal of Economic Geography.

Fosl C. 2016. Kentucky LGBTQ Historic Context Narrative, 2016. Report Prepared by the Anne Braden Institute for Social Research.

Fosl C. 2012. It Could Be Dangerous! Gay Liberation and Gay Marriage in Louisville, Kentucky, 1970. Ohio Valley History Vol. 12 (1). 45-64.

Gallup Poll. 2016. Gay and Lesbian Rights. Poll conducted on 22-24 April 1993.

Gao H. \& Zhang W. 2016. Employment Nondiscrimination Acts and Corporate Innovation. Management Science 1-18.

Gates G. 2014. Transgender Military Service in the U.S. Report by the Williams Institute.

Gates G. 2010. Sexual Minorities in the 2008 General Social Survey: Coming Out and Demographic Characteristics. Report by the Williams Institute.

George J. \& Mulvihill G. “Gay-Bias Law Debate Draws Crowd,” Lexington-Herald Leader, July 2, 1999, Front Page, Final Edition.

Glaeser E. 2004. "Book Review of Florida's 'The Rise of the Creative Class." Harvard Book Review.

Grigg K. 2014. Member reflection: Bereans for Fairness has already made a difference. Kentuckians for the Commonwealth.

Haberkorn J. \& Gerstein J. “Court sides with Hobby Lobby” Politico 30 June 2014.

Halkitis P., Green, K., \& Carragher D. 2006. Methamphetamine use, sexual behavior and HIV seroconversion. Journal of Gay and Lesbian Psychotherapy, 10(3). 95-109.

Halkitis P., Green K., \& Mourgues P. 2005. Longitudinal investigation of meth- amphetamine use among gay and bisexual men in New York City. Journal of Urban Health: Bulletin of the New York Academy of Medicine, 82. 18-25. 
Hamilton C. \& Mahalik J. 2009. Minority stress, masculinity, and social norms predicting gay men's health risk behaviors. Journal of Counseling Psychology, 56. 132-141.

Hanson F. 2009. Stress Weakens the Immune System. Report for The American Medical Association.

Hanhardt, H. 2013. Gay Neighborhood History and the Politics of Violence. Duke University Press: Durham, NC.

Harrison S. (2016a). "McCrory: If Charlotte approves LGBT protections, 'immediate' state response likely" Charlotte Observer 22 February 2016.

Harrison S. (2016b). "Charlotte City Council approves LGBT protections in 7-4 vote" Charlotte Observer 22 February 2016.

Hartman C. 2017. "Letter to the LGBT Community of Kentucky". Human Rights Campaign

Hatzenbuehler M., Bellatorre A., Lee Y., Finch B., Muennig P., \& Fiscella K. 2014. Structural stigma and all-cause mortality in sexual minority populations. Social Science \& Medicine Vol. 103. 33-41.

Hebl M., King E., \& Madera J. 2012. Bringing Social Identity to Work: The Influence of Manifestation and Suppression on Perceived Discrimination, Job Satisfaction, and Turnover Intentions. Cultural Diversity and Ethnic Minority Psychology 18(2). 165-170.

Hegel G. 1977. Phenomenology of Spirit. Translated by Miller A. Oxford: Clarendon Press. Print.

Herald Editorial Board. "Faltering Fairness: City officials fail to meet the low bar of open discussion" WKU Herald 27 February 2017.

Herek G. \& Garnets L. 2007. Sexual orientation and mental health. Annual Review of Clinical Psychology, 3. 353-375.

Herman J. 2011. The Cost of Employment Discrimination against Transgender Residents of Massachusetts. Report for the Williams Institute.

Hewlett S., Marshall M., \& Sherbin L. 2013. How Diversity Can Drive Innovation. Harvard Business Review.

High Tech Gays, et al. v. Defense Industrial Security Clearance Office, et al. 668 F.Supp. 1361 (1990).

House Bill 105. Kentucky House of Representatives. Introduced 03 January 2017.

House Bill 106. Kentucky House of Representatives. Introduced 03 January 2017.

House Bill 141. Kentucky House of Representatives. Introduced 13 January 2017.

Human Rights Campaign. 2017a. Preview 2017: Pro-Equality and Anti-LGBT State and Local Legislation. Report.

Human Rights Campaign. 2017b. Municipality Equality Index 2016. Report.

Human Rights Campaign. 2016a. Cities and Counties with Non-Discrimination Ordinances. 
Human Rights Campaign. 2016b. LGBTQ Equality at the Fortune 500.

Human Rights Campaign. 2013. Transgender Workers at Greater Risk For Unemployment, Poverty.

Hunt J. 2012. A State-by-State Examination of Nondiscrimination Laws and Policies. Report for the Center for American Progress.

Hunter L. 2013. Gay mayor promotes LGBT fairness in small-town Kentucky. The Washington Post.

Hyman H. \& Wright C. 1979. Education's Lasting Influence on Values. University of Chicago Press.

Indiana Senate Enrolled Act No. 101, Section 8, Subsection A. XXXX

Isidore C. "This is how much loss of NBA All-Star Game will cost Charlotte” CNN 22 July 2016.

Jefferson County Ord. 36-1999.

Johnson G. 2004. Workplace Discrimination. Report for $L G B T Q$.

Johnson A., Noble K., \& Richmand A. 2011. Business Impacts of Flexibility: An Imperative for Expansion. Corporate Voices for the Working Family.

Johnson J. 2012. Case Update. FAPAC National Leadership Conference of the EEOC.

Johnson J. Greetings from Executive Director Johnson. Kentucky Commission on Human Rights.

Jones J. 2015. “Indiana lawmakers approve 'religious freedom' bill.” Jurist.

Kaiser, C. 1997. The Gay Metropolis. Grove Press: New York.

Kalichman S. \& Cain D. 2004. A prospective study of sensation seeking and alcohol use as predictors of sexual risk behaviors among men and women receiving sexually transmitted infection clinic services. Psychology of Addictive Behaviors: Journal of the Society of Psychologists in Addictive Behaviors, 18. 367-373.

Kashubeck-West S. \& Szymanski D. 2008. Risky sexual behavior in gay and bisexual men: Internalized heterosexism, sensation seeking, and substance use. Counseling Psychologist, 36. 595-614.

Kennedy L. "Author of Religious Freedom bill frustrated by backlash” WISH News 26 March 2015.

Kentucky Competitive Workforce Coalition. 2017. "About the Coalition”.

Kentuckians for the Commonwealth. "To be Fair." Podcast (https://soundcloud.com/user-611665944/pttp6-to-be-fair)

Kiel R. \& Wilson D. 2008. The Real Creative Class. Social and Cultural Geography. 9(8). 841-847.

King R. 2015. RFRA: Boycotts, bans and a growing backlash. Indianapolis Star.

(KRS) Kentucky Revised Statutes Chapter 82.082.

(KRS) Kentucky Revised Statutes Chapter 344.010.

(KRS) Kentucky Revised Statutes Chapter 344.040. 
(KRS) Kentucky Revised Statutes Chapter 344.320.

Ketzenberger J. "Fear of lawsuits unites Indiana Chamber against 'religious freedom' bill" The Indy Star 06 March 2015

Kocher G. Debate about human rights panel tests Berea's tradition of openness. Lexington Herald-Leader. 31 July 2011.

Kohler W. "Small Kentucky Town Wages Dirty War with Itself Over LGBT Fairness Ordinance." River City News. January 19, 2014.

Kozloski M. (2010) Homosexual Moral Acceptance and Social Tolerance: Are the Effects of Education Changing? Journal of Homosexuality, 57(10) 1370-1383

Lacour G. "HB2: How North Carolina Got Here (Updated).” Charlotte Magazine. 05 April 2016.

Lambda Legal. 2017. Leaked Draft of Trump's Religious Freedom Order Reveals Sweeping Plans to Legalize Discrimination.

Lambda Legal. 2015. Lambda Legal to Seventh Circuit: Federal Law Prohibits Discrimination Against Lesbian Instructor.

Legislation Research Commission: http://www.lrc.ky.gov/

Leigh N. \& Blakely E. 2013. "Local Economic Development Strategy" in Planning Local Economic Development $\left(5^{\text {th }}\right.$ Ed.). Sage: London.

Lexington-Fayette County Human Rights Commission. LGBT Workplace Discrimination Claims, 20102016.

Lexington-Fayette County Ordinance No. 201-99

Line J. "Fairness ordinance supporters will keep fighting" Bowling Green Daily News. 02 March 2017.

Link B. \& Phelan J. 2006. Stigma and its public health implications. Lancet, 367. 528 -529.

Litchfield L., Swanberg J., \& Sigworth C. 2011. Increasing Visibility in the Invisible Workplace. Carrol School of Management at Boston College.

Love C. 2014. LGBT Discrimination and Executive Orders. American College Personnel Association.

Long T. 2016. Why NC's first GOP governor in a generation lost. News and Observer.

Lorenz B. 2015. "New HRC Poll Shows Overwhelming Support for Federal LGBT Non- Discrimination Bill”. Human Rights Campaign.

Louisville, Kentucky, Municipal Code 187, 2004.

Louisville Metro Human Rights Commission. Complaints filed against employers due to workplace discrimination between 01 January 2010 and 31 December 2016. 
Lowery W. 2015. Gov. Pence signs revised Indiana religious freedom bill into law. Washington Post.

Lowry, D. Personal Communication, November 21, 2015.

Mallony J. "Charlotte to host the 2019 NBA All-Star Game following the HB2 repeal" CBSSports 24 May 2017.

Mallory C. \& Sears B. 2016. Discrimination, Diversity, and Development: The Legal and Economic Implications of North Carolina's HB2. Report. Williams Institute.

Mallory C. \& Sears B. 2015. Employment Discrimination based on Sexual Orientation and Gender Identity in Kentucky. Report. Williams Institute.

Mallory C. \& Sears B. 2011a. Documented Evidence of Employment Discrimination and its Effects on LGBT People. Report. The Williams Institute.

Mallory C. and Sears B. 2011b. Economic Motives for Adopting LGBT-Related Workplace Policies. Report. The Williams Institute.

Marcosson S. 1992/3. Harassment on the Basis of Sexual Orientation: A Claim of Sex Discrimination Under Title VII. Georgetown Law Journal Vol. 81. 1-38.

Markusen A. 2006. Inappropriate, Irrelevant, Important: Richard Florida's 'Gay Index' and the Quest for Creativity. Environment and Planning A Vol. 38(10) 1921-1940.

Marshall, J. 2015. Identifying Education's Political Effects with Incomplete Data: Instrumental Variable Estimates Combining Two Datasets. Harvard University.

Martin N. "Unlike The NCAA, Some States And Cities Didn't Bite On North Carolina's Weak HB2 Repeal" DeadSpin 18 April 2017.

McBride S. 2016. The Economic Cost of Overly Broad RFRAs. Center for American Progress.

McCabe B. 2010. “Public Opinion on ‘Don’t Ask, Don’t Tell’”. Washington Post.

McCrory P. 2016. Executive Order 93.

McDonald A. "Berea Council rejects 'fairness' ordinance 5-3" The Richmond Register. October 07, 2014.

McGowan K. 2016. "EEOC Loses Transgender Bias Claim Against Funeral Home”.

McLaughlin E. “North Carolina's HB142: Repeal? Compromise? What does it all mean?” CNN 30 March 2017.

Meister J. \& Willard K. 2010. The 2020 Workplace: How Innovative Companies Attract, Develop, and Keep Tomorrow's Employees Today. New York: Harper Collins.

Meyer I. 1995. Minority Stress and Mental Health in Gay Men. Journal of Health and Social Behavior. Vol. 36 (1). 38-56. 
(MDoCR) Michigan Department of Civil Rights. 2013. Report on LGBT Inclusion Under Michigan Law.

Minnesota Population Center. National Historical Geographic Information System: Version 11.0 [nhgis0013_ds176_20105_2010_plac]. Minneapolis: University of Minnesota. 2016.

Minter P. "Bowling Green too late on civil rights for all” Lexington Herald 21 March 2017.

Muñoz S. \& Kalteux D. 2016. LGBT, the EEOC, and the Meaning of "Sex". The Florida Bar Journal. Vol. 90(3). 43-62.

Movement Advancement Project. 2015-a. LGBT Spotlight: Local Employment Nondiscrimination Ordinances. Report.

Movement Advancement Project. 2015-b. Paying an Unfair Price: The Financial Penalty for Being Transgender in America. Report.

NCAA Press Release. NCAA to relocate championships from North Carolina for 2016-17.

NCAA. NCAA Board of Governors' position on HB2 repeal. Press Release.

(NCSL) National Conference of State Legislatures. 2017. State Religious Freedom Restoration Acts.

Negro G., Perretti F., \& Carrol G. 2013. Challenger Groups, Commercial Organizations, and Policy Enactment: Local Lesbian/Gay Rights Ordinances in the United States from 1972 to 2008. American Journal of Sociology Vol. 119(3) 790-832.

Nelson M. 2015. Sexual Orientation Discrimination Under Title VII After Baldwin v. Foxx. Washington and Lee Law Review Vol. 72(2). 255-277.

New York Times. "Election Results.” 16 December 2016.

Nie J. "City Commissioner responds to Fairness Ordinance not getting a second" WBKO 22 February 2017.

Noble A. "Federal lawsuit accusing North Carolina of transgender discrimination dismissed" Washington Times 14 April 2017.

North Carolina General Assembly. Legislation Website: http://www.ncleg.net/gascripts/

BillLookUp/BillLookUp.pl?Session=2017\&BillID=H142

North Carolina General Assembly Extra Session. House Bill 2. 23 March 2016.

Office of National AIDS Policy. 2010. National HIV/AIDS strategy for the United States. Report.

Ohlander J., Batalova J., Treas J. 2005. Explaining educational infl16uences on attitudes toward homosexual relations. Social Science Research 384 781-799.

Peralta K. "HB2 'hasn't moved the needle' on NC's economy, Commerce Secretary says" Charlotte Observer 24 October 2016.

Peralta K. \& Rothacker R. “American Airlines, Apple, NBA denounce NC law ending LGBT protections” Charlotte Observer 24 March 2016. 
Perlmutt D. "13 groups drop plans for Charlotte events, more could come over HB2" Charlotte Observer 08 April 2016.

Phelan J., Link B., Stueve A., \&. Moore R. 1995. Education, Social Liberalism, and Economic Conservatism: Attitudes toward Homeless People. American Sociological Review Vol. 60(1) 126140 .

Phillips M. 2012. "Title VII Prohibits Discrimination against Transgender Workers, EEOC Decides". Jackson Lewis.

Pizer J. 2014. "What the Supreme Court's Hobby Lobby Decision Means for LGBT People" Lambda Legal.

Politico. 2016. 2016 Kentucky Presidential Election Results. Accessed: http://www.politico.com/2016election/results/map/president/kentucky/

Porter B. \& Nelson R. “COMMENTARY: Proposed Bowling Green ordinance unfair, unnecessary”. Daily News

Portillo E. \& Price M. "Charlotte LGBT ordinance fails 6-5 in contentious meeting" Charlotte Observer 02 March 2015.

Posner S. “Leaked Draft of Trump's Religious Freedom Order Reveals Sweeping Plans to Legalize Discrimination." The Nation. 01 February 2017.

Public Policy Poll. 2016. HB2 Continues To Have Little Support From North Carolinians

Public Religion Research Institute. 2015. Beyond Same-sex Marriage: Attitudes on LGBT Nondiscrimination Laws and Religious Exemptions from the 2015 American Values Atlas.

Pullen W., Hartjes, A., Metselaar, W., Canchola, S. and Murtough, J. 2002. The Role of the Workplace in Human Resource Management: A Discussion Paper by the World Wide Workplace Web. Learning Partnership.

Riggle E., Rostosky S., \& Horne S. 2010. Does It Matter Where You Live? Nondiscrimination Laws and the Experiences of LGB Residents. Sexuality Research and Social Policy Vol. 7(3) 168-175.

Riley J. “Gay Rights Issue Arrives.” Park City Daily News. September 21, 1999.

Riley J. \& Pedigo M. "Fair or Foul: Gay Rights Supporters, Opponents Speak Out”. Park City Daily News. November 6, 1999. Front Page.

Rimmerman C., Wald K., Wilcox C. 2000. The Politics of Gay Rights. University of Chicago Press.

Ring T. 2016. The Most Anti-LGBT States by Legislation. Lambda Legal.

Robinson B. "New officials not in favor of fairness ordinance." The Richmond Register January 5, 2011.

Rothacker R. "Charlotte loses 730-job operations center over House Bill 2" Charlotte Observer 25 October 2016.

Ryan J. "Statewide Fairness Law Gets Support From 150 Kentucky Companies" WFPL. 19 November 2015. 
Schoon I., Cheng H., Gale C., Batty D., Deary I. 2010. Social status, cognitive ability, and educational attainment as predictors of liberal social attitudes and political trust. Intelligence Vol. 38(1) 144150.

Schwartz J. 2010. Investigating Differences in Public Support for Gay Rights Issues. Journal of Homosexuality Vol. 57(6) 748-758.

Scott E. \& Wright D. 2017. Trump continues Obama order protecting LGBTQ federal workers. CNN.

Segal J. 2014. Social Media Use in Hiring: Assessing the Risks. Society for Human Resource Management.

Senate Bill 180. Kentucky Senate. Introduced 15 January 2016.

Senate Bill 17. Kentucky Senate. Introduced 05 January 2017.

Sisk R. "The struggle to pass a Fairness Ordinance in Bowling Green” LEOWeekly 01 March 2017.

Shapp M. 1975. Executive Order 1975-5.

Shaw S. 2015. The EEOC Settles Its First Transgender Suit Filed Under Title VII. From EEOC Countdown.

Shi Y. 2016. Cross-cutting Messages and Voter Turnout: Evidence from a Same-Sex Marriage Amendment. Political Communication Vol. 33. 433-459.

Small Business Council. 2012. Small Business Facts. Report.

Steiger K. 2015. “The Growing Backlash Against Indiana’s New LGBT Discrimination Law.” Think Progress.

Stern M. 2016. It Looks Like Pat McCrory, North Carolina's Anti-LGBTQ Republican Governor, Is Out of a Job. Slate.

Stokes K. "LGBT Fairness ordinance requested of city" Georgetown News-Graphic March 2, 2017.

Surridge, P. (2016). Education and Liberalism: Pursuing the Link. Oxford Review of Education, 42(2).

Swietek W. "Fairness ordinance fails to even get discussion" Bowling Green Daily News 21 February 2017.

Taghva1 F., Rezaei1 N., Ghaderi1 J., Taghva R. 2014. Studying the Relationship between Critical Thinking Skills and Students' Educational Achievement. International Letters of Social and Humanistic Sciences Vol. 25 18-25.

Tashman B. “Indiana Activist: Don't Clarify That 'Religious Freedom' Law Won't Allow Discrimination" Right Wing Watch 30 March 2015.

Taylor C. 1994. "The Politics of Recognition" in Multiculturalism. Ed. Amy Gutmann. Princeton University Press. 25-74. Print.

Taylor J. “FIX THIS NOW”. Indiana Star. 31 March 2015. Page 1. 
The Task Force. 2009. National Transgender Discrimination Survey. A report made by the National Center for Transgender Equality for the National Lesbian and Gay Task Force

Thomas C. 2011. The Personnel Model at the Mid-20th Century: Thoughts from the Past. Journal of Business and Management 9(1): 112-138.

Tilcsik A. 2011. Pride and Prejudice: Employment Discrimination against Openly Gay Men in the United States. American Journal of Sociology Vol.117(2). 586-626.

Title IX, Chapter 92: Discriminatory Practices. Louisville-Jefferson County’s Ordinance Code.

Tolbize A. 2008. Generational Differences in the Workplace. The University of Minnesota Review.

Transgender Law Center. 2013. Federal Agency Rules Transgender Employees Protected by Sex Discrimination Law.

Truman, C. "UnCommonwealth: Researchers seek stories, places important in Kentucky LGBT history" Lexington-Herald Leader, 28 December 2015.

United States Bureau of Labor Statistics. 2017.

United Nations World Tourism Organization. 2012. Annual Report.

Velez B. 2013. Workplace Support, Discrimination, and Person-Organizational Fit: Tests of the Theory of Work Adjustment with LGB Individuals. University of Florida Review.

Volokh E. "What Is the Religious Freedom Restoration Act?" Volokh Conspiracy 02. December 2015.

Wald K., Button J., \& Rienzo B. 1996. The Politics of Gay Rights in American Communities: Explaining AntidiscriminationOrdinances and Policies. American Journal of Political Science Vol. 40(4). $1152-1178$

Weil, F. 1985. The Variable Effects of Education on Liberal Attitudes: A Comparative- Historical Analysis of Anti-Semitism Using Public Opinion Survey Data. American Sociological Review, Vol. 50(4) $458-474$.

WBKO. "Bowling Green city commission candidate: Joe Denning” News Report. 25 February 2015.

WFPL News. “Berea City Council Considering Fairness Law” 09 May 2011.

Wimark, T. 2014. Migration motives of gay men and lesbians: A cohort study from Malmö, Sweden. Social and Cultural Geography

Wimark, T. \& Östh, J. 2013. The city as a single gay magnet? Gay and lesbian geographical concentration. Sweden. Population, Space and Place

Whiteck-Combs Communications. 2006. Majority of Americans: Companies not government should decide benefits offered to same-sex employees. Poll.

The Williams Institute. 2010. Kentucky: A Snapshot. Report. 
Williams P. "LGBT Job Discrimination Is Prohibited by Civil Rights Law, Federal Appeals Court Rules." NBC News. 04 April 2017.

Williams D. 1999. “Louisville Passes Fairness Ordinance”. Gay Today.

Wilson, R. 2016. "Kentucky Legislative Session Comes to a Close; Fails to Pass Anti-LGBT Legislation." Human Rights Campaign.

WKYT News. "Governor's office responds to California's Kentucky travel ban.” 23 June 2017.

Wynn M. \& Loftus T. "Bevin takes ax to Beshear's executive orders". The Courier Journal. 22 December 2015.

Wong C. "Indiana's Memories Pizza Reportedly Becomes First Business To Reject Catering Gay Weddings.” Queer Voices 01 April 2015.

World Travel and Tourism Council. 2016. Travel and Tourism: Economic Impact United States. Report.

Zeek, F. 2016. Chief Executive Boards. 


\section{CURRICULUM VITA}

Christopher Wales

Phone: (502) 507-8053

Email: christophermichaelwales@gmail.com

Address: $2501 \mathrm{~S} 4^{\text {th }}$ St. Louisville, KY 40208

Education:

Master of Public Administration, University of Louisville: Expected December 2017

Bachelor of Arts, Northern Kentucky University: May 2014

Professional Experience:

Graduate Research Assistant: August 2016 - Present 